\title{
V. Products, Traditional and New
}

\section{1. Production of Iron and Steel}

\section{1. 1. Overview}

Under the impact of oil crisis, the growth rate of the GNP of the Japanese economy suffered a great decrease from around $10 \%$ per year to around $4 \%$. With regard to the iron and steel industry, in particular, the steel production, which had been growing faster than the GNP growth rate, had changed to negative growth, as may be seen in Table V.1.1 and Fig. V.1.1. This fact, namely even though the GNP was still growing, the steel production had ceased to increase, is worthy of note.

There are several causes that may be ascribed to this. The first is the decrease in the total fixed capital formation ratio in the GNP (Table V.1.1). This means that the demands for those kinds of investment, such as construction and shipbuilding, which call for a large steel consumption, were greatly decreased due to stock adjustment of facilities to accommodate the slowdown of economic growth, as shown in Fig. V. 1.2 .

The second cause is the decrease due to changes in the investment pattern. For example, in the private business sector, the relative weight has been shifted from the heavy equipment-intensive industries to the

Table V.1.1. Changes in annual average increments of GNP, iron and steel indices, and fixed capital formation ratio.

\begin{tabular}{l|rrrr}
\multicolumn{1}{|l|}{ Increments (\%) } & $\begin{array}{l}1955 \sim \\
1965\end{array}$ & $\begin{array}{l}1965 \sim \\
1973\end{array}$ & $\begin{array}{l}1973 \sim \\
1979\end{array}$ & $\begin{array}{l}1979 \sim \\
1982\end{array}$ \\
\hline GNP & 8.9 & 9.5 & 4.0 & 3.7 \\
$\begin{array}{l}\text { Grude steel produc- } \\
\text { tion }\end{array}$ & 15.4 & 12.1 & $\Delta 1.0$ & $\Delta 5.2$ \\
$\begin{array}{l}\text { Steel export } \\
\begin{array}{l}\text { Total fixed capital } \\
\text { formation ratio }\end{array}\end{array}$ & 18.0 & 12.9 & 2.1 & $\triangle 2.3$ \\
& 26.3 & 36.2 & 33.0 & 31.4
\end{tabular}

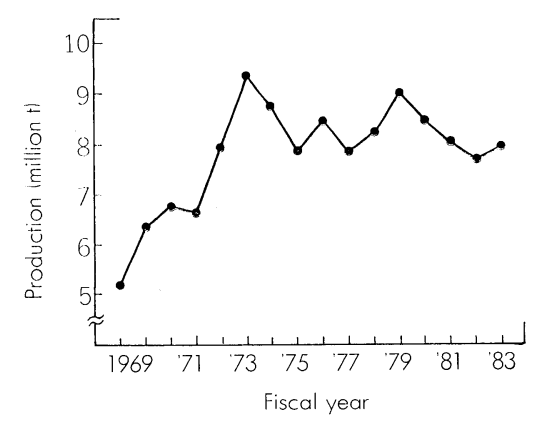

Fig. V.1.1. Changes in production of hot-rolled steels. light machinery industries, such as electronics and robots, and also to the services industry. As regards public investment, further, the emphasis was shifted from the industrial infrastructures, such as highways, railways, and harbor works, to the civil life infrastructures, such as city sewerage and parks. In short, in either sector, the trend in the steel consumption has been from heavy to light.

The third cause is the decrease in specific consumption in the general trends toward lighter, thinner, shorter, and smaller products, as may be seen in Fig. V.1.3. In the automotive industry, for example, which is the largest customer of steels in the manufacturing industries, the steel consumption per automobile decreased from $1068 \mathrm{kgm}$ in 1973 to $859 \mathrm{kgm}$ in 1982, even though the total demand for steel was increased as shown in Fig. V.1.2, owing to the greatly expanded production. This is due to the relative decrease in the production of the heavy trucks and buses and to weight reduction in the passenger cars. The situation is quite similar for the industrial machinery and the electrical machinery sectors, where, even though the production index has grown due to expansion in the mechatronics, electronics, etc., the steel consumption decreased in the former, held unchanged in the latter (Fig. V.1.2).

The fourth cause is depression of exports, as shown in Table V.1.1. Before the oil crisis, the exports grew at an annual rate of about $13 \%$, but after it, the growth became completely stopped due to stagnated world steel trade and the rise of advancing steelmaking countries.

Thus, though the past decade, the iron and steel production has been on the low keynote as a whole,

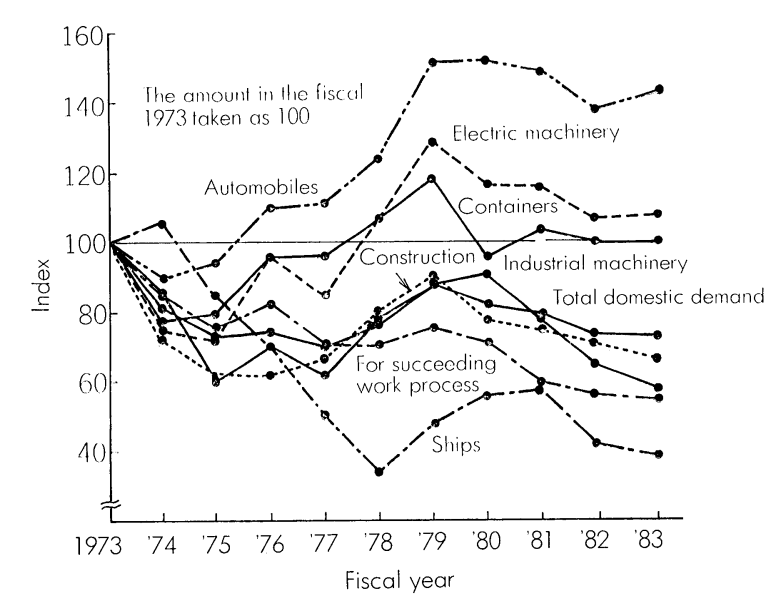

Fig. V.1.2. Changes in the amounts of orders received from various customer industries. 


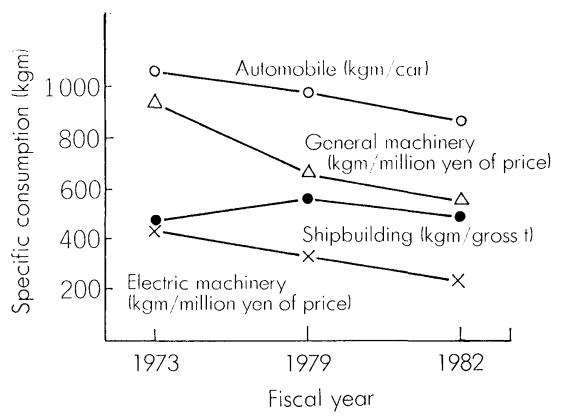

Fig. V.1.3. Changes in specific consumption of steels by the uses.

but, for high quality steels alone, the demand became increased.

\section{1. 2. Upgrading of Steels}

The oil crisis exerted a great influence on the quality of steels also. Namely, oil industries demanded steels that can be used in the aggravated or difficult energy production environments, while industries that consume energy called for steels that can aid in resources-saving and energy-saving. This may be exemplified by the surface treated sheet steels and the high strength steels as may be seen in Fig. V.1.4.

(1) Increased Severity of Environment in Oil Development

The world energy situation demanded such lessprofitable sources as the highly corrosive sour gas field and hitherto unaccessed deep-sea, super-deep, or arctic oil fields to be explored. All of those meant very severe work conditions, for which low alloy structural steels and high strength steels of excellent toughness, good weldability, and high corrosion resistance were developed for line pipes, oil well drilling and tubes, offshore rigs and platforms, and many other special apparatuses and facilities.

For another example, LNG, whose liquefaction temperature is $-162{ }^{\circ} \mathrm{C}$, came to be imported in bulk to replace oil in city gas and electrical power generation, and for the LNG carriers, storage tanks, line pipes, evaporators, and so on, low temperature service high strength steels such as $9 \% \mathrm{Ni}$ steel were developed to compete with $\mathrm{Al}$ and 18-8 stainless steel.

(2) Weight Reduction and Rust Prevention for Automotive Industry

In the automotive industry, the only industry that allowed the steel consumption to grow, the lightening of automobile weight for the sake of reducing the fuel cost has been achieved by employing high strength sheet steels having a tensile strength of $35 \mathrm{kgf} / \mathrm{mm}^{2}$ or above; in the latest models, 30 to $40 \%$ of the steel sheets for the body is now the high strength steels. Also, plastic laminated sheet steels have become employed for further reduction of weight and vibration, and for soundproofness.

Furthermore, in the automobiles exported to North America and Europe, where salt is sprayed to melt snow on the road, heavy-duty rust prevention became necessary, and various rust preventive steel sheets

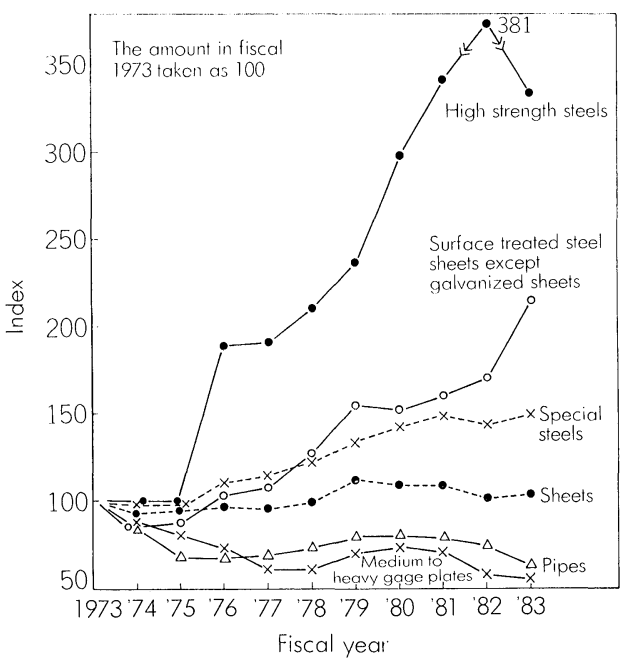

Fig. V.1.4. Changes in amount of orders received for various steels.

were developed.

At present, Zn-base coating, Zn-Fe-base coating, $\mathrm{Zn}-\mathrm{Ni}$-base coating, and $\mathrm{Zn}$-rich paint coating sheets are widely used. To cope with severer rust preventive requirements (10 year guarantee against pitting and 5 year guarantee against outer surface corrosion) and to provide material that is easier to use, further, various kinds of double-layer coating type rust preventive steel sheets are being developed.

As for the bar steels, which are still mainly for structural application, cold forgeable steels for automotive parts are now available owing to greatly improved ladle refining technologies, which have made fine adjustment of chemical compositions, therefore hardenability, possible. From the viewpoint of energy-saving, many kinds of steels such as non-heat treated steel, low $\mathrm{Pb}$ free-cutting steel, and soft-nitriding steel were developed.

(3) Cost-saving Steels for the Shipbuilding and Industrial Machinery Industries

In the shipbuilding field, the $50 \mathrm{kgf} / \mathrm{mm}^{2}$ class high strength plate steel, which does not need preheating for welding, has been introduced. In the industrial machinery industry, clad plate steels, which have high corrosion resistance and are inexpensive, were developed for chemical machinery.

(4) Energy-saving and Cost-saving Steels for Electric Machinery Industry

Super-low watt loss electro magnetic sheet steels, which greatly decrease the power loss in power generation and power transformation, have been put to practical use. In the home appliance field, the sheet steel is being shifted from cold rolled steel to rust preventive coating steel, and further to precoated steel.

(5) Enlargement of Products Size in the Construction Industry

The construction industry, which used to be among the greatest consumers, is still under depression, nevertheless, as the structures such as bridges became larger, the demand for high strength steels of good 
weldability, weatherability steels which need not be coated, and sea water resisting steels is expanding. In the architecture industry, earthquake-proof design has recently been made severer, and columns (large square-shaped steel pipe) came to be widely used for medium- to low-rise buildings. In the civil engineering field, the steel pipe and sheet pile well foundation method has been well spread for making the bridge substructures, enlarging the use of the sheet pile steel.

\section{1. 3. Future Prospects and Tasks}

The general trend in the economy toward softwareand knowledge-intensive structure will not change. Consequently, such increase of demand for iron and steel as observed in the economic high growth period cannot be expected. Therefore, it is rather obvious that the iron and steel industry should comply with the customers demands for lower cost and higher quality, in order to keep competing with other materials and developing countries.

\section{2. Fundamentals of Materials Develop- ments}

\section{2. 1. Physical Metallurgy of Production Technologies}

The oil crises have resulted in the needs for materials with a variety of higher performances and for cost savings both in the production of steel and in the fabrication of products by the user. Remarkable progresses have been achieved in the production technologies of steels in terms of energy saving, simplification and continuation of the processes, in the developments of new products particularly with inexpensive alloying and high purity steels on the basis of research results with sophisticated analytical techniques.
(1) Controlled Rolling and Low Carbon Low Alloy Steels

Controlled rolling (CR) technique has made a remarkable progress in Japan since the late 1960s as the production method of high strength and high toughness steel plates containing a small amount of $\mathrm{Nb}$ and $\mathrm{V}$ for line pipes in the Arctic. The controlled rolling produces an improved strength and toughness through grain refinement during rolling at lower temperatures after interruption of rolling at an intermediate stage in the rolling of steels with or without addition of $\mathrm{Nb}$ or $\mathrm{V}$ (Fig. V.2.1). Practice of the conventional rolling consists of slab reheating at 1250 to $1200{ }^{\circ} \mathrm{C}$ and finishing at 950 to $1100{ }^{\circ} \mathrm{C}$ depending upon the plate thickness (Fig. V.2.1). Austenite $(\gamma)$ grains are successively refined by recrystallization after the respective rolling pass; the recrystallized grains are finer for the finer grain size prior to rolling, the higher draft per pass, and the lower rolling temperature. Recrystallization proceeds during rolling down to $800 \sim 850{ }^{\circ} \mathrm{C}$ in the plain $\mathrm{Si}-\mathrm{Mn}$ steels. In the $\mathrm{CR}$ of plain $\mathrm{C}$ steels free from special alloying elements, refinement of ferrite $(\alpha)$ grains is mainly achieved by the phase transformation from $\gamma$ grains finely recrystallized by low temperature rolling (Fig. V.2.1(b)).

The roles of $\mathrm{Nb}$ added in ferrite-pearlite steels in a amount of 0.02 to $0.04 \%$ are: strengthening and improvement of toughness by $\alpha$ grain refinement through transformation of unrecrystallized $\gamma$ grains caused by fine precipitation of $\mathrm{Nb}(\mathrm{C}, \mathrm{N})$ and strengthening by precipitation of fine $\mathrm{Nb}(\mathrm{C}, \mathrm{N})$ to generate a coherent strain. Addition of $\mathrm{V}$ is known to produce similar effects, but a larger amount of alloying is necessary to be effective.

When rolling is carried out below the recrystallization temperature, the deformed grains are elongated in the rolling direction and provide finer $\alpha$ grains after transformation than the equiaxially recrystallized

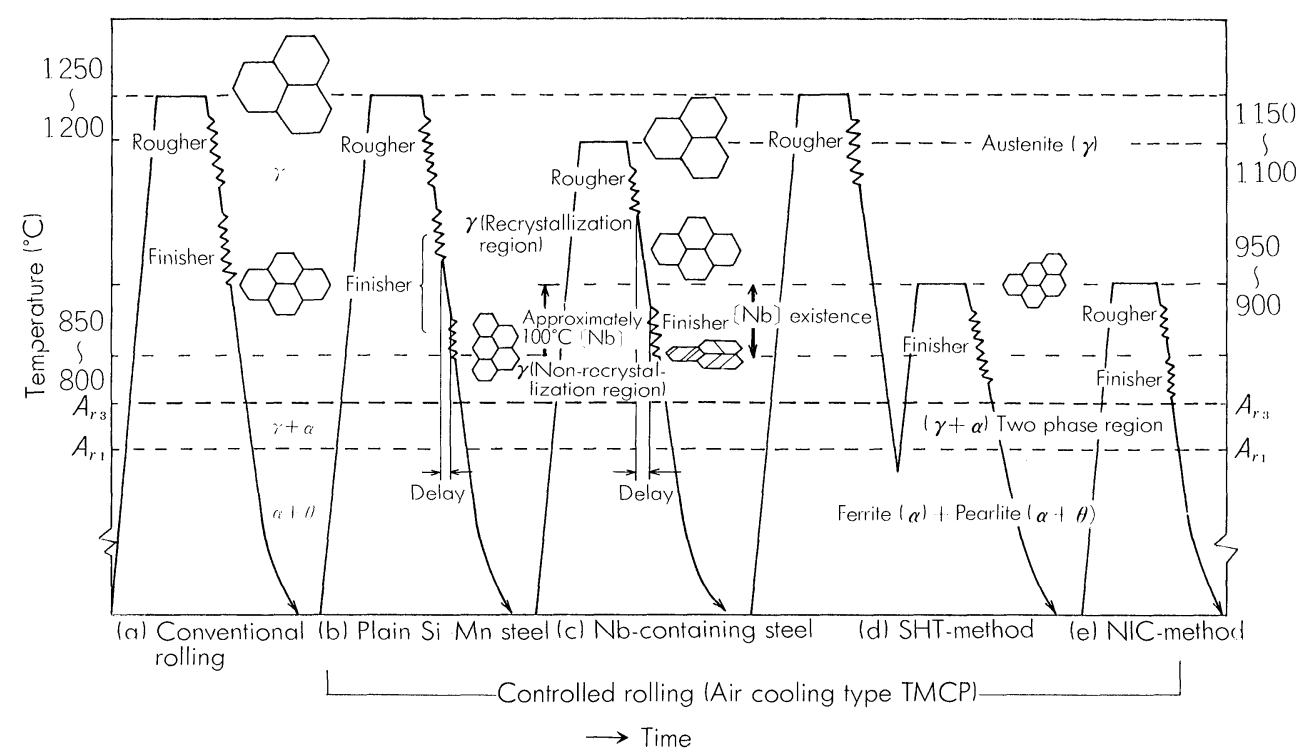

Fig. V.2.1. Development of controlled rolling technique.

Source: Sekine et al.: Welding Technique (Yosetsu Gijutsu), 31 (1983), No. 10, 85. 
grains. Fine precipitation of $\mathrm{Nb}(\mathrm{C}, \mathrm{N})$ in $\gamma$ phase during hot rolling retards recrystallization of the deformed grains and raises the recrystallization temperature as much as $100^{\circ} \mathrm{C}$. The $\mathrm{GR}$ of $\mathrm{Nb}$ bearing steels is performed with $\gamma$ unrecrystallized and the larger integrated drafts below the recrystallization temperature arise finer $\alpha$ grains from extensively elongated $\gamma$ grains (Fig. V.2.1(c)). Rolling of $\gamma$ without recrystallization is also effective in plain $\mathrm{Si}-\mathrm{Mn}$ steels. Addition of $\mathrm{Nb}$ makes the processing easy by shifting the recrystallization temperature to a higher temperature. Resistance to deformation is higher in finishing at low temperatures especially of the unrecrystallized $\gamma$ structure and a high power is needed for GR. The new rolling mills in Japan have greatly contributed to the establishment of CR technique.

Strengthening is attained by precipitation hardening in the steels containing $\mathrm{Nb}$ and $\mathrm{V}$; therefore, improvements of the toughness and weldability are easier by decreasing of $\mathrm{C}$ content than in the conventional steels. However the accompanied rise of $\gamma-\alpha$ phase transformation temperature leads to coarsening of $\alpha$ grains and precipitates of $\mathrm{Nb}(\mathrm{C}, \mathrm{N})$ or $\mathrm{VN}$ in $\alpha$ phase, and consequently to lowering of the strength and toughness. Therefore it is important to maintain the $A_{3}$ temperature low enough by increase of the content or alloying of the austenite forming elements such as $\mathrm{Mn}, \mathrm{Ni}$, and $\mathrm{Cu}$. Combination of the low $\mathrm{C}$ content, grain refinement, and precipitation hardening provides a high yield ratio in the products, making advantageous for production of the materials of line pipes required for the guarantee of yield strenth in the specification.

Low temperature reheating of slabs followed by low temperature rolling produces finely recrystallized grains. A finer and more homogeneous structure is obtained when the $\gamma$ grain size is finer prior to the start of rolling in the unrecrystallized state. Low temperature reheating meets the requirements of energy saving by reduction of the heat consumption, increase of the productivity by shortening of the delay time, and improvements of the properties of products without regard to the use of alloying elements. The low temperature reheating has come to be a common procedure in accordance to the needs for production of plates with heavier gages and higher performances (Fig. V.2.1(c)). Extremely low temperature reheating as low as the normalizing temperature is carried out in the mill equipped with powerful machines by installation of a special reheating furnace (Fig. V. 2.1 (d) \& (e)).

The effects of $\mathrm{Nb}$ addition mentioned above are based on the presence of dissolved $\mathrm{Nb}$ in $\gamma$ before rolling or before transformation. Since $\mathrm{Nb}(\mathrm{C}, \mathrm{N})$ is difficult to dissolve, a part of the $\mathrm{Nb}(\mathrm{C}, \mathrm{N})$ precipitated in slab sometimes cannot be brought into solution during the low temperature reheating. Consequently, as the reheating temperature becomes low, precipitation hardening of $\mathrm{Nb}$ becomes small and disappears at normalizing. Since this tendency is small for $\mathrm{V}$-bearing steel, combined addition of $\mathrm{Nb}$ and $\mathrm{V}$ has come to be popular for high strength steel. To make up for the strength decrease caused by the low temperature reheating, rolling temperature has come to be extended to $\gamma / \alpha$ two phases region for the high grade heavy plate containing Nb. Moreover, the extra low temperature reheating enables the GR of non$\mathrm{Nb}$-bearing and $\mathrm{V}$-bearing steels which are not required for high strengths.

In the production of high strength and high toughness steels of the grades higher than $500 \mathrm{MPa}$, application of $\mathrm{CR}$, by addition of $\mathrm{Nb}$ or $\mathrm{V}$ if necessary, can reduce the $\mathrm{C}_{\mathrm{eq}}$ easier than normalizing. It has been known that, regardless of alloying of $\mathrm{Nb}$ or $\mathrm{V}$, the steels rolled in unrecrystallized region or further in the two phases region, show a better brittle-fracture arresting-property than the heat treated steels. Owing to the advantages in properties, the low temperature reheating and $\mathrm{CR}$ techniques are widely applied to the production of steels for guarantee of the high toughness and yield strength and of the $500 \mathrm{MPa}$ grade for low temperature use which were conventionally produced by heat treatments, together with reduction of the production processes and shortening of the delivery time.

Further reduction of the $\mathrm{C}$ content as low as 0.05 $\%$ in $\mathrm{Nb}$-bearing steel is effective in dissolving $\mathrm{Nb}$ during the low temperature reheating through reduction of the solubility product, $[\mathrm{Nb}] \cdot[\mathrm{C}]$, however, it brings about a higher yield ratio. This results in a remarkable decrease of the yield strength in a test piece sampled after pipe making due to the Bauschinger effect, to be not adequate for the material of pipes. In the earlier 1970s acicular ferrite steel of extra low C-high Mn-Nb-Mo was developed. The steel have a structure basically of fine bainite, different from the conventional precipitation hardening type ferrite-pearlite steels, and a high tensile strength as well as the continuous yielding behavior characteristic of transformation hardened steel leading to a rise of yield strength after pipe making. $\mathrm{Nb}$ is liable to give a harmful coarse acicular structure. This tendency was suppressed by enrichment of the polygonal $\alpha$ grains through low temperature slab reheating and intensive CR for the conventional ferrite-pearlite steel. However, for a high $\mathrm{Mn}-\mathrm{Mo}$ steel which retains a substantial hardenability after $\mathrm{CR}, \mathrm{Nb}$ is more effective in producing the low temperature transformation product than in precipitation hardening. Afterwards it has been shown that, besides high hardenability, Mo produces finely recrystallized grains and suppress recrystallization of $\gamma$, without regard to the slab reheating temperatures. Development of this transformation hardened type CR steel ensures the production of steel plates of thicker gages and higher grades.

By addition of $\mathrm{Ti}$ about $0.01 \%$ chemically equivalent to the quantity of $\mathrm{N}$ in L.D. steel, fine precipitation of TiN which is virtually insoluble at high temperatures, restrains coarsening of $\gamma$ grains during the slab reheating and also at the welded bond sections. Thus, by the addition of $0.01 \% \mathrm{Ti}$, the steel for large heat-input welding has come to be manufactured by $\mathrm{CR}$ after reheating at a temperature where coarsening 
of grains does not proceed but a sufficient amount of dissolved $\mathrm{Nb}$ is insured. Microalloying of $\mathrm{Ti}$ has extended to development of a new acicular ferrite steel having an extra low $\mathrm{C}$-high $\mathrm{Mn}-\mathrm{Nb}-\mathrm{Mo}$ and an extra low $\mathrm{C}$ bainite steel by the substitution of Mo with B. Alloying of $\mathrm{Ti}$ with $0.02 \%$ or above also has effects of recrystallization suppression of $\gamma$ and precipitation hardening of $\alpha$ matrix by $\mathrm{TiC}_{\mathrm{C}}$, showing an intermediate level of effects between $\mathrm{Nb}$ and $\mathrm{V}$. By taking advantage of these functions of $\mathrm{Ti}$, a low cost type CR steel plate with high strength has been developed.

\section{(2) Continuous Annealing}

Among the manufacturing processes of cold rolled steel sheets and surface treated steel sheets, annealing after cold rolling is a significantly important process for controlling of the mechanical properties of products. Conventional batch annealing of coiled steel strips takes about one week in the cycle of heating and cooling. However, the product is provided with good formability because of the slow heating and slow cooling. On the other hand the continuous annealing process can be performed within $10 \mathrm{~min}$. However, owing to the rapid heating and rapid cooling, good press formability of the products is not achieved except for a special type of steel like IF (Interstitial Free) steel, so that the application of continuous annealing was limited to the surface treated steel sheet.

Continuous annealing of the formable steel sheets has been developed by using the materials with scavenging effects mentioned below. Since these techniques were industrialized in 1972 in Japan, about 10 units of the equipments have come to be operated in several countries. The line consists of a series of electrolytic cleaning, continuous annealing, skinpass rolling and inspection (Fig. V.2.2). Furthermore direct connection of the cold rolling mill and annealing line has been achieved.

In order to obtain an excellent formability, high $\bar{r}$ value and high elongation, by rapid heating and short time annealing as in the continuous annealing, elimination of the impurity elements such as $\mathrm{C}, \mathrm{N}$, and $\mathrm{S}$ in steel is effective. High purification in the steel making process is not economical, and therefore fixing of the impurity atoms is done in the following processes. The IF steels is a typical example; a small amount of retained $\mathrm{C}$ and $\mathrm{N}$ after vacuum degassing is fixed with $\mathrm{Ti}$ or $\mathrm{Nb}$. Such scavenging effects include the stabilization of $\mathrm{O}$ and $\mathrm{S}$ by $\mathrm{Mn}, \mathrm{N}$ and $\mathrm{O}$ by $\mathrm{Al}$, and $\mathrm{N}$ by $\mathrm{B}$, which can be also applied to various types of steels other than the IF steels. It is important to control the amounts of alloying elements to be in the stoichiometric ratio for impurity elements to combine into precipitates. In many cases high temperature coiling of hot rolled sheets is effective for scavenging.

In the continuous annealing process a large amount of $\mathrm{C}$ is retained in solution by rapid cooling after holding at about $700{ }^{\circ} \mathrm{C}$ or above to make the product poor in ductility and susceptible to strain aging. Overaging treatment at 300 to $450{ }^{\circ} \mathrm{C}$ is executed to precipitate the solute $\mathrm{C}$ as carbide. The faster cooling rate and the wider temperature range of cooling after annealing is effective for reduction of the solute $\mathrm{C}$ and fine precipitation of the carbides. An optimum cooling rate is selected to provide a distribution of carbides producing the minimum precipitation hardening.

Recently, from the needs of weight reduction of vehicle for energy saving, demands for high strength steel sheets are increasing. The continuous annealing process is favorable for production of these types of steels; quenching and tempering treatments are possible and dual phase steels, which will be mentioned in the next section, can be easily obtained. Since the continuous annealing enables homogeneous heating of strip in its full length, the uniformity of fine grained structure by low temperature annealing and the strengthening by recovery annealing are ensured.

\section{(3) Dual-phase Steels}

Of many kinds of the formable high strength steel sheets, development of dual-phase (DP) steel having not only high strength but high ductility has a great meaning in the history of technology. This is of a kind of composite materials; the soft phase bears the ductility and the hard phase the strength. This type of steel brings a new strengthening mechanism in the steel sheet besides the conventional precipitation hardening and solid solution hardening. The name of dual-phase steel has been firstly proposed by Japanese researchers at the international conference held in Washington, D.C. in 1975, and thereafter research and development of this type of steel were actively con-

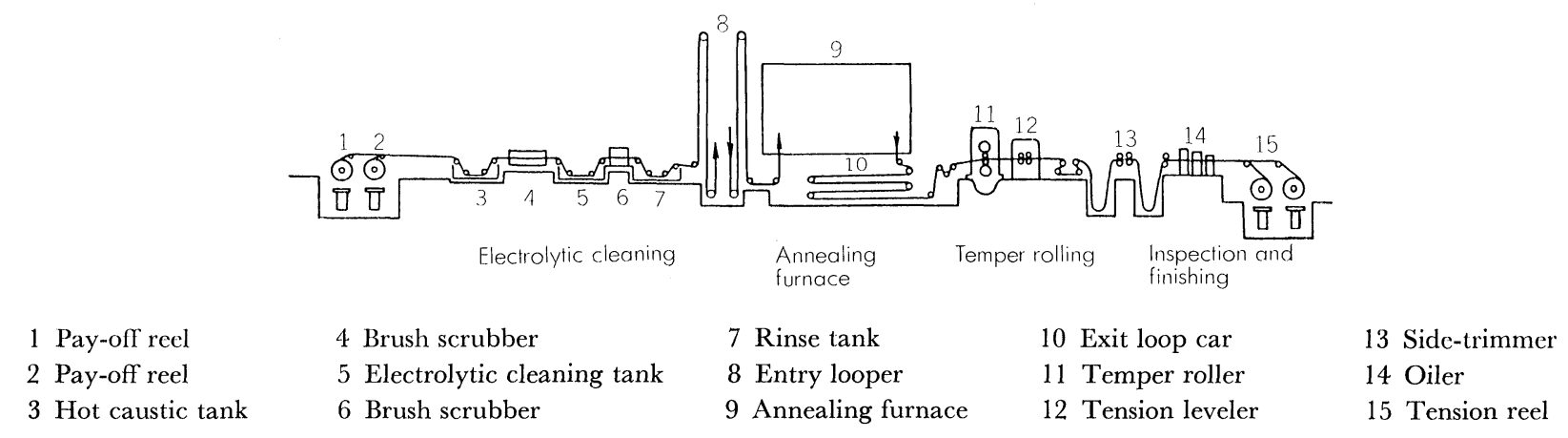

Fig. V.2.2. Typical layout of continuous annealing line.

Source: Toda et al.: Iron and Steel Engineer, 50 (1973), Oct., 44. 
ducted throughout the world, particularly in Japan and the USA.

The manufacturing of DP steel is based on the following principle. Carbon steel is held in the range of $A_{1}$ to $A_{3}$ temperatures to disperse fine $r$ phase with a high concentration of $\mathrm{C}$ homogeneously in the $\alpha$ phase matrix, and then cooled under the condition for the $\gamma$ phase to be transformed into martensite. This procedure is easily applicable in continuous annealing, thus the DP steels can be said to open up a new application of continuous annealing. The tensile strength depends upon the volume fraction of hard martensite and the high ductility is due to the matrix of soft $\alpha$ phase. The total elongation is several to $10 \%$ larger than that of the precipitation hardened steel with the same level of tensile strength. In view of the cost and weldability as the material for automobile, the normal chemical composition is $0.1 \% \mathrm{C}$ or below and 0.3 to $1.0 \% \mathrm{Mn}$, to give the volume fraction of martensite less than $25 \%$ and the tensile strengths up to $1000 \mathrm{MPa}$. The cooling rate necessary for producing martensite is closely related to the chemical composition, and the variations are the low Mn-type for rapid cooling and the high Mn-type for rapid cooling together with substitution of a part of $\mathrm{Mn}$ by $\mathrm{Cr}$ and B. The low Mn-type is favorable for bake hardening after painting and the high Mn-type for formability with the lower yield ratio and high ductility. The metallurgical understanding of dual phase steels has progressed. Retained $\gamma$ often observed in the slow cooling type is considered to improve the ductility by some researchers. Purification of $\alpha$ phase and high concentration of $\mathrm{G}$ in $\gamma$ phase by two phase region annealing and retention of $\gamma$ after cooling is almost the same technical concept that was established earlier in the development of high $\mathrm{Ni}$ quenched and tempered high toughness steel plates for low temperature use, and the study on the roles of retained $\gamma$ might be a certain direction of development in the near future.

The techniques to obtain DP steel directly as hot rolled steel have been proposed since about 1977, based on the 2 technical concepts. One is the technique of the type dependent upon alloying elements; Mo and Cr are alloyed for formation of the proeutectoid $\alpha$ phase during cooling after hot rolling to partition $\mathrm{C}$ preferentially in the untransformed $\gamma$ and to effectuate the martensite transformation during slow cooling after coiling. This technique is considered to be promising in the USA for the time being. This idea was conceived by the researchers who were engaged in the development of CR steel plates for line pipes. The other concept is a direct transfer from the pattern of continuous annealing of cold rolled steel into the processing through continuous hot rolling and cooling on run-out table (ROT), by the use of less expensive plain $\mathrm{Si}-\mathrm{Mn}$ steel and coiling below the $M_{s}$ point. At present the latter process seems to be more advantageous in terms of the alloy costs. Since both techniques require occurrence of proeutectoid $\alpha$ at the beginning of transformation, low temperature finish rolling is effective as in the GR for a heavy plate, and also slow cooling at the earlier stage of ROT. These techniques are fruitful results for the effective use of continuous hot rolling line to obtain dual phase structures. However, needless to say, there are some restrictions from the capacities of rolling mill, water cooling equipment, and coiling machine, especially for manufacturing the latter steel having a low chemistry.

For expansion of the use of DP steel sheet, the steel makers are making efforts to improve its flangeability and deep drawability by such methods as texture control and changing the hard phase into bainite. Analysis of the plastic deformation behavior of DP structure is progressing. When the analytical techniques including a dynamic model for deformation of both the hard and the soft phases and the morphology of a hard phase could be significantly developed, manifold applications of the dual phase structure can be expected.

(4) Introduction of Accelerated Cooling into Heavy Plate Rolling

The techniques of thermo-mechanical control process (TMCP) or thermo-mechanical processing is an integrated procedure that provides the as rolled steels with the mechanical properties comparable to the conventional heat treated steels in a sequence of heating, working, and cooling as an effective combination of the elementary techniques containing controlling of slab reheating to air cooling after GR (air cooling type TMCP), or accelerated cooling after GR including DQ (water cooling type TMCP). Here the water cooling type TMCP will be mainly described.

Process of DQ and the subsequent tempering was applied on a small scale to reduce the heating cost for quenching. However, there was a difficulty to install a DQ equipment for a throughput of about $10 \%$ of the total product in the plate mill designed for the mass production of as rolled plates. A lot of trials have been made to increase the strength or lower the $\mathrm{C}_{\mathrm{eq}}$ of steels by water-cooling after rolling, but failed to be a practical application because of the problems of bad shape, inuniformity of the properties in the width and thickness of plate, and scatter of the ductility and toughness.

In the continuous hot strip mills, controlling of the water-cooling and coiling as well as the rolling condition has resulted in successful production of hot strips, including the as rolled DP steels, of excellent properties particularly with a less scatter along the longitudinal direction than those of the CR heavy plates. Water cooling and coiling facilities, which were primarily installed to make short the overall length of mill, has come to operate as an in-line heat treatment facility for the CR steels. Furthermore, these facilities are modified for these particular purposes.

Based on the understanding of the relationship between decrease of hardenability and grain refinement by $\mathrm{CR}$, and the grain refinement by rapid cooling on ROT after GR, together with the experiences in manufacturing of high strength steel plates with a low $\mathrm{C}_{\mathrm{eq}}$ as water-cooled from the normalizing temperature in off-line processing, the on-line accelerated cooling 
combined with $\mathrm{CR}$ has come to be considered a possible solution. High grade and heavy gage plates for line pipes which can be obtained only as the transformation hardened CR steels and saving of the expensive alloying elements like $\mathrm{Ni}$ and $\mathrm{Mo}$ by accelerated cooling have been strongly required. Moreover needs for the $500 \mathrm{MPa}$ grade plate with the weldability comparable to the $400 \mathrm{MPa}$ grade and also the plates of low temperature use with an excellent crack arrestability and reduced $\mathrm{C}_{\mathrm{eq}}$ have increased. The former is to be used for energy saving ships and the latter for storage tanks. Extensive applications of the CR technique besides the material for line pipes have brought a prospect that the effect of the introduction of thorough water-cooling equipment at the backward of rolling mill can cover a significant range of products. Triggered by the first report in 1977 that the accelerated cooling after CR could raise the strength without decrease in the toughness, the world's first accelerated cooling facility began to operate in Japan in 1980. Many steel makers followed to apply the method.

Two types of accelerated cooling equipments are available: the type with an optional DQ equipment separately set and the other with facility of DQ covering rapid cooling. Even the former has come to attain a cooling rate of more than $3{ }^{\circ} \mathrm{C} / \mathrm{s}$ to effectuate the further grain refinement. The positions of levelers behind rolls or water cooling equipments, the cooling of plates in motion or stationary and so on, are many different in present accelerated cooling systems, and the average cooling rate for $25 \mathrm{~mm}$ thickness ranges from 3 to $30^{\circ} \mathrm{C} / \mathrm{s}$. There are three basic cooling patterns as shown in Fig. V.2.3. Initial goals were reduction of the $\mathrm{C}_{\mathrm{eq}}$ in the available steel grades, saving of the alloy elements, and operation of the direct quenching. The further progress has extended to the production of steels used for the arctic zone offshore structures and the line pipes for sour environment service. These steel plates cannot be manufactured without use of the water cooling type TMCP. Right now no one can predict the most prospective cooling technique among the wide variety of cooling techniques mentioned above, including systematization of the DQ and tempered steel which is getting under way.

The accelerated cooling of heavy plate, different from the cooling on continuous hot rolling, requires a very strict control of water pouring for homogeneous cooling because of the large thickness and width of plate and the slow line speed. There remains difference in the thermal histories through plate thickness direction. Even by the interruption of water cooling at an intermediate temperature as (b) type in Fig. V.2.3, the subsequent air cooling does not produce the effect of structure stabilization similar to the isothermal transformation during extremely slow cooling after coiling. In the following various characteristics of the water cooling type TMCP will be explained.

The hardness variation through the thickness of plate cooled after CR, is more uniform than that water cooled after the conventional rolling or reheating.
This is because hardenability of $\gamma$ after rolling is lower in the subsurface than that in the interior by the temperature difference below the plate surface during GR.

A rise in the strength by accelerated cooling is achieved owing to increasing fraction of pearlite or low temperature transformation products and grain refinement of $\alpha$, and further strengthening of $\alpha$ matrix in water cooling below $300{ }^{\circ} \mathrm{C}$ (Fig. V.2.3 (c)). Therefore the water cooling should be started at a temperatures higher than the $A_{r 3}$ under its CR condition. Although a rise of 50 to $100 \mathrm{MPa}$ in strength is obtained by the accelerated cooling, the toughness equivalent to the air cooled steel is maintained since embrittlement caused by the change in second phase is compensated for by the further refinement of transformed structure. Consequently to guarantee the toughness, CR is indispensable. However, when the rolling of unrecrystallized $\gamma$ is extensively applied, especially for heavy gage plate, through-the-thickness variation of hardness becomes remarkable.

Precipitation hardening of $\alpha$ matrix by $\mathrm{Nb}$ or $\mathrm{V}$ may be theoretically more effective by interrupting water cooling at 600 to $500{ }^{\circ} \mathrm{C}$ than in overall air cooling, but due to the temperature difference in the plate thickness direction, this hardening is practically not reproducible. The practical use of $\mathrm{Nb}$ may be to minimize the decrease of strength in stress relief annealing and to stabilize the bainitic structure by reduction of the addition amount and application of the water cooling down to a lower temperature. High strength plates for line pipes and heavier plates for offshore structures have come to be manufactured by extra low temperature reheating of the low $\mathrm{C}-$ low $\mathrm{Nb}-\mathrm{B}-\mathrm{Ti}$ steel as ferrite-bainite steels.

Medium C-low Mn-steel steadily exhibits the strength of $500 \mathrm{MPa}$ by the cooling type of (c) shown in Fig. V.2.3 even when the $\mathrm{C}_{\mathrm{eq}}$ is less than 0.30, but the strength of weld joint is inevitably lowered by large heat-input welding. However, this steel is lowpriced and easy for manufacturing, and therefore, depending upon the results of the joint study between shipbuilders and steel makers in progress, it might be-

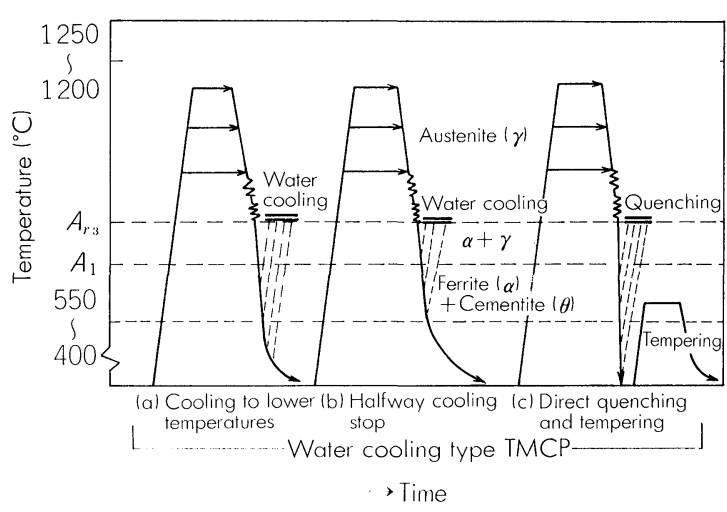

Fig. V.2.3. Thermo-mechanical history of water cooling type TMCP.

Source: Matsuda et al.: Seitetsu Kenkyu, (1982), No. 310, 277. 
come the main type of steel for shipbuilding in future.

The technique, which substitutes the off-line quenching of the conventional tempered steel with the direct quenching (Fig. V.2.3(c)), significantly depends upon the hardenability of rolled steel. In Ni-containing steel for low temperature use with sufficient hardenability, higher strength and toughness than in the reheated and quenched steel can be obtained by DQ after rolling in the non-recrystallization region. In the $800 \mathrm{MPa}$ grade steel, when low temperature rolling is strengthened beyond the refinement of recrystallized $\gamma$ grains, the hardenability becomes insufficient. Since the grain size obtained by rolling and recrystallization is coarser than those during reheating for quenching, hardenability of the as rolled steel is higher; reduction in the $\mathrm{C}_{\mathrm{eq}}$ becomes possible and the toughness is secured by tempering at a higher temperature than that of reheated steel. In the 600 $\mathrm{MPa}$ grade steel with low hardenability, there are 2 different opinions. One is that the same processing as in the $800 \mathrm{MPa}$ grade is applicable. The other is that, because even the reheated steel is not perfectly quenched, it is more effective to refine the structure by rolling in the non-recrystallization region. The difference between 2 opinions are based on the fact that the quenched structure of the conventional tempered steel significantly varies in these grades of steel. Consequently, a dialogue between metallurgy and equipment techniques might make it possible to switch the main stream of the $600 \mathrm{MPa}$ class steel into as-accelerated-cooled bainitic steel.

For future developments of the water cooling type TMCP steel, Nb and B will play great roles. Precipitation hardening and bainite stabilization by $\mathrm{Nb}$, which could have not been effectively used in the QT steels, can be made use of in a sequence of CR from a temperature for the complete solution of $\mathrm{Nb}$, water cooling, and tempering. The effectiveness of $B$ which raises hardenability may become different when B is used in the water cooling process directly after rolling. Taking into account of the needs for suppression of grain coarsening during slab reheating, high hardenability and application of the large heat-input welding, the basic composition should be Ti-B-low N-based steel. High strength dual phase steel plate for large heat-input welding has been developed by use of an extra low C-low N-Nb-BTi-chemistry and Delayed Direct Quenching (DDQ) process, which is the transfer of the experiences of DP hot rolled strip. In this DDQ process steel is controlled rolled and directly quenched after the appearance of proeutectoid $\alpha$ in deformed $\gamma$ matrix. The method, in which accelerated cooling is started when the temperature of surface becomes below the $A_{r 3}$ temperature, is also effective to homogenize the strength distribution in the thickness direction in the production of high toughness thicker plates being intensively controlled rolled.

\section{(5) Grain Boundary Segregation}

The general method of property control of steels is made by the microstructural control and controls of grain size, transformation products, and precipitates have made possible improvements of the material properties and reduction of the production costs. The properties related to grain boundary including intergranular embrittlement, intergranular corrosion, stress corrosion cracking, and intergranular hydrogeninduced embrittlement, which were relatively special problems, have become important with increasing strength of steels and use in severe environments. Progress in understanding of the grain boundary segregation characteristics in steels has made a great contribution to the improvements of these properties.

Temper brittleness was known to be induced by the impurity elements such as $\mathrm{P}, \mathrm{Sb}$, and $\mathrm{Sn}$. Observations on the intergranular fracture surface of prior $\gamma$ grains with the surface analysis methods like Auger Electron Spectroscopy have revealed the segregation behavior of impurity atoms to prior $\gamma$ grain boundaries during heat treatment in $\alpha$ region, leading to clarification of the relationship with mechanical properties. Important results are summarized in the followings.

(a) Impurity elements like $\mathrm{P}, \mathrm{Sb}$, and $\mathrm{Sn}$ are segregated in the prior $\gamma$ grain boundaries in a concentration $10^{2}$ to $10^{3}$ times higher than the matrix, the degree of concentration being well correlated to the embrittlement of steel.

(b) The segregation occurs in a limited zone of 2 or 3 atomic layers along grain boundaries.

(c) The grain boundary concentration of the impurity elements, which was measured quantitatively in various types of steels, can be interpreted in terms of the thermal history of steels and the equilibrium and kinetics of grain boundary segregation derived by $\mathrm{Mc}$ Lean.

(d) Effects of the alloying elements such as Si, Mn, Mo, and B are classified into the types having influences on the diffusion velocity of impurity atoms, their equilibrium segregation and the degree of embrittlement without change in the equilibrium segregation.

Following the pioneering studies in the USA, a systematic study has been made on the properties of steels and grain boundary segregation under auspices of the Joint Society on Iron and Steel Basic Research since 1975 to accumulate a lot of data on the contribution of metallurgical factors in available steels. Recently the studies have progressed into the more fundamental problems such as the grain boundary structure and segregation behavior, the state of impurity elements in boundaries, the effects of alloying in ternary systems, and the roles of $\mathrm{C}$ as a strengthening element of grain boundary.

On the basis of the studies on grain boundary segregation, prevention of temper embrittlement in high strength steels is intended through elimination of the impurities, purification of the steels, lowering of $\mathrm{Si}$ and $\mathrm{Mn}$ which promote the grain boundary embrittlement, and addition of REM, Ti, and $\mathrm{Nb}$ to suppress segregation of the impurities.

On the problems of low temperature embrittlement related to the grain boundary segregation of impurities in $\gamma$ region, there are little observations because 
of the difficulty in intergranular fracture.

(6) Elemental Concentration on Sheet Surface

Surface quality of annealed low $\mathrm{C}$ steel and bright annealed stainless steel sheets is influenced by segregation of the constituent elements on the sheet surface during annealing. With the surface analysis by means of SIMS, AES, and ESCA, concentration of the elements such as C, Mn, P, S, Cr, Ti, Al, B, and $\mathrm{N}$ on the surface of low $\mathrm{C}$ steel sheets and concentration of $\mathrm{Si}$ as high as 30 to $45 \mathrm{~atm} \%$ together with $\mathrm{Cr}, \mathrm{Mn}$, and $\mathrm{Al}$ on the surface of stainless steel sheets are reported.

The surface segregation behavior varies with the atomosphere; nonmetallic elements such as $\mathrm{S}, \mathrm{P}, \mathrm{N}$, and $\mathrm{C}$ are highly concentrated after vacuum annealing and $\mathrm{Si}, \mathrm{Mn}, \mathrm{Cr}, \mathrm{P}, \mathrm{Al}$, and $\mathrm{Ti}$ which have high potentials to oxidation than $\mathrm{Fe}$ are concentrated by forming the oxides after annealing in atmospheres. In both annealing conditions precipitation occurs on the sheet surface: graphite from $\mathrm{Fe}_{3} \mathrm{C}$ in steel, $\mathrm{BN}$ during atmospheric annealing of B-bearing low $\mathrm{C}$ steel (Fig. V.2.4), and TiN and $\mathrm{BN}$ precipitate on vacuum annealed stainless steel sheets.

The surface segregation under vacuum annealing is characterized in that the segregated layer is very thin, theoretically as thin as one atomic layer in spite of the extensively high concentration. The segregation behavior in the system free of interaction between segregating elements can be explained in terms of the equilibrium segregation theory by McLean with the driving force due to the Gibb's free energy. An extension of the McLean model has been proposed to apply in the presence of interaction between segregating elements and the occurrence of simultaneous segregation of different elements.

The surface concentration during atomospheric annealing is due to selective oxidation, producing a concentrated layer as thick as several tens to thousand A and sometimes precipitates of granular oxide. In the mixture of $\mathrm{H}_{2}$ and $\mathrm{N}_{2}$ gas, selective oxidation proceeds by the reaction with a small amount of water in the gas: $x \mathrm{M}+y \mathrm{H}_{2} \mathrm{O}=\mathrm{M}_{x} \mathrm{O}_{y}+y \mathrm{H}_{2}$. Therefore all the elements with a higher oxidation potential than $\mathrm{Fe}$ have thermodynamically a possibility to concentrate on the surface. Once the oxides form, the constituent elements move to the surface because of the concentration gradient below the surface formed by deple-

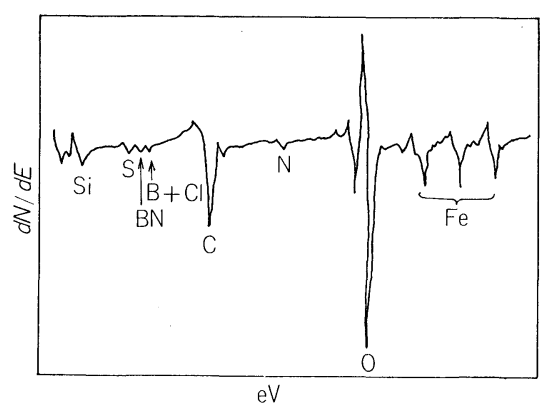

Fig. V.2.4. Auger electron spectrum of continuous annealed Ti-B steel.

Source: Maeda et al.: Tetsu-to-Hagané, 70 (1984), S459. tion due to oxidation and the thickness of concentrated layer increases successively.

In 1978 the presence of $\mathrm{C}$ on sheet surface is pointed out by Ford Motors to deteriorate the corrosion resistance after painting. Graphite was found in the segregated C. Since the findings that the presence of $\mathrm{Mn}$ suppresses surface segregation of $\mathrm{G}$ and enhances the phosphatability of steel sheets, controlling of the Mn contents and the dew point of atmospheres is made for prevention of the $C_{1}$ segregation and promotion of the concentration of $\mathrm{Mn}$ on the surface.

(7) Impurity Elements, High Purification, and Microalloying

The remarkable developments of steel products during the past decade were achieved by the effective use of microalloying elements and high purification, especially to overcome the problems associated with revolution of the processing by replacement of the ingot slabbing with the continuous casting and the batch annealing with the continuous annealing. Progresses of the analytical techniques in physical metallurgy have enabled understanding of the effectiveness of the individual alloying element, the harmfulness of the impurity elements and the mechanisms of stabilization of impurities by microalloying. The new knowledges have promoted the strict controlling of alloy addition and high purification, particularly in terms of elimination of $\mathrm{S}, \mathrm{P}$, and $\mathrm{N}$ in the steel making and the operation of rolling to effectuate the metallurgical controlling factors.

$\mathrm{S}$ in steel has an influence on the mechanical properties mainly as $\mathrm{MnS}$ inclusion elongated along the rolling direction in hot rolling. Since the brittle crack initiates from the $\mathrm{MnS}$ inclusion, lowering of $\mathrm{S}$ is effective for improvement of the susceptibility of brittle crack initiation in the transverse direction of heavy plate. There occurs a characteristic mode of fracture called separation in GR products; the frequency of separation increases with intensive $\mathrm{CR}$ and a higher $\mathrm{S}$ content for the same CR condition. The elongated $\mathrm{MnS}$ is considered to cause the separation or to favor the formation of texture to promote the separation. The occurrence of separation improves both the characteristics of initiation and arrest of brittle fracture. Therefore, in the CR plates, the initiation characteristics show a minimum at a certain level of $\mathrm{S}$ content, while the arrest characteristics deteriorate with an extensive reduction of $\mathrm{S}$. Ductility and toughness in the normal direction are improved by lowering of $\mathrm{S}$. Stabilization of S by $\mathrm{Zr}, \mathrm{REM}$, and Ca is effective for the inclusion shape control to change the $\mathrm{MnS}$ into undeformable in hot rolling as well as reduction of the amount of solute $S$. In wire rods and bars, lowering of $\mathrm{S}$ improves the drawing limit and drawability with increase in the reduction of area, since inclusions provide the sites of crack initiation.

Reduction of $\mathrm{S}$ content is effective for improvements of the resistance to oxidation at high temperatures and to corrosion in both austenitic and ferritic stainless steels. Observations on the extensive oxidation and also the initiation of corrosion arround $\mathrm{MnS}$ 
are reported.

Fixation of a small amount of solute $\mathrm{S}$ with Ca suppresses the cracking at SR, which is considered to be promoted by segregation of $\mathrm{S}$ on the surface of cavity or grain boundary crack by lowering the surface energy to sharpen the edge of crack for easy propagation.

Reduction of $\mathrm{P}$ effectively suppresses the hydrogen induced cracking (HIC) of high strength, especially continuously cast, steels for line pipes in the sour service. HIC, a kind of $\gamma$ intergranular fracture, is promoted by grain boundary segregation of $\mathrm{P}$ which enhances the susceptibility of $\gamma$ grain boundary embrittlement due to hydrogen. Solution hardening in the segregated zone of $\mathrm{P}$ is considered to be another factor for HIG. Lowering of $\mathrm{P}$ improves the stretch formability of ferritic stainless steels by decrease in the yield strength and rise in the work hardening coefficient owing to the high purification.

Besides the relation between $\mathrm{P}$ and temper brittleness mentioned in Sec. V.2.1.(5), the followings are known: enhancement of the embrittlement by segregation of $\mathrm{Mn}$ and by segregation of $\mathrm{P}$ promoted by $\mathrm{Mn}$ in the prior $\gamma$ grain boundary, recovery of the embrittlement accompanied by segregation of $\mathrm{P}$ and $\mathrm{Mn}$ through lowering of $\mathrm{Si}$ content, and effectiveness in the suppression of $\mathrm{P}$ diffusion to grain boundary by addition of Mo rather than by lowering of $\mathrm{Mn}$.

Elimination of solute $\mathrm{N}$ improves the toughness of base metal, as is well known in the normalizing of Alkilled steels. Even if $\mathrm{N}$ is stabilized by $\mathrm{Ti}$, a substantial amount of TiN is brought into solution in the HAZ, especially in the bond during large heat welding. Therefore the toughness of weld joint even in Ti-stabilized steels is remarkably increased by reduction in $\mathrm{N}$. There are cases when an excessive amount of $\mathrm{Al}$ is added to capture $\mathrm{N}$ in the bond during cooling.

Reduction of $\mathrm{G}$ and $\mathrm{N}$ effectively prevents the stress corrosion cracking in Gr-bearing structural steels and ferritic stainless steels. This is because high purification decreases the amount of carbonitrides in grain boundary and suppresses the formation of Cr-depleted zone.

Pure iron had been thought subjective to intergranular failure at low temperatures, however high purification is proved to suppress intergranular embrittlment even at $4.2 \mathrm{~K}$. Embrittlement of iron by addition of $0.1 \% \mathrm{P}$ is shown to be recovered by the presence of $0.001 \% \mathrm{C}$, possibly by the segregation of C along grain boundary. Further increase in the $\mathrm{C}$ content leads to occurrence of the cleavage fracture, indicating that a small amount of $\mathrm{G}$ strengthen the bond of grain boundaries by segregation.

As mentioned above, the addition of $\mathrm{Nb}$ and $\mathrm{Ti}$ less than $0.1 \%$ and $\mathrm{B}$ about 10 to $20 \mathrm{ppm}$ most strongly manifests the effects of alloying. These elements are the carbonitride forming elements and combines preferentially with $\mathrm{N}$. Their improper usage adversely results in a harmful effect. The addition of $\mathrm{Nb}$, which is effective for improving the mechanical properties of low $\mathrm{C}$ low alloy steels, brings about a reduction of ductility in the low temperature $r$ region particularly under low strain rate, and increases the susceptibility to cracking in continuously cast slabs. The cracking progresses along grain boundary as a consequence of the strain induced precipitation of $\mathrm{Nb}(\mathrm{C}, \mathrm{N})$ along grain boundary in the as-cast coarse $\gamma$ grains. Lowering of $\mathrm{N}$ is effective for prevention of the cracking, because it is considered to decrease the content of $\mathrm{N}$ in $\mathrm{Nb}(\mathrm{C}, \mathrm{N})$, the total amount of the precipitates, and to proceed the temperature of precipitation after the unbending point in casting. The addition of $\mathrm{Nb}$ is also effective for improvement of the weldability through lowering of $\mathrm{C}_{\mathrm{eq}}$. However $\mathrm{Nb}$ tends to diffuse into the weld metals and causes the development of coarse bainitic structure both in the bond and the weld metal, bringing about deterioration of the toughness of joint. Thus alloying of $\mathrm{Nb}$ must be kept at a necessary minimum.

The press formability of low $\mathrm{G}$ steel sheets is improved by addition of $\mathrm{Nb}$ to fix $\mathrm{G}$ and $\mathrm{N}$ in the $\alpha$ matrix. $\mathrm{Nb}$ acts for reduction of $\langle 001\rangle / / \mathrm{RD}$ component in the annealing texture which reduces the planar anisotropy of $r$-value and total elongation. Furthermore, increase in the total reduction in finishing stands of hot rolling contributes for the improvements of total elongation and $\bar{r}$-value which may be a result of coarsening of $\mathrm{Nb}(\mathrm{C}, \mathrm{N})$ in the hot rolling stage to effectuate the extensive grain growth in the final annealing.

In bar and rod, a combination of $\mathrm{Nb}$ addition and low temperature rolling enables the production of case hardened steel excellent in the cold forgeability. This is based on the improvement of toughness through prevention of the grain coarsening during carburization with the fine dispersion of $\mathrm{Nb}(\mathrm{C}, \mathrm{N})$ as in the normalizing of $\mathrm{Nb}$-bearing steels.

$\mathrm{Ti}$, in accordance with the alloying content mentioned above, is effective for suppression of the $r$ grain coarsening, improvement of the weldability, maintaining of the effectiveness of solute $\mathrm{B}$, and good press formability in the low $\mathrm{C}$ steel sheets.

The combined addition of $\mathrm{Ti}$ and $\mathrm{B}$ improves not only the toughness HAZ of the base metals but their addition to welding materials also improves the toughness of the weld metals. The effectiveness of B is to inhibit the formation of coarse $\alpha$ grains at the prior $\gamma$ grain boundary to be mentioned later. $\mathrm{Ti}$ combines with oxygen in the molten metal to be $\mathrm{TiO}_{2}$ which acts as the site for nucleation of $\alpha$ in $\gamma$ grain to refine the trasformation structure. Studies on the occurrence of $\alpha$ grains in the interior of prior $\gamma$ grains intended for improvement of the toughness both of HAZ and weld metal will extend to the effective use of the complex types of inclusions and precipitates in addition to the separate use of $\mathrm{TiN}$ or $\mathrm{TiO}_{2}$.

The presence of solute $B$ restrains the appearance of proeutectoid $\alpha$ in the quenched and tempered steels and the TMCP steels of water cooling or air cooling type and produces a structure rich in bainite and martensite. Stabilization of $\mathrm{N}$ by $\mathrm{Al}$ and $\mathrm{Nb}$ reduces the waste of solute $B$ due to the precipitation of $B N$. Addition of the stronger nitride-forming element like 
$\mathrm{Ti}$ together with reduction in $\mathrm{N}$ content increases the effectiveness of water cooling type TMCP and further microalloying of $\mathrm{Nb}$ stabilizes the bainitic structure. Since BN has a low solubility and a high precipitation rate, this is known to precipitate finely in the prior $\gamma$ grain boundary during tempering so as to induce an intensive intergranular embrittlement under a certain condition. Therefore stabilization of $\mathrm{N}$ by $\mathrm{Ti}$ is more indispensable in the TMCP steels than the quenched and tempered steels. B is also effective for improvement of the toughness of HAZ in large heat input welding, because the HAZ becomes brittle by formation of massive proeutectoid $\alpha$ at the prior boundary of coarse $\gamma$ grain. A combined addition of $\mathrm{Ti}$ and $\mathrm{B}$ or REM and B effectively produces a fine structure in the HAZ contributing to improvement of the toughness. In this case the occurrence of $\alpha$ grains in the interior of prior $\gamma$ grains is also observed.

$\mathrm{B}$ in cold rolled DP steels is considered to be highly partitioned in $\gamma$ phase during annealing in the two phase region and to suppress the diffusional transformation in the subsequent rapid cooling, providing an optimal dual phase structure of ferrite and martensite. There may be a possibility that $\mathrm{B}$ concentrates in the front of transforming $\gamma / \alpha$.

In the high strength rephosphorized steel sheets of deep drawing quality, elimination of the solute $\mathrm{C}$ by alloying of $\mathrm{Ti}$ tends to cause intergranular fracture in the redrawing of deep drawn article, in the similar way to the grain boundary embrittlement observed in pure iron. Addition of $\mathrm{B}$ as much as several ppm is effective to reduce the susceptibility to intergranular embrittlement. Segregation of B with a small atomic radius is considered to strengthen the grain boundary.

\section{2. 2. Evaluation and Utilization Technologies}

\section{(1) Unstable Fracture}

The toughness of irons and steels, used to be expressed by such V-Charpy impact values as $15 \mathrm{ft}-\mathrm{lb}$ or $35 \mathrm{ft}-\mathrm{lb}$ as empirically determined on the occasion of successive brittleness fracture accidents occurred in cargo ships and other structures, is now evaluated based on the fracture mechanics that has been developed to prevent fracture of machines and structures.

In other words, safety against a brittle fracture is considered to be satisfied when $K<K_{C}$ in the liner fracture mechanics approach, $\delta<\delta_{C}$ in the crack opening displacement (COD) concept in the elastoplastic fracture mechanics approach, and $J<J_{C}$ in the $J$ integral approach, the subscript $C$ denoting the critical value, and subscript $I$ (to appear presently), the plane strain condition. Here, the left side is the dynamic parameters which indicate the distribution condition of stress and strain near the crack tip, where $K$ is the stress intensity factor, of which the $K_{C}$ is often called the fracture toughness of the material concerned, $\delta$ the crack opening displacement, and $J$, the $J$ integral, any of which can be analytically or numerically determined for the particular material, crack geometry, dimensions, force, and displacement. Figure V.2.5 shows the application range of each parameter; here
$K_{I C}$ is for the cases of unstable fracture up to point A, while GOD and $J$ are for from A to B.

With the advancement in actual application, various standards have been established, first in the USA (ASTM, ASME, and others), and in U.K. (BS) and in Japan (JSME, JIS, WES). Namely, ASTM E399 (1970/1972) and BS 5447 (1977) were established as the $K_{I C}$ test method, BS $5763(1979)$ as the COD test method, and ASTM E813 (1981), JSME S001 (1981), as the $J_{I C}$ test method. Further, WES 3003 (1977), which gives a criterion for low temperature structure steels, and the ASME Code Section III, Appendix G (1972 and 1974), which is for steels for nuclear power generation equipment, made a great contribution in implementing the linear fracture mechanics notions in the actual designing.

Here, it is to be noted that WES Standard is intended to serve as criterion for quality control, so that it allows the steel to be ultimately evaluated by the easy-to-perform V-Charpy testing. This has been made possible by empirically as well as theoretically establishing, in much the same manner as accomplished by ASME between $K_{I C}$ and NDT of the NRL drop weight testing values, a correlation between the critical COD $\delta_{C}$ and the absorbed energy transition temperature ${ }_{\mathrm{V}} \mathcal{T}_{\mathrm{E}}\left({ }^{\circ} \mathrm{G}\right)$ in the $\mathrm{V}$-Charpy test and plate thickness $t(\mathrm{~mm})$, such that

$$
\begin{aligned}
& \delta_{c}=\left(117+T-\sigma_{y}-5 \sqrt{t}-{ }_{\mathrm{v}} \mathcal{T}_{\mathrm{E}}\right) / 125 \\
& \delta=3.5 \bar{a}\left(\sigma+0.6 \sigma_{y}\right) / E
\end{aligned}
$$

where, $\bar{a}$ : the one half of the assumed crack length (mm) which is given by $\bar{a}=309 \cdot \exp$ $\left(-0.0522 \sigma_{y}\right)$

$\sigma:$ the working stress $\left(\mathrm{kgf} / \mathrm{mm}^{2}\right)$.

Thus, today, the fracture mechanics method of designing is practiced in many fields such as pressure vessels, ship hulls, offshore structures, bridges, LNG tanks, aircrafts, and power turbine rotors.

Furthermore, even though the ductile fracture is generally stable, there can be an unstable ductile fracture that proceeds with ductile crack generation, crack stable growth (repetition of local fracture at the crack tip), and propagating shear fracture, particularly in such structures as the high-pressure gas pipeline. Here, because the natural gas has a larger compressibility than petroleum, the pressure reducing rate be-

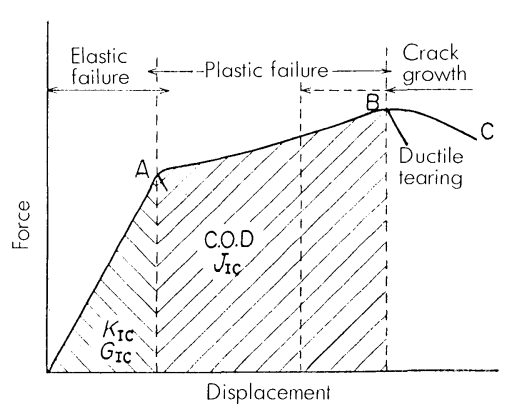

Fig. V.2.5. Relation between load and displacement in the fracture toughness testing.

Source: Mimura: Tetsu-to-Hagané, 64 (1978), 906. 
ing only about $400 \mathrm{~m} / \mathrm{s}$ compared with petroleum's about $2000 \mathrm{~m} / \mathrm{s}$, fracture of NG structures in an unstable ductile manner became a matter of grave concern as it became known that a ductile fracture can propagate at 100 to $300 \mathrm{~m} / \mathrm{s}$, and that this fracture is liable to occur in larger diameter and higher pressure pipelines.

Thus, full-scale pipe bursting test and laboratoryscale fracture reproducing tests have been carried out by the Battelle Memorial Research Institute, AISI, U.K., EG, Italy, and ISIJ. As a result, it has been made clear that separation observed in ordinary control-rolled (CR) steels does not affect the arresting performance of unstable ductile fracture, that an unstable ductile fracture is more liable to occur as notch ductility (ductile COD limit value) and notch toughness become lower, and that unstable propagation conditions are given by V-Charpy absorbed energy $C_{\mathrm{TV}}$ at the bursting test temperature:

$$
C_{\mathrm{VTT}} \geqq 5.2 \times 10^{-5} \sigma_{\mathrm{HO}}^{2} \sqrt{ } D B
$$

where, $\sigma_{\text {Но }}$ : the initial hoop stress $\left(\mathrm{kgf} / \mathrm{mm}^{2}\right)$ of the pipeline

$D:$ the diameter $(\mathrm{mm})$

$B$ : the thickness $(\mathrm{mm})$.

\section{(2) Fatigue Strength}

Fatigue crack propagation behavior is described by a $d a / d \mathcal{N}$ vs. $\Delta K$ curve on a $\log -\log$ plot as shown in Fig. V.2.6. Here, the region $\mathrm{I}$ is where the fatigue crack is initiated and starts to propagate at a rate $d a / d \mathcal{N}$ of about $10^{-8} \mathrm{~m} /$ cycle or lower, and there exists a lower limit to the $\Delta K$, under which the crack does not propagate, i.e., the threshold stress intensity factor, $\Delta K_{\text {th }}$. $\Delta K_{\text {th }}$ has been experimentally determined by analyzing available data determined in either the $K$ decreasing test method or the constant load test method. Thus,

for ductile steels:

$$
\begin{aligned}
& \Delta K_{\mathrm{th}}=32.1\left(5.88 \times 10^{-3}\right)^{1 / m} \\
& d a / d \mathcal{N}=1.70 \times 10^{-7}(\Delta K / 32.1)^{m}-10^{-9}
\end{aligned}
$$

for brittle steels :

$$
\Delta K_{\mathrm{th}}=15.5\left(8.64 \times 10^{-3}\right)^{1 / m}
$$

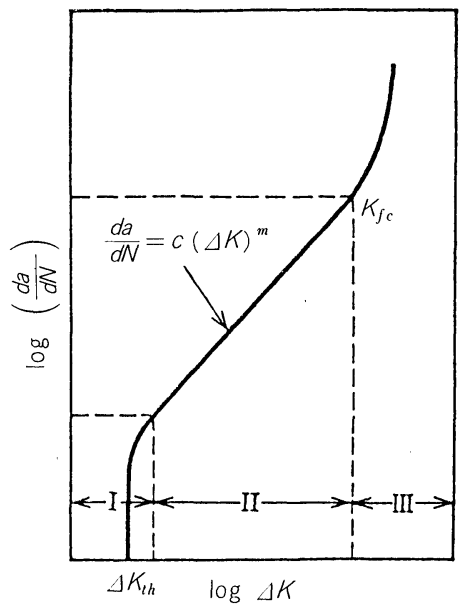

Fig. V.2.6. A typical $d a / d \mathcal{N}-K$ curve in fatigue.

$$
d a / d \mathcal{N}=2.89 \times 10^{-8}(\Delta K / 15.5)^{m}-2.5 \times 10^{-10}
$$

where, exponent $m$ is given by the Paris' power law, $d a / d \mathcal{N}=c(\Delta K)^{m}$, which is known to hold true in the region II. As $\Delta K_{\text {th }}$ may probably be related to the fatigue limit, which is one limit value in the fatigue fracture, researches on relationship between the two are being promoted.

The fatigue crack propagation rate $d a / d \mathcal{N}$ in the region II is $10^{-6}$ to $10^{-8} \mathrm{~m} /$ cycle, and it obeys the Paris' power law, where,

$$
\begin{aligned}
c & =A / \Delta K_{0}^{m} \\
A & =1.7 \times 10^{-4} \mathrm{~mm} / \text { cycle }
\end{aligned}
$$

and

$$
\Delta K_{0}=103.6 \mathrm{kgf} / \mathrm{mm}^{3 / 2}=32.1 \mathrm{MPam}^{1 / 2} .
$$

For the low temperature tempered martensite type low toughness steels of a $K_{I C} 200 \mathrm{kgf} / \mathrm{mm}^{3 / 2}$ or less, they are:

$$
\begin{aligned}
& c=A / \Delta K_{0}^{m} \\
& A=2.89 \times 10^{-9} \mathrm{~mm} / \text { cycle } \\
& \Delta K_{0}=49.9 \mathrm{kgf} / \mathrm{mm}^{3 / 2}=15.5 \mathrm{MPam}^{1 / 2} .
\end{aligned}
$$

Aside from the $\Delta K$, which is an elasticity concept, the effective stress intensity factor range $\Delta K_{\text {eff }}$, which was proposed to take the plastic deformation at the crack tip into consideration, is being examined. Namely, the opening / closing of the crack tip does not correspond to the tension / compression of the external force, as the crack may close before the load becomes nil, or even under a tensile load, due to the tensile residual deformation incurred on the newly created fracture surface. By correcting the formal $\Delta K_{C}$ for this fact through introducing the stress ratio $R=\sigma_{\min } / \sigma_{\max }(-1<R<0.7)$,

$$
d a / d \mathcal{N}=c\{(0.5+0.4 R) \Delta K\}^{m} .
$$

Since this equation includes the stress ratio, it is effective in evaluating crack propagation under a variable load with mean stress effects and excess stress effects.

In the region III, where $d a / d \mathcal{N}$ is about $10^{-6} \mathrm{~m} /$ cycle or more, the maximum value $K_{\max }$ is used, and $K_{\max }$ at the start of unstable fracture is called the fatigue fracture toughness $K_{\mathrm{fc}}$. Parameters $c, m, \Delta K_{\mathrm{th}}$ and $\Delta K_{\mathrm{fc}}$ are affected by the stress ratio (mean stress.)

Also, a stochastic approach to the fatigue crack propagation life is being tried. Namely, as the crack propagation life is deterministically decided since crack propagation rate $d a / d \mathcal{N}$ is unequivocally determined by $c(\Delta K)^{m}$, the variation of the fatigue fracture life must be due to the variation in the life expended in generating the crack in the region $\mathrm{I}$, and actually most of the fatigue life of real parts is consumed in I. Since the fatigue life is a sum of the crack initiation life $\mathcal{N}_{\mathrm{c}}$ and crack propagation life $\mathcal{N}_{\mathrm{p}}$, the total fatigue life distribution can be determined by the convolution integral of $\mathcal{N}_{\mathrm{c}}$ and $\mathcal{N}_{\mathrm{p}}$ if each life distribution is known. For this Monte Carlo simulation analysis is being tried. 
(3) Environmental Strength

\section{(i) Corrosion Fatigue}

The corrosion fatigue crack propagation velocity is described by the relation with $\Delta K$ or $\Delta K_{\text {eff }}$. Namely, in the crack opening / closing, besides the plastic deformation the wedge effect in which the corrosion product pushes the crack walls sideways acting as a wedge during the compression period of the cycle, has been observed in low carbon steels and high strength steels in $1 \% \mathrm{NaCl}$ solution, pure water, and other environments, though not for 304 stainless steel. And it has been shown that this wedge effect adapts itself well to the $\Delta K_{\text {eff }}$ analysis.

Correlations between fatigue, corrosion fatigue, stress corrosion cracking, creep, and creep fatigue are shown in Fig. V.2.7 for the homologous temperature and oxygen partial pressure. Here, the characteristics of the corrosion fatigue that have been ascertained are: (1) there is no fatigue limit; (2) since abrupt lowering in stress is sometimes observed near $t=500$ to $1000 \mathrm{~h}$ in the $S-\mathcal{N}$ (or $S-t$ ) curve following the initial descent, the long-term strength cannot be obtained by extrapolating the short-term $S-t$ curves; (3) though the stress corrosion cracking (SGG) occurs only for certain particular combinations of environment and material, but there is no such limitation for the corrosion fatigue; and (4) for 304 stainless steel, even though $d a / d \mathcal{N}$ is greater in pure water than in dried air, unlike SCG, it is not affected by $\mathrm{Cl}^{-}$concentration in 0.001 to $3 \% \mathrm{NaCl}$ solutions.

Contrarily, in high strength steels, interaction with SCG is evident. For example, in the cyclic SCG, where large stress amplitude loading (tension-tension) is repeated at a low speed, or in the dynamic SCG, where a small stress amplitude-high frequency loading is superimposed on a constant static load, the respective lower limit of the crack propagation $\Delta K_{\mathrm{s}}$, $\Delta K_{\mathrm{FSCC}}$ and $\Delta K_{\mathrm{DSCC}}$, are lowered as compared with $K_{\text {ISCC }}$ in static SCG.

The corrosion fatigue as well as SCG imposed on fatigue can be quite damaging for offshore oil drilling

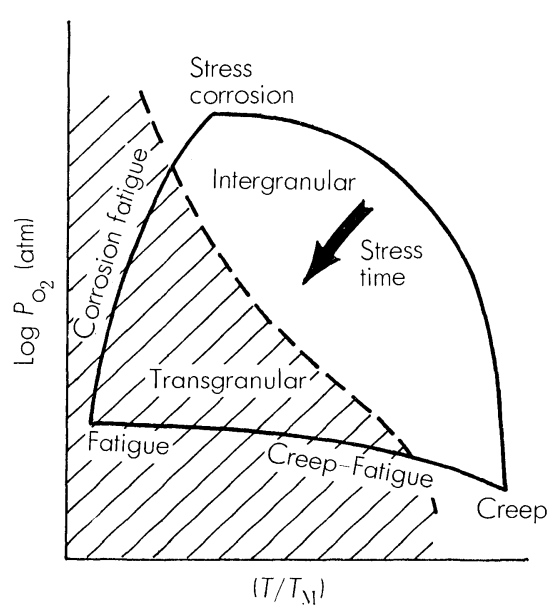

Fig. V.2.7. Mutual correlation between creep, fatigue, and stress corrosion cracking.

Source: C. H. Wells: High Temperature Fatigue in Fatigue and Microstructure, ASM, (1978), 307. equipments, but the corrosion prevention measures often adopted, such as heavy-duty paint coating for parts above the sea level, use of heavier gage plates or Monel overlay for the splash zone, and galvanic protection for the immersed portions. Those will help to improve the corrosion fatigue life and decrease the crack propagation velocity, provided an optimum cathode potential is chosen.

(ii) Stress Corrosion Cracking (SCC)

The SCG is a phenomenon which proceeds under static load accompanied by anodic dissolution. The relation between SGG crack propagation velocity $d a$ / $d t$ and $K_{\mathrm{I}}$ is divided into regions I, II, and III as in Fig. V.2.5. In I, there is a lower limit $K_{\text {ISCC }}$ for which $d a / d t$ becomes nil, in II, $d a / d t$ becomes almost constant irrespective of $K_{\mathrm{I}}$, and in III, an unstable fracture is caused when $d a / d t$ becomes $K_{\mathrm{IC}}$.

More recently, attempts at estimating the SGC life by means of the extreme-value statistical analysis are being made. Namely, since SCG, unlike the pitting corrosion, takes a long incubation time until crack initiation and propagation, the life distribution determined by the laboratory acceleration test must be stochastically evaluated and the relation between distribution parameters and the stress levels (severity of mechanical factors and environmental factors) must be made clear. Then, it has been shown that SCG life distribution of $18-8$ steel in $45 \% \mathrm{MgGl}$ solution approximates the Weibull distribution, and that for low carbon steels and 18-8 steel in high temperature pure water $\left(250{ }^{\circ} \mathrm{C}\right)$, it is approximately the exponential distribution. Relations between the distribution parameters and the stress levels (stress and temperature) are now being studied.

It has been known that SCG and fatigue are the damage modes which occupy a great portion of the accidents, and it turned out that the nuclear power plant was no exception; SCG had been found in a heat exchanger tube of alloy 600 of PWR, and in 304 stainless steel piping and others of BWR. For the latter, in particular, strenuous studies were conducted in the USA. and in Japan on a co-ordinated research basis on the occasion of the inter-granular SCG (IGSCG) accident discovered in a heat affected zone of a 304 piping welded joint in the USA in 1974. It was duly confirmed then that SCG in a BWR high temperature, pure water environment could occur only when three factors of the stress (strain), sensitization of material, and oxidizing environment (dissolved oxygen) were coexistent. Accordingly, effective SCG prevention measures have been established by developing a method of alleviating the welding residual stress, new stainless steels having no or little sensitization susceptivity, and the methods of deaeration for plant starting-up.

In the mean time, the study of low temperature sensitization (LTS) phenomenon, evaluation by means of the creviced bent beam (CBB) testing method or the slow extension rate test (SERT or SSRT), and nondestructive measurement of the degree of sensitization by the EPR (electrochemical potentio-kinetic reactivation) method had made a good progress into 
maturity.

(iii) Hydrogen Brittle Cracking

According to ASTM STP No. 543 Hydrogen Embrittlement Testing (1974), the embrittlement and fracture of steel due to hydrogen are categorized into (1) the internal reversible hydrogen embrittlement such as delayed fracture, welding low temperature cracking, hydrogen embrittlement (hydrogen brittle cracking), plating brittleness, SCG, etc., which ceases to operate further when the dissolved hydrogen is discharged from steel; (2) the hydrogen environment embrittlement, which is an embrittlement phenomenon of steel in high pressure hydrogen near room temperature, for example, fracture of the hydrogen storage tank at NASA; and (3) the hydrogen reaction embrittlement such as hydrogen induced cracking and hydrogen attack, which is due to methane gas formation or to hydrogen molecules occurring at a high temperature, different from (1) as it is irreversible phenomenon in that the defect that has occurred does not disappear even after discharging hydrogen. As those kinds of hydrogen attack are feared for the $\mathrm{Cr}-$ Mo steels, with or without a stainless steel overlay to improve corrosion resistance used in a large quantity in pressure reactor vessels for oil desulfurization, hydrocracking, coal liquefaction, etc., in direct contact with high temperature, high pressure hydrogen and hydrogen sulfide, measurement of hydrogen absorption, study of superimposition of the temper embrittlement, separation behavior of the stainless steel overlay, etc. are being carried out.

Concerning hydrogen induced cracking (HIG) in a humid environment containing hydrogen sulfide, vigorous studies have been undertaken until the latter half of the 1970s mainly in this country with the accident of Arabian gulf offshore linepipe made from the control-rolled API 5LX60 as an incentive. Influences of various metallurgical factors on $\mathrm{HIC}$ were satisfactorily clearified.

As for the sulfide SCG (SSGG), even though the NAGE standards have it that cracking will not occur for HRC 22 or below, according to recent studies, the hardness should be Hv 220 or lower (HRG 22 is equivalent to $\mathrm{Hv} 248$ ) for services in a severe environment.

With regards to the high tension bolts for bridges and railway bridges, those having a tensile strength of up to $130 \mathrm{kgf} / \mathrm{mm}^{2}$ have been used in this country. However, as the delayed cracking has been found in all the F13T class bolts, the use of those bolts has come to be prohibited by the JIS B1186. Further, in the $110 \mathrm{kgf} / \mathrm{mm}^{2} \mathrm{~F} 11 \mathrm{~T}$ class bolts were found delaycracked in 1977, and recommendation against their use has been issued.

In the meanwhile, it has been made clear in a statistical analysis of failures experienced that the life distribution to initiation of first cracking and the probability distribution of bolt fracture are both presented well by the Weibull distribution, and that the lowest hardness which generates the delayed fracture as determined in laboratory is HRG 41, though there have been examples of accidents with HRG 37.5.

\section{(4) Corrosion}

Local corrosion life estimation such as for pitting according to the extreme-value statistical analysis has been invigorated. This is to estimate the local corrosion life, of a machine or structure as a whole by stochastically analyzing the maximum local corrosion depths measured for small sections so as to estimate the maximum local corrosion depth of the machine and structure concerned by means of an appropriate local corrosion velocity equation. As an example of analysis of pitting of an oil storage tank base plate used for 13 years, the maximum pit depths, which were measured for 10 test pieces sampled at random, were plotted on an extreme-value probability chart. As a result, since the maximum value, $6.46 \mathrm{~mm}$, estimated with a probability of $68 \%$ exceeds the base plate initial thickness of $6 \mathrm{~mm}$, it was concluded that the possibility of leakage was high. In another example, low carbon steel feed / drain pipes for a water turbine, which had been used for 3 to 20 years at a hydroelectric power station, were examined by the extreme-value statistic analysis method. It was found that the local corrosion depths could be approximated with Poisson's distribution, and hence that the wall thickness for 30 service years should be $4.8 \mathrm{~mm}$ at a confidence level of $90 \%$.

As regards recent trends in the field of high temperature oxidation and corrosion, investigation of oxidation behavior in low oxidation potential atmosphere (He) and introduction of electrochemical method for the study of molten salt corrosion are worth mentioning. Salt corrosion is a contemporary subject, because it is related to grain boundary attack due to sulfudization in automotive engines, and to the development of coal-fired ultrahigh temperature, high pressure boilers and coal gasification plants.

In the study of molten salt corrosion, the past methodology had been measurement of mass change, microscopic observation of corrosion products, its interpretation based on the equilibrium theories, and material selection. Today, however, electrochemical measurement has come to be carried out as a combination of anode-dissolution reaction of steel and cathodic reducing reaction of molten salt in much the same manner as in aqueous solutions. Since a molten salt itself becomes an electrolytic bath, and measurements are performed at high temperatures the experimentation is rather difficult.

As for the development of high temperature gas cooled nuclear reactor (HTGR), it has been shown that corrosion resistance of materials in a high temperature HTGR atmosphere (to $1000^{\circ} \mathrm{C}$ ) shows a different behavior from that in a strong oxidizing atmosphere such as air, and that some alloys display inferior corrosion resistance. A simulated gas composed of $\mathrm{H}_{2} 200, \mathrm{H}_{2} \mathrm{O} 1$ to 2, $\mathrm{CO} 100, \mathrm{CO}_{2} 1$ to 2, $\mathrm{CH}_{4} 5$, $\mathrm{O}_{2}<5, \mathrm{~N}_{2}<5$, and He balance (in $\mu \mathrm{atm}$ ) has been proposed by the Japan Atomic Energy Research Institute. 
(5) High Temperature Strength

(i) High Temperature Fatigue

For estimation of creep cracking and high temperature fatigue cracking, elastoplasticity fracture mechanics has been applied. The crack propagation velocity $d a / d t$ in creep is evaluated in terms of the creep integral $\dot{J}$, which is a modified $J$ integral, as $d a / d t=$ $c \boldsymbol{J}^{m}$, where $c$ and $m$ are constants.

The crack propagation velocity $d a / d \mathcal{N}$ in high temperature fatigue, on the other hand, is indicated by the fatigue $J$ integral $\Delta J_{f}$ as $d a / d \mathcal{N}=c_{f} \Delta j_{f}^{m_{f}}$ where $c_{f}$ and $m_{f}$ are constants.

For fatigue in the creep temperature range, the linear damage rule that stipulates the fracture to take place when $\sum\left(t_{i} / t_{r}\right)+\sum\left(\mathcal{N}_{i} / \mathcal{N}_{f}\right)=1$, is satisfied. Here, $t_{r}$ and $\mathcal{N}_{f}$ are respectively the creep rupture time and the fatigue rupture cycles under a certain load condition, and $t_{i}$ and $\mathcal{N}_{i}$ are respectively the creep loading time and actually accumulated repetition under a load condition $i$. For nuclear power equipments, the ASME Section III Code Case N47 makes use of the following equation on the basis of this linear damage rule:

$$
\sum_{j=1}^{p}\left(t / T_{A}\right)_{j}+\sum_{k=1}^{q}\left(n / \mathcal{N}_{d}\right)_{k} \leq D
$$

where, $\mathcal{T}_{A}:$ the allowable creep time

$\mathcal{N}_{d}:$ the allowable repetition

$t$ : the creep loading time

$n$ : the actual accumulated repetition.

Substituting the linear damage rule, the strain partitioning method has been proposed as a more accurate estimation method. According to this, fracture occurs when

$$
\sum n / \mathcal{N}_{\mathrm{pp}}+\sum n / \mathcal{N}_{\mathrm{pc}}+\sum n / \mathcal{N}_{\mathrm{cp}}+\sum n / \mathcal{N}_{\mathrm{cc}}=1
$$

where $\mathcal{N}$ 's are to be empirically determined to correspond to the 4 typical cases, into which the hysteresis loop of fatigue concerned is divided as shown in Fig. V.2.8. Namely, for each, a relation between
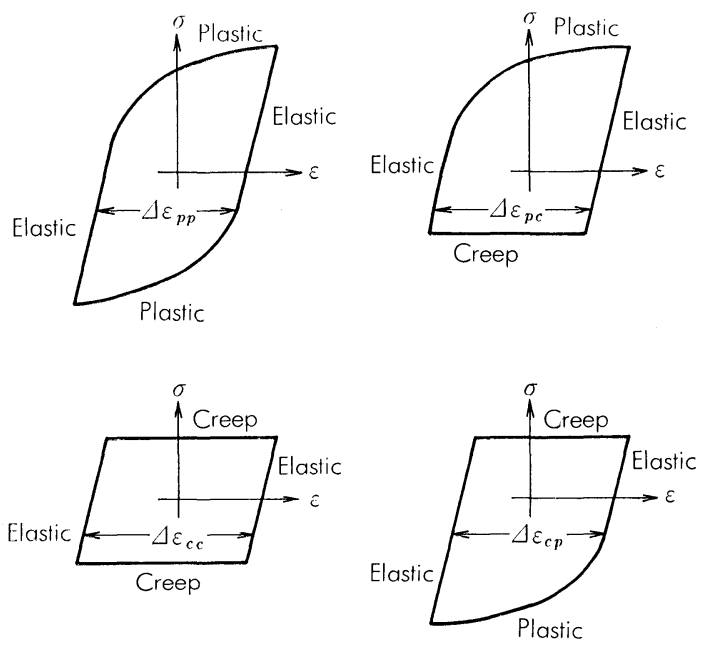

Fig. V.2.8. The 4 basic hysteresis loops in nonelastic strain range in the strain range dividing method.

Source: G. R. Halford et al.: NASA TMX 68023, (1972). plastic strain amplitude and the life is experimentally determined, and the actual loading is presented as the combination of those 4 cases, where $\mathcal{N}_{\mathrm{pp}}, \mathcal{N}_{\mathrm{pc}}, \mathcal{N}_{\mathrm{cp}}$ and $\mathcal{N}_{\text {ce }}$ are the repetition of $\varepsilon_{\mathrm{pp}}, \varepsilon_{\mathrm{pc}}, \varepsilon_{\mathrm{cp}}$, and $\varepsilon_{\mathrm{cc}}$, respectively, and the damage per a cycle is obtained as the reciprocal of $\mathcal{N}_{\mathrm{pp}}$, etc.

(ii) Creep

When a structure is designed in accordance with the ASME Code Case N47, the stress corresponding to the $1 \%$ creep strain, that to the onset of the tertiary creep, the creep constitutive equation, as well as the creep rupture time need be determined. Therefore, the creep strain and the creep curve have now come to be measured in the long-term creep testings.

Along with this development, evaluation of the strength of nickel-base superalloys in low oxidation potential atmosphere ( $\mathrm{He}$ ), and mapping of the deformation mechanisms for 304 stainless steel, $\mathrm{Cr}-\mathrm{Mo}-$ $\mathrm{V}$ steel, and others have made a progress.

(6) Evaluation of Defect and Estimation of Remaining Life

The JIS Z3060, 3061, 3104, together with the ASME Section V Nondestructive Examination (1971) cover 7 methods of X-ray, ultrasonic, magnetic particles, liquid penetrant, eddy current, visual, and leakage. Of these, the ultrasonic flaw detection method has made a remarkable advance in the practical uses such as development of the quantitative evaluation techniques pertaining to the position, shape, dimensions of cracks and to improvement in reliability under a strong urge on the part of the nuclear power plants. As for the evaluation of allowable cracks on the basis of the fracture machanics, the ASME Section XI Appendix A (1974), WES 2805 (1977) and some other provide plausible approaches.

Other notable progress achieved in the past decade include the application of fractography to fracture analysis, application of the extreme-value statistical analysis method and the corrosion monitoring technique for local corrosions, and development and application of the remaining life estimation through the quantitative micrography to power turbine rotors, boiler tubes, reformer tubes, and cracking tubes of petrochemical plants, and many others.

Also, the collaborative data base formulation for fatigue, creep, and other high temperature properties of metals and alloys, being undertaken by the ISIJ and the National Research Institute for Metals, the Agency of Industrial Science and Technology of MITI, has made a great progress.

\section{(7) Design Philosophy}

There has been a drastic change in the design philosophy. Namely, where designing used to be infinite life basis, in that the parts so designed cannot conceptually fail for ever, the increased size and improved performance of machines and structures have made such demands unrealistic. As a result, the finite life design, in which the parts are designed not to fracture at least during the given service time period and for loading repetition, has come to be adopted as in ASME Sections III and VIII. 
Also, there has been a change over from the traditional safe-life philosophy, in which designing is to be done so as not to let fatigue crack and creep crack occur, to fail-safe philosophy. Examples are the ASME Section (1972) and the MIL STD 1530A (1975), which have been drawn under a realization that defects can exist in machines and structures that cannot or could not be detected. Accordingly, the philosophy of designing is to ensure that the soundness of remaining members is not impaired even if some parts have been cracked, and that the crack which has occurred will not damage the soundness of remaining members before discovered on the next inspection.

Diffusion of this notion and accumulation of necessary data is steadily progressing here.

\section{3. Steel Products}

\section{3. 1. Steel for Structures}

\section{(1) Overview}

The demands for heavy plate, which is the main material for welded structure, have remarkably varied due to the changes of needs in the market from mass consumption and transportation as exemplified by the colossal oil tankers and tanks and large-scale public investments such as construction of large bridges into a variety of products with high performances to meet for extensive saving and exploitation of energy.

The changes in market needs have brought a new field of usage, changes in design philosophy, improvements in reliability, pursuit of economy, developments of softwares for effective and efficient use of the products, and innovation of the steel production technology. The followings are the examples: extensive adoption of the low carbon equivalent of HT-50 for energy-saving ships, and development of the high strength and high toughness steel for offshore structures in the North Sea and the Arctic Ocean.

As regards the manufacturing techniques, great progresses have been achieved in the highly pure and clean steel manufacturing technique, the continuous casting and the thermo-mechanical controlled process (TMCP), for fulfilment of the improved and diversified requirements of material properties. High purity steels with $\mathrm{P}$ and $\mathrm{S}$ as low as $10 \mathrm{ppm}$ can be manufactured on an industrial scale according to the development of hot metal treatment and the molten steel secondary refining, resulting in improvements in various properties of the steel. The ratio of continuous casting process has reached about $95 \%$ at the end of 1983 and the hot charging of slabs into reheating furnace has been widely executed with improvement in the surface quality. Developments in the techniques of electromagnetic stirring and steel-making for elimination of the central segregation in slabs have enabled an expansion of steels applicable to continuous casting as far as the $9 \% \mathrm{Ni}$ steel and the steels for pressure vessels. The technologies of TMCP have reached to the stage of practical application as an integrated processing system of controlling rolling and cooling as an extension of the developments in direct quenching and controlled rolling after the 1960s. These new processes are applied for production of the steels of $50 \mathrm{kgf} / \mathrm{mm}^{2}$ grade for shipbuilding and offshore structures and may become the main manufacturing technique of the steels for welded structures, together with application of direct quenching and tempering to high tension steels having tensile strengths of $60 \mathrm{kgf} / \mathrm{mm}^{2}$ or larger, to meet for the market demands of improved strength, good weldability, and high toughness.

In the processes throughout the making, shaping, and shipment, establishment of the managing system of automation, quality control, and integration has made a great contribution to the production of steels with high quality, good uniformity, and improved reliability.

Also, in the materials and methods of welding which is closely related to the weldable structural steels, great improvements were made to cope with the requirements for higher performances and efficiency in welding. The large heat input welding method, the high toughness welding materials ( $\mathrm{Ti}-\mathrm{B}$ alloyed), and the narrow gap welding method have become available on a commercial basis.

Greater safety for welded structures has been required year after year, and studies concerning the rational criterion for prediction of fractures in various modes are being actively carried out world wide under the auspice of the relevant societies and institutes. As a consequence WES3003G (Evaluation Criterion of Structural Steels for Low Temperature Application) was revised based on the COD concept on December 1, 1983. A joint group studying the criteria for the use of TMCP steel has started recently.

In the fields in which the new type of steel is applied for new uses such as the offshore structures, properties of fatigue (corrosion fatigue), SCC, and corrosion resistance are the important problems for further studies.

Together with these activities associated with the changes in market structure, the basic studies sponsored by the Joint Society on Iron and Steel Basic Research and the Comittee on Hot Rolling Process Metallurgy have provided the basic understandings of underlying metallurgy of the processing and the properties of steels.

The main improvements in various types of steels in the last decade will be reviewed in the following together with the future problems.

\section{(2) Steel for Welded Structures \\ (i) Steel for Shipbuilding}

Extensive adoption of the welding for shipbuilding and large increase in the building of ships after the war, promoted application of the block construction method and enlargement of the vessels. However, the amounts of cargo movements and shipbuildings have drastically decreased as a consequence of the slump in the world economy since the oil crisis in 1973. Steel for shipbuilding has been changed from semikilled steel into killed steel as the wide adoption of continuous casting. Also, a remarkable improve- 
ment in internal quality of steel has been observed during this period. Improvements in rolling techniques, especially introduction and improvements of the process computer, increase in the accuracy of various sensors, development of the FFAGG (Feed forward AGG) combined with hydraulic AGC and process computer, and the technique of AGG by absolute thickness model have lead to precise control of the dimension and shape of the rolled products. The Steel Material Specification for Shipbuilding was revised in 1978 together with unification of the Rules for the Construction and Classification of Steel Shops of various countries and revision of the standard for each grade of the steel which is used for various parts of ship vessel.

Construction of a variety of vessels for special purpose also progressed: bulk carriers, container ships, and LPG carriers. The first full-scale large roll on/ roll off ship was constructed in 1978 and MRV type LNG carriers which load five spherical LNG tanks, appeared in 1977.

On the other hand, use of high tension steel (50 $\mathrm{kgf} / \mathrm{mm}^{2} \mathrm{HT}$ ) for reduction of vessel weight to save energy has promoted the development of a new grade of HT-50 which could be welded at a large heat input. High tensile steels with improved weldability have been successfully produced by the new controlled rolling technique in 1978. The improved weldability also resulted in labor saving welding operation. Especially, since the successful application of HT-50 with low weld-cracking sensibility having $\mathrm{C}_{\mathrm{eq}}$ of 0.30 to 0.36 produced by TMCP of accelerated cooling type, the trend of using high tension steel further expanded (Fig. V.3.1). Employment of stainless clad steels in product carriers and chemical tankers is also to be noted.

In the future, ships for special purposes will increase in their number and type, and various ships which require developments of new technologies, such as coal-burning ships, ice breaking ships, COM ships (loading coal and oil mixture) and gas turbine ships, are expected to be built, and the new steel products of heavier gages with high toughness and good weldability will be required.

\section{(a) Steel for Large Heat Input Welding}

Employment of the block construction method and the larger heat input welding progressed for increase in the productivity of building and the size of the hull. Efficient welding with a large heat input has been successfully applied by developments of the steels highly resistant to deterioration of toughness in the heat affected zone (HAZ). Since Charpy impact requirements for the welded joints were specified in the Rules of Classification Society of Ships in 1978, this development has been remarkably promoted. Table V.3.1

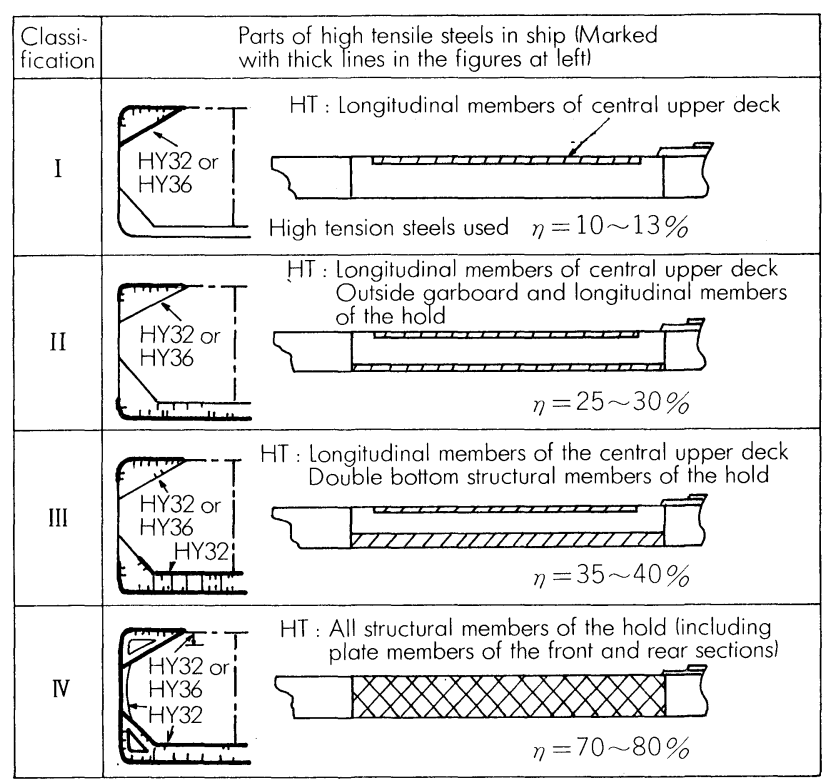

Fig. V.3.1. Parts of ship applied high tensile steels.

Source: Symp. of Application of New TMCP Steels to Welded Structures, Japan Shipbuilding Soc., (1983).

Table V.3.1. Causes and method of reducing embrittlement in HAZ by large heat-input welding.

\begin{tabular}{|c|c|c|c|c|}
\hline \multirow{2}{*}{ Factor } & \multirow{2}{*}{$\begin{array}{l}\text { Causes for } \\
\text { embrittlement }\end{array}$} & \multicolumn{2}{|c|}{ Embrittlement reduction method } & \multirow{2}{*}{$\begin{array}{l}\text { Steel grade for } \\
\text { the measure to } \\
\text { be applied }\end{array}$} \\
\hline & & Metallurgical measure & Concrete measure & \\
\hline \multirow{4}{*}{$\begin{array}{l}\text { Crystal } \\
\text { grains } \\
\text { Structure }\end{array}$} & $\begin{array}{l}\text { Coarsening } \\
\text { of } \gamma \text { grains }\end{array}$ & $\begin{array}{l}\text { Fine dispersion of precipitates } \\
\text { stable at high temperature }\end{array}$ & Fine dispersion of $\mathrm{TiN}$ & $\begin{array}{l}\text { Al killed steels } \\
\text { for low temper- } \\
\text { ature use }\end{array}$ \\
\hline & $\begin{array}{l}\text { Formation of } \\
\text { upper bainite } \\
\text { (Formation } \\
\text { of island } \\
\text { martensite) }\end{array}$ & $\begin{array}{l}\text { Formation of fine ferrite and } \\
\text { pearlite }\end{array}$ & $\begin{array}{l}\text { Dispersion of TiN, BN, REM- and } \\
\text { Ca-compounds which act as nuclei } \\
\text { ferrite transformation } \\
\text { - Lowering } \mathrm{C}_{\mathrm{eq}}\end{array}$ & $\begin{array}{l}\text { HT }-50 \\
\text { HT }-60\end{array}$ \\
\hline & & $\begin{array}{l}\text { Decreasing the amount of island } \\
\text { martensite in the coarse upper } \\
\text { bainitic structure }\end{array}$ & $\begin{array}{l}\circ \text { Decreasing } \mathrm{C} \text {, Lowering } \mathrm{C}_{\mathrm{ou}} \\
\circ \text { Decreasing } \mathrm{Si}\end{array}$ & $\begin{array}{l}\text { HТ }-60 \\
\text { НТ }-80\end{array}$ \\
\hline & & Formation of lower bainite & $\begin{array}{l}\text { Addition of elements enhancing hard- } \\
\text { enability (Ni, Cr and Mo), elc. }\end{array}$ & $\begin{array}{l}\text { HT }-80 \\
\text { HT-100 }\end{array}$ \\
\hline $\begin{array}{l}\text { Toughness } \\
\text { of matrix }\end{array}$ & - & $\begin{array}{l}\text { Decreasing impurity elements } \\
\text { Addition of elements improving } \\
\text { toughness }\end{array}$ & $\begin{array}{l}\text { - Decreasing } \mathrm{P}, \mathrm{S} \text { and } \mathrm{N} \\
\circ \text { Addition of } \mathrm{Ni}\end{array}$ & $\begin{array}{l}\text { All steel grades } \\
\text { HT-80 } \\
\text { HT-100 }\end{array}$ \\
\hline
\end{tabular}


summarizes the metallurgical concepts for prevention of embrittlement in HAZ. In the early stage, the aiming of development was mainly at fine dispersion of insoluble TiN to prevent the coarsening of $\gamma$ grains due to welding heat. However, since the high $\mathrm{C}$ island martensite which generates in the portion heated to the $\alpha-\gamma$-two-phase area during welding, was found to embrittle HAZ together with $\gamma$ grain coarsening, reduction of $\mathrm{G}$ in steel progressed. Recently, achieving substantial reduction in $\mathrm{C}_{\text {and }} \mathrm{C}_{\mathrm{eq}}$ by adoption of the accelerated cooling type TMCP and by newly developed low $\mathrm{N}$ refining techniques, led to production of the heavy plates for shipbuilding for which large heat input welding is applicable, especially without addition of alloying elements for prevention of $\gamma$ grain coarsening.

\section{(ii) Steels for Offshore Structures}

Natural gases and oil were mainly exploited in shallow sea zones, however, after the oil crisis in order to obtain low-priced energy, the sources of natural gases and oil have come to be sought in cold districts and deep sea areas such as the North Sea and the Arctic Ocean, with highly corrosive environments for the steels. Consequently, the marine structures for exploitation have been not only enlarged but specialized for particular purposes, and the demands for HT-50 and high tensile strength steels having special performances such as the good fatigue strength in sea water and $K_{\text {ISCC }}$ (Fracture toughness for stress corrosion cracking) besides the general performances such as weld-cracking resistance, are increasing.

\section{(a) Steels Resistant to Lamellar Tear}

Occurrence of lamellar tear has been known in the ship building field since around 1954. With increase in the building of offshore structures, research and development of lamellar-tear-resistant steel has rapidly progressed. This is because there is a high possibility of lamellar tearing at a node connected with a truss, where the long fillet welding has been carried out. The evaluation method of resistance to lamellar tear has recently progressed and has been standardized by the Classification Society of Ships thereby making it possible to manufacture the steels which have almost no problems. The following types of researches on improvement of lamellar-tear-resistance were carried out: Control of inclusion shape by $\mathrm{Ca}$ injection, study of reducing $\mathrm{S}$, de-hydrogenation and countermeasures to prevention of porosity defects and segregation. As a result of these researches, successful production of lameller-tear-resistant steels has been established.

(b) HT-50 with High Toughness for Offshore Structures

Enlargement of the marine structures in deep sea zone resulted in the needs to saving costs and shortening the construction time and a new type rig was studied, which brought about the need for new steels. Due to the capsizing of the Alexander L. Kielland which took place in Ekofisk field in the North Sea in 1980 , this requirement is rapidly progressing and more attention is being paid to the performance of welded portions. Requirements for restrictions of the hardness and the COD value in welded joint are mounting and these countermeasures are being realized by development of the accelerated cooling type and nonaccelerated cooling type TMCP. HT-50 by TMCP was used for the artificial island in the Beaufort Sea in Canada and for production rigs in the North Sea. The steels used for off shore structures have come to be of excellent properties as shown in Table V.3.2.

\section{(c) High Tensile Strength Steel}

Until now HT-60 has not been greatly used for offshore structures; however, a plan to use HT-60 for low temperature use for rigs employed in deep seas is being considered, and a technical study is being made. Extra heavy gage HT-80 plate, 100 to $180 \mathrm{~mm}$ thickness, are used for the racks of elevator by modification of the weldability of $\mathrm{Ni}-\mathrm{Cr}-\mathrm{Mo}$-steel.

(iii) Steel for Bridges and Buildings

Due to the fatigue strength problems Japan has regulations for use of the high tensile steels for railway bridge, practically impossible to use. However, the steels are approved for road bridges, and HT-60 has been widely used for many bridges since 1960 .

On the other hand, an example of the proper use of high tensile steels of HT-70 and above in Japan

Table V.3.2. Examples of HT-50 steel using in the latest offshore structures.

\begin{tabular}{|c|c|c|c|c|c|}
\hline $\begin{array}{c}\text { Type } \\
\text { Sea area under operation }\end{array}$ & $\begin{array}{l}\text { Owner Classification } \\
\text { society of ships }\end{array}$ & Steel grade & $\begin{array}{c}\text { Thickness } \\
(\mathrm{mm})\end{array}$ & $\begin{array}{l}\text { CVN requirement } \\
\text { for base metal }\end{array}$ & $\begin{array}{l}\text { CVN requirement } \\
\text { for welded joint }\end{array}$ \\
\hline $\begin{array}{l}\text { Conical type drilling rig } \\
\text { Arctic Ocean }\end{array}$ & $\begin{array}{l}\text { GULF GANADA } \\
\text { ABS }\end{array}$ & $\begin{array}{l}\text { EH } 36 \text { (II) } \\
\text { EH } 32 \text { (II) }\end{array}$ & $\leq 38$ & $-60^{\circ} \mathrm{C}, \geq 3.5 \mathrm{kgf} / \mathrm{m}$ & $\begin{array}{l}-60^{\circ} \mathrm{C}, \geq 3.5 \mathrm{kgf} / \mathrm{m} \\
\text { Heat input } \leq 50 \mathrm{~kJ}\end{array}$ \\
\hline $\begin{array}{l}\text { Semi-submergible type drilling rig } \\
\text { Beaufort sea in Canada }\end{array}$ & $\begin{array}{l}\text { SEDCO } \\
\text { ABS }\end{array}$ & EH 32 & $\leq 20$ & $-50^{\circ} \mathrm{C}, \geq 3.5 \mathrm{kgf} / \mathrm{m}$ & $\begin{array}{l}-50^{\circ} \mathrm{C}, \geq 3.5 \mathrm{kgf} / \mathrm{m} \\
\text { Heat input } 50 \mathrm{~kJ}\end{array}$ \\
\hline $\begin{array}{l}\text { Tension leg platform } \\
\text { North Sea }\end{array}$ & CONOCO & BS $50 \mathrm{E}$ & $\leq 80$ & $-40^{\circ} \mathrm{C}, \geq 35 \mathrm{~J}$ & $\begin{array}{l}-30^{\circ} \mathrm{C}, \geq 35 \mathrm{~kJ} \\
\text { Heat input } \leq 35 \mathrm{~kJ}\end{array}$ \\
\hline $\begin{array}{l}\text { Man-made island } \\
\text { Arctic Ocean }\end{array}$ & GULF & EH $36-060$ & $\leq 38$ & $-60^{\circ} \mathrm{C}, \geq 2.8 \mathrm{kgf} / \mathrm{m}$ & $-60^{\circ} \mathrm{C}, \geq 2.8 \mathrm{kgf} / \mathrm{m}$ \\
\hline $\begin{array}{l}\text { Semi-submergible type drilling rig } \\
\text { Arctic Ocean }\end{array}$ & SONAT & $\begin{array}{ll}\text { N } 36 & \text { E-2 } \\
\text { N } 32 & \text { E-2 }\end{array}$ & $\leq 80$ & $-60^{\circ} \mathrm{C}, \geq 34 \mathrm{~J}$ & $\begin{array}{l}-60^{\circ} \mathrm{C}, \geq 34 \mathrm{~J} \\
\text { Heat input } \leq 50 \mathrm{~kJ}\end{array}$ \\
\hline
\end{tabular}


was that for the Minato-ohashi, the bridge in Osaka in 1974; large quantities of HT-70 and HT-80 with the maximum thickness of $75 \mathrm{~mm}$, reduced $\mathrm{C}_{\mathrm{eq}}$ for prevention of weld cracking, and secured for the toughness in weldments by application of the submerge arc welding with restriction for heat input.

After that there has been no case of full-scale use of HT-70 and HT-80 for a large bridge, however, these grades of steel are going to be used for the Bannosu, (length: $2939 \mathrm{~m}$ ) and the Yoshima elevated bridges on the Kojima to Sakaide route of the connecting road between the Japan main land and the Shikoku island in the near future.

Atmospheric corrosion resisting steels have been used in large quantity for bridge girders of highways and buildings with stabilization treated or coated. After standardization in JIS of atmospheric corrosion resisting steel (SMA 50W) in 1982, bridges employing steels without painting began to be built in Japan. The development of high grade atmospheric corrosion resisting steel plates of low-C-high-P steels and the modified steels by TMCP have been made, which are promising for wider application owing to their excellent weld-cracking resistance.

(iv) Steel for Storage Tanks and Spherical Pressure Vessels

Since the accident at Mizushima in 1974, technical standard for oil storage tank was reviewed for safety. After 1979 the petroleum reservation plan of the Japanese government has been promoted, which results in building a large number of petroleum storage tanks with HT-60 at many places in Japan. Storage tanks built in cold districts such as Tomakomai required high notch toughness even of welded joints by the electro gas welding, and therefore HT-60 with large heat-input weldability was developed, and used.

For the spherical pressure vessels, Structure Standards for Pressure Vessles JIS B 8243, were established in 1976, as a result of the review by taking account of the past experiences with spherical tanks. Application Standards of High Tensile Strength Steel (Notification complementing High Pressure Gas Control Law) were laid down in 1980, thus standardizing the steels for spherical tanks. The switch-over from city gas to LNG for a calorie rise in the leading gas companies, the number of large scale spherical tanks built using HT-80 has decreased. Instead of HT-80, use of the crack-free type HT-60 whose weld-cracking resistance was significantly enhanced by reducing $\mathrm{P}_{\mathrm{CM}}$, was generalized. Structure Standard, JIS B 8250, was established in 1982 by reviewing the design specifications of pressure vessels, but it has not seen the light of day because the High Pressure Gas Control Law has not been amended.

\section{(v) Steels for Earth Moving Machinery}

In the earth moving machinery such as truck cranes, shoveldozers, bulldozers and dump trucks has become larger and of high performance, high tension steels such as HT-60 and HT-80 have been used. To pursue economical efficiency, as-rolled type HT-70 and economical type HT-80 having no expensive al- loying elements have been developed.

A series of abrasion resistant steels have been developed for bulldozer blades, dump truck beds, shovel buckets, etc., which are all exposed to severe wear, and also the abrasion-proof steels guaranteeing HB-400 have been developed and used.

\section{(vi) Power Station Facilities}

It was 1960 when HT-60 were applied in this field for the first time in Japan. Considering the increase in $H \times D$ ( $H$ : head in meters, $D$ : inside diameter of pipe shell in meters) accompanied by the construction of pumping-up hydraulic power station, the use of high tensile steels such as HT-70 and HT-80 have become universal. The highest capacity now existing in Japan belongs to the Okuyoshino Power Station (1 $200000 \mathrm{~kW}$ ) of the Kansai Electric Power, and HT-80 steel of the maximum $78 \mathrm{~mm}$ thick, has been employed for its penstocks, by reducing the $\mathrm{C}_{\mathrm{eq}}$ below $0.53 \%$ for welding in the high humidity inside tunnels. Soft joints have been utilized for HT-80 of $50 \mathrm{~mm}$ thickness in the Honkawa Power Plant (Shikoku Electric Power) for the first time in Japan.

A plan has been made to construct a number of pumped storage power plants to make use of night surplus electricity along with the increase in nuclearpower generation ratio in the future. Many of these power plants are provided with a fall exceeding $1000 \mathrm{~m}$ so as to enhance $H \times D$, and HT-100 steels are also being developed to reduce the construction costs.

For facilities of the nuclear power plants, ASME Code Case 1714 was set up for the container materials in 1977 to avoid complexity in PWHT by increase in the wall thickness corresponding to enlargement of the diameter of the nuclear power pressure vessel and for the improvement in credibility of the primary loop in the nuclearreactor, and HT-60 steels (SPV 50) were used first in the Kashiwazaki-Kariha No. 2 P.C.V. of the Tokyo Electric Power.

\section{(vii) Steel Tower}

Steel towers for the power transmission were conventionally built of angle bars, but today the main columns and web members are made of steel pipes and the arm members are made of angle steel bars. Steel towers became larger along with the increase in transmission voltage. In 1972, the Electric Equipment Technique Standard was revised, and the steel pipes with a yield point of $40 \mathrm{kgf} / \mathrm{mm}^{2}$ or above and tensile strength of $55 \mathrm{kgf} / \mathrm{mm}^{2}$ or larger, were added as the materials for power-transmission steel towers. In 1974 STK-55 (JIS G 3444) was standardized in JIS, and then application of STK-55 to steel pipes for power transmission steel towers was stipulated in Electric Equipment Technique Standard revised in 1976, and is still in effect.

The present transmission voltage of $500000 \mathrm{~V}$ is projected to be increased up to $1000000 \mathrm{~V}$ in view of the increase in the number of nuclear reactor power station accompanied with the increase in long-distance power transmission in future. From the point of view of the necessity of making steel towers even larger, 
$60 \mathrm{kgf} / \mathrm{mm}^{2}$ high tension steel plates were developed by modification of susceptibility to embrittlement by galvanizing.

\section{(3) Ultra High Strength Steel}

In the field of ultra high strength steel, steady studies are being made of the available grades of steels for the performance improvement and toward their practical use.

In the low alloy steel, 4340 steel with strength (TS) of $183 \mathrm{kgf} / \mathrm{mm}^{2}$ class and the modification $4340 \mathrm{M}$ steel (193 kgf/ $/ \mathrm{mm}^{2}$ class) have been used for the aircraft landing gears. As a successor of these steels, the manufacturing procedure of HP 310 having a higher $\mathrm{Si}$ and $\mathrm{V}$ than the $4340 \mathrm{M}$ steel, was established. The steel shows $T S$ equal to $218 \mathrm{kgf} / \mathrm{mm}^{2}$ or greater, and $K_{\text {IC }}$ about $150 \mathrm{kgf} / \mathrm{mm}^{3 / 2}$, with good fatigue resistance.

$10 \mathrm{Ni8CO}$ steel was studied for their practical use in building a deep sea research vehicle. The studies on its manufacturing, working and welding were carried out, proving that the yield strength larger than $120 \mathrm{kgf} / \mathrm{mm}^{2}, K_{\text {IC }}$ equal 600 to $700 \mathrm{kgf} / \mathrm{mm}^{3 / 2}$ and satisfactory delayed failure characteristics in sea water ( $\left.K_{\text {ISCC }}\right)$ could be obtained in the plate of $50 \mathrm{~mm}$ or greater thickness.

The practical use of maraging steels of an even higher strength showed a big leap together with progress of the understanding of the strengthening mechanism. The maraging steels of $18 \mathrm{Ni}$-base proved to be easily heat-treated and to have good toughness, and consequently became the most practical steels. While these steels were used for rocket chambers, their welding joint performance and delayed failure characteristics were studied to secure safety. This type of steels has the of strengths of $245 \mathrm{kgf} / \mathrm{mm}^{2}$ with satisfactory toughness. An attempt to improve the strength up to $260 \mathrm{kgf} / \mathrm{mm}^{2}$ by increasing the content of Mo and $\mathrm{Ti}$ adequately.

For further strengthening, the content of $\mathrm{Ni}$ is reduced in $13 \mathrm{Ni}$-maraging steels, however the solution temperature must be raised above $1000{ }^{\circ} \mathrm{C}$ for complete dissolution of the carbides of Mo to ensure the strength, which adversely causes coarsening of grains. Enhancing of strength would make it impossible to obtain the strength corresponding to the hardness of materials by the notch effect because of micro structural defects inside the materials. Kawabe et al. have succeeded to obtain the strengths approximately of $400 \mathrm{kgf} / \mathrm{mm}^{2}$ with a combination of grain refinement, prevention of coarse precipitation of carbides by special thermo mechanical processing in the temperature range other than 900 to $1000^{\circ} \mathrm{C}$ after solution treatment at $1250{ }^{\circ} \mathrm{C}$, together with cold working. Heavier cold working leads to scattering of the strength obtained, the maximum value being $438 \mathrm{kgf} / \mathrm{mm}^{2}$, which is considered to be the maximum strength obtained experimentally in the available structural steels. Morphologies of the precipitates such as $\mathrm{Ni}_{3} \mathrm{Ti}, \mathrm{FeMo}$ and $\mathrm{Ni}_{3} \mathrm{Mo}$ are shown to cotribute to the strengthening of the steels.

Maraging steels, which can be easily heat treated and fabricated, have been applied to various tools, dies, plastic emboss-forming dies, hot extruding stems of seamless steel pipes and special-purpose springs as well as the above-mentioned rockets. There is an example of using sintered maraging steel for an engine piston equipped with turbo-charger to obtain heat resistance and abrasion resistance. However, the maraging steels are not used unless special advantages are expected because they contain considerable quantities of Ni, Co, and Mo and are therefore expensive. Extensive use of the maraging steels is a future subject to tackle in view of the fact that their domestic annual production is still only a few hundred tons.

The practical application of other ultra high tensile steels, (e.g., PH stainless steels) are also being studied to make the best use of the properties.

Ultra high strength steels will continue to be more and more important and to be required for a higher performance as important structural elements together with the advancement of high technologies such as space exploitation and ocean development.

\section{(4) Non-magnetic Steel}

Non-magnetic steel was not taken up in the 60th aniversary special issue, but a great amount of nonmagnetic steels is now in demand as the structural materials in strong magnetic fields. Needs in the developments for new energy sources like the nuclear fusion experimental reactor and MHD power generator and extensive energy saving like the magnetically levitated railways and high power generator have made it necessary to utilize a extremely strong magnetic fields by superconductive electromagnets. The Japanese steel makers have developed non-magnetic steels for practical uses. Since the superconductive materials are used under the liquid He temperature $(4.2 \mathrm{~K})$, therefore, the development of non-magnetic steels has accompanied the developments of high toughness steels at cryogenic use.

Relative magnetic permeability $(\mu)$ of 1.02 or below is generally required as specifications for non-magnetic steels: accordingly, two types of austenitic steels, $\mathrm{Ni}-$ Cr stainless steels and high Mn steels are employed. The general problems associated with the structural use of austenite steels lie in the low yield strength $(Y S)$ at the range of room to cryogenic temperatures and the phase stability, weldability and machinability at the cryogenic temperatures and in cold working. Modifications of SUS 304 have progressed to overcome the difficulties with strengthening by $\mathrm{N}$ (SUS 304 N 2), by phase stabilization in cold working by $\mathrm{Cu}$ (SUS XM 7) and moreover with strengthening and stabilizing by alloying of Ni, $\mathrm{Cr}$ and Mo. The Hadfield steel (1.1C-13Mn steel), well known as the high Mn steel, has been improved of its strength, toughness, phase stability and thermal expansion coefficient by reduction of $\mathrm{C}$ content, increase in $\mathrm{Mn}$, and alloying of $\mathrm{Ni}, \mathrm{Cr}, \mathrm{Mo}$, and $\mathrm{N}$ to meet for a variety of applications at given temperatures. The representative compositions are $0.6 \mathrm{C}-14 \mathrm{Mn}, 0.4 \mathrm{C}-18$ $\mathrm{Mn}$ and $0.2 \mathrm{C}-25 \sim 32 \mathrm{Mn}$, to which 1 to $5 \% \mathrm{Cr}$ and $\mathrm{Ni}$ are usually added. As the characteristics of high $\mathrm{Mn}$-steels, it is indicated that the solution hardening 
effect of $\mathrm{N}$ is higher than that in $\mathrm{Ni}-\mathrm{Cr}$-steels and that, even if weld metals are completely austenitic, hot cracking does not occur.

Examples of the developments and practical applications of non-magnetic steels are indicated below, and any of them can be understood as a good example showing that the national projects have promoted the material development.

1) Materials for the guide ways of magnetically leviated vehicle (Japanese National Railways)

$\mathrm{H}$-shape steel: $\quad Y S \geqq 235 \mathrm{MPa}$, $\mu \leqq 1.1$;

$0.7 \mathrm{C}-15-\mathrm{Mn}-1 \mathrm{Ni}$ steel

Steel Bar for Reinforced Concrete:

Equivalent to SD35,

$\mu \leqq 1.1$;

$0.7 \mathrm{C}-15-\mathrm{Mn}-1 \mathrm{Ni}-0.5 \mathrm{~V}$ steel,

$0.9 \mathrm{C}-14 \mathrm{Mn}$ steel

2) Coil supporting materials and the upper and lower structural materials for JT60. (Japan Atomic Energy Research Institute)

Plates: $\quad Y S \geqq 294 \mathrm{MPa}$, $\mu \leqq 1.02$; $0.6 \mathrm{C}-14 \mathrm{Mn}-2 \mathrm{Cr}-2 \mathrm{Ni}$ steel

Forged Materials: $Y S \geqq 343 \sim 637 \mathrm{MPa}$, $\mu \leqq 1.02$; $0.5 \mathrm{C}-18 \mathrm{M}-5 \mathrm{Cr}-0.4 \mathrm{~N}$ steel (for cold working)

3) Coil case for LCT (Japan Atomic Energy Research Institute and IEA)

Plates and Forged Materials: $Y S \geqq 686 \mathrm{MPa} ; \quad$ SUS $304 \quad$ LN $\quad$ (ESR ingot)

4) Center column for LCTF and upper and lower structures (IEA)

Forged materials : $Y S \geqq 686 \mathrm{MPa} ;$ SUS $304 \mathrm{~N}$

5) Structural materials for the next nuclear fusion experimental reactor (FER) (Japan Atomic Energy Research Institute)

Plates: $Y S \geqq 1200 \mathrm{MPa}, K_{\mathrm{IC}} \geqq 200 \mathrm{MPa} \sqrt{ } m$, stainless steel; no specifications permeability, $0.02 \mathrm{G}-25 \mathrm{Cr}-13 \mathrm{Ni}-0.35 \mathrm{~N}$ and $0.05 \mathrm{C}-$ $22 \mathrm{Mn}-13 \mathrm{Cr}-5 \mathrm{Ni}-0.2 \mathrm{~N}$ steels

(All of them are under development.)

6) Laminated core for superconductive magnet for TRISTAN (KEK, National Laboratory for High Energy Physics)

Sheets: $\quad 0.15 \mathrm{C}-32 \mathrm{Mn}-7 \mathrm{Cr}, \quad 0.2 \mathrm{C}-25 \mathrm{Mn}-5 \mathrm{Cr}-$ $1 \mathrm{Ni}$ and $0.02 \mathrm{C}-25 \mathrm{Cr}-13 \mathrm{Ni}-0.35 \mathrm{~N}$ steels The steels described in Item 3 ) and thereafter are used under $4 \mathrm{~K}$. Especially, the specification of 4 ) is recognized as a standard of future super-conductive magnet structural materials, and it is not too much to say that the steels complying with the specifications are the steels with the best toughness for use at cryogenic temperatures in the world. Keeping pace with the development of steels, the welding techniques are being developed. These results have been reported every year at the International Cryogenic Materials Conference (ICMG). It can be said that Japan has held an leading position in this field. The future demand for them is steadily increasing; accordingly, the standardization of steel grades, establishment of the design standards for extra low temperature and permission/approval as pressure vessel steels are expected as quickly as possible.

A remarkable progress was observed both in steel production and fabrication technology to meet the required properties becoming more stringent and diversified in all the above fields.

However, more research and development are needed from now on to deal with the increasingly higher levels of required properties and to pursue optimization of the entire process from steel production, fabrication, and practical usage in terms of economization.

As the themes for the above, the following can be indicated: more basic understandings of the controlling factors of various properties of materials, and creation of new seeds for further development, establishment of the reasonable criteria for required performances, and integration of application technology incorporating the relevant field like welding and corrosion protection.

For resolving solution of the above themes it may be effective to promote close cooperations among the related fields including international joint studies.

\section{3. 2. Pressure Vessel Steels}

(1) Overview

With the oil crises as background, various subjects concerning the pressure vessel steels were taken up for consideration: development of technology and equipment for coal liquefaction by hydrogenation under high temperature and pressure, construction and operation of large direct heavy oil desulfurizer, etc. Accordingly, various studies, for example, on the technology for making extra thick $2 \frac{1}{4} \sim 3 \mathrm{Cr}-1$ Mo steel exceeding $400 \mathrm{~mm}$ in thickness, improvement of tempering resistance, hydrogen embrittlement and hydrogen attack resistance, and greater strength were actively conducted.

In 1977, answering an appeal from the PVRG (Pressure Vessel Research of Welding Research Council) of the USA, the JPVRG, the Japanese counterpart, was organized, and its three divisions of steel, design, and fabrication have been actively working ever since, contributing to Japan-USA joint studies concerning many subjects. In the steel division, special committees such as the pressure vessel steels, the hydrogen embrittlement, the creep and fatigue, and the non-destructive examination were formed. In addition, the MPG (Metal Properties Council, Inc.) in the USA, a fundamental research institution for standardizing in ASME and ASTM, conducted a study of strengthening the $2 \frac{1}{4} \mathrm{Cr}-1 \mathrm{Mo}$ steel under the auspices of the Research Committee for studying pressure vessels used for high temperature and pressure hydrogeneous atmosphere; in this Japanese steel makers and fabricators participated and helped in supply- 
ing steel and studying steel degradation by hydrogen, etc., thereby promoting international cooperation for the development of pressure vessel technology.

Furthermore, after various accidents concerning pressure vessels for petrochemical plants had occurred successively in the early 1970s, the studies to ensure structural reliability became more active. In addition, with the brittle fracture accident of a low temperature LPG tank that occurred in Qatar in 1977 as a momentum, the studies concerning fracture toughness improvement of the welded joint of Al-killed steel, $2 \frac{1}{2} \mathrm{Ni}$ steel, $3 \frac{1}{2} \mathrm{Ni}$ steel, etc., were widely conducted.

For example, the Japan Welding Society formed a number of research committees such as the WSD (for defect evaluation of welded joints from the standpoint of brittle fracture), FTC (for a study concerning fracture toughness standards), FTR (for examination of GOD requirement value) and RTW (for examination of toughness requirement of welded joint). These committees examined the safety of low temperature pressure vessels from various angles. For another, the Pressure Vessel Steel Special Committee of the JPVRG mentioned above has collected data on fracture toughness of welded joints of storage tanks and examined its variation. Moreover, based on the study results of the LTV Committee of the Japan High Pressure Technology Association, the "Special Standards on Low Temperature Pressure Vessels" have been established.

The damage to an oil refining catalytic contact reformer has given birth to renewed recognition of $1 \frac{1}{4} \mathrm{Cr}-\frac{1}{2} \mathrm{Mo}$ steel creep embrittlement; accordingly, not only relationships with the damage and countermeasures were studied from the angles of steel and design, but also studies on estimation of the remaining life of high temperature pressure vessels became promoted.

Furthermore, to meet the increasing energy demand, the plants in the petroleum and chemical industries tended to be of a greater capacity and higher efficiency, and the equipment was getting larger and larger. Under the circumstances, Japanese official standards for steels and design for room to intermediate temperature service pressure vessels proved to be extremely disadvantageous in terms of allowable stress, compared to those of Europe, and the weakness of Japanese international competitiveness became apparent as export of urea, ammonia, or other plants increased about the middle of 1970 . To cope with this situation, under the guidance of the Agency of Industrial Science and Technology and the Japan Welding Association, studies on design and steel were actively carried out and made a great progress.

As regards the new developments in the manufacturing technology of pressure vessel steels in the past decade, the establishment of the hollow ingot method of manufacturing the shell ring of wall thickness as much as $400 \mathrm{~mm}$ for a large desulfurization reactor, and the application of controlled-rolled steel to low temperature pressure vessel steel may be pointed out. In the 1980s, further, controlled-cooling equipment was installed in the plate rolling facilities in Japan, and studies on plate direct quenching technology as applied to steels for low temperature pressure vessels, $9 \% \mathrm{Ni}$ steel for example, and steels for high temperature pressure vessels, $2 \frac{1}{4} \mathrm{Cr}-1 \mathrm{Mo}$ steel for instance, were conducted to improve their quality. Thus, Japan led the world in the fundamental research and development of the pressure vessel steels.

(2) Steels for Room to Intermediate Temperature Service Pressure Vessels

In the field of chemical industries of ammonia, urea, oil refining, etc., where plant construction was vigorous both domestically and in overseas since about 1975, many pressure vessels are for the service in the room to intermediate temperature range, i.e., below the creep region. In Japan, however, there was no steel standards specifying the strength in this temperature range (up to $400^{\circ} \mathrm{C}$ ). Further, as the design basis was tensile strength in general accordance with the ASME "Boiler and Pressure Vessel Code" Sec. VIII, Div. 1 (with a safety factor on T.S. of 4), the allowable stress was lower and the wall thickness of a pressure vessel $30 \%$ larger compared with those designed on the European standards that adopted the yield point design such as TRD 500, BS 5500, and ISO DIS 2694 (with a safety factor on T.S. at room temperature of 2.4, and that on Y.S. at the design temperature of 1.5). As the boilers and pressure vessels became larger, the Japanese steel and design, in term of competitiveness with European countries, had to work under a great disadvantage as regards welding labor, transportation, foundation work, etc. For those reasons, ASME had established Sec. VIII, Div. 2 (with a safety factor on T.S. at room temperature of 3 , and that on Y.S. at the design temperature of 1.5) and prepared the way to high stress design.

Under such circumstances, in 1976, the Pressure Vessel Specific Standard Special Committee was established in the Agency of Industrial Science and Technology, and relevant JIS incorporating the recommendations of the ISO and also including the requirements on strength guarantee of the steel in the room to intermediate temperature range and on quality control of vessels have been established in 1983.

Thereupon, the Japan Welding Association organized a committee, called the PMS Committee, to draft the standards for steels for room to intermediate temperature service pressure vessels. Then, in 1977, the Japan Welding Association duly published the standard on the plate steels as the WES 3005 and the standard on the forgings as the WES 3006.

(i) PMS 25, 30, and 35 Steels

Table V.3.3 gives the specifications for chemical compositions and mechanical properties of the steels for room to intermediate temperature service pressure vessels according to the WES 3005. The steels are categorized into three levels of PMS 25, 30, and 35 by the guarantee Y.S. at $350^{\circ} \mathrm{C}$, and for any of them, Y.S. values at temperatures between room and $400{ }^{\circ} \mathrm{C}$ are guaranteed.

Taking hot workability in the fabrication of vessels 
Table V.3.3. The Japan Welding Society Standards for high strength steels for room to intermediate temperature service pressure vessels (WES 3005).

\begin{tabular}{|c|c|c|c|c|c|c|c|c|c|c|c|}
\hline \multirow{2}{*}{$\begin{array}{l}\text { Classifi- } \\
\text { cation }\end{array}$} & \multirow{2}{*}{$\begin{array}{l}\text { Plate } \\
\text { thickness } \\
(\mathrm{mm})\end{array}$} & \multicolumn{9}{|c|}{ Chemical compositions (\%) } & \multirow{2}{*}{$\begin{array}{l}\mathrm{C}_{\mathrm{eq}}{ }^{1)} \\
(\%)\end{array}$} \\
\hline & & $\mathrm{C}$ & $\mathrm{Si}$ & Mn & $\mathrm{P}$ & $S$ & $\mathrm{Cu}$ & Mo & $\mathrm{Nb}$ & $\mathrm{V}$ & \\
\hline PMS 25 & $\begin{array}{r}6 \leqq t \leqq 75 \\
75<t \leqq 150\end{array}$ & $\leqq 0.20$ & $0.15 / 0.60$ & $0.80 / 1.60$ & $\leqq 0.035$ & $\leqq 0.035$ & $\leqq 0.35$ & $\leqq 0.35$ & $\leqq 0.050$ & $\leqq 0.10$ & $\begin{array}{l}\leqq 0.53 \\
\leqq 0.60\end{array}$ \\
\hline PMS 30 & $\begin{array}{r}6 \leqq t \leqq 75 \\
75<t \leqq 150\end{array}$ & $\leqq 0.19$ & $0.15 / 0.60$ & $0.80 / 1.60$ & $\leqq 0.035$ & $\leqq 0.035$ & $\leqq 0.35$ & $0.10 / 0.40$ & $\leqq 0.050$ & $\leqq 0.10$ & $\begin{array}{l}\leqq 0.56 \\
\leqq 0.61\end{array}$ \\
\hline PMS 35 & $\begin{array}{r}6 \leqq t \leqq 75 \\
75<t \leqq 150\end{array}$ & $\leqq 0.19$ & $0.15 / 0.60$ & $0.80 / 1.70$ & $\leqq 0.035$ & $\leqq 0.035$ & $\leqq 0.35$ & $0.15 / 0.50$ & $\leqq 0.050$ & $\leqq 0.10$ & $\begin{array}{l}\leqq 0.60 \\
\leqq 0.62\end{array}$ \\
\hline
\end{tabular}

\begin{tabular}{|c|c|c|c|c|c|c|c|c|c|c|c|c|c|}
\hline \multirow{5}{*}{$\begin{array}{l}\text { Classifi- } \\
\text { cation }\end{array}$} & \multirow{5}{*}{$\begin{array}{l}\text { Plate } \\
\text { thickness } \\
(\mathrm{mm})\end{array}$} & \multicolumn{12}{|c|}{ Mechanical properties (Transverse) } \\
\hline & & \multicolumn{4}{|c|}{$\begin{array}{c}\text { Tensile properties at room } \\
\text { temperature }\end{array}$} & \multicolumn{7}{|c|}{ Tensile properties at elevated temperature } & \multirow{4}{*}{$\begin{array}{c}\text { Impact } \\
\text { properties }^{2)} \\
\\
\text { Absorbed } \\
\text { energy at } \\
0^{\circ} \mathrm{C}(\mathrm{kgf} \cdot \mathrm{m})\end{array}$} \\
\hline & & \multirow{3}{*}{ 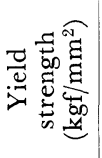 } & \multirow{3}{*}{$\begin{array}{c}\text { Tensile } \\
\text { strength } \\
\left(\mathrm{kgf}^{\prime} /\right. \\
\left.\mathrm{mm}^{2}\right)\end{array}$} & \multirow{3}{*}{$\begin{array}{c}\text { Elon- } \\
\text { gation } \\
(\%)\end{array}$} & \multirow{3}{*}{$\begin{array}{c}\text { Test } \\
\text { specimen }\end{array}$} & \multirow{2}{*}{\multicolumn{6}{|c|}{$\begin{array}{c}\text { Minimum yield strength }\left(\mathrm{kgf} / \mathrm{mm}^{2}\right) \\
\text { Test temperature }\left({ }^{\circ} \mathrm{C}\right)\end{array}$}} & \multirow{3}{*}{$\begin{array}{c}\text { Test } \\
\text { method }\end{array}$} & \\
\hline & & & & & & & & & & & & & \\
\hline & & & & & & 100 & 150 & 200 & 250 & 300 & $350 \quad 400$ & & \\
\hline PMS 25 & $\begin{array}{c}6 \leqq t \leqq 50 \\
50<t \leqq 150^{3)}\end{array}$ & $\begin{array}{l}\geqq 38 \\
\geqq 36\end{array}$ & $52 / 66$ & $\begin{array}{l}\geqq 16 \\
\geqq 20\end{array}$ & $\begin{array}{l}\text { JIS No. } 1 \text { A } \\
\text { JIS No. } 14 \text { A }\end{array}$ & 34 & 32 & 30 & 28 & 26 & 25 & \multirow{3}{*}{$\begin{array}{l}\text { JIS } \\
\text { G } 0567\end{array}$} & \multirow{3}{*}{$\begin{array}{l}\geqq 3.2 \text { in av. } \\
\geqq 2.6 \text { in } \min \end{array}$} \\
\hline PMS 30 & $\begin{array}{c}6 \leqq t \leqq 50 \\
50<t \leqq 150^{3)}\end{array}$ & $\begin{array}{l}\geqq 43 \\
\geqq 41\end{array}$ & $55 / 70$ & $\begin{array}{l}\geqq 15 \\
\geqq 19\end{array}$ & $\begin{array}{l}\text { JIS No. } 1 \text { A } \\
\text { JIS No. } 14 \text { A }\end{array}$ & 39 & 37 & 35 & 33 & 31 & 30 & & \\
\hline PMS 35 & $\begin{aligned} 6 & \leqq t \leqq 50 \\
50 & <t \leqq 150^{3)}\end{aligned}$ & $\geqq 44$ & $60 / 75$ & $\begin{array}{l}\geqq 14 \\
\geqq 18\end{array}$ & $\begin{array}{l}\text { JIS No. } 1 \text { A } \\
\text { JIS No. } 14 \text { A }\end{array}$ & 40 & 39 & 38 & 37 & 36 & 35 & & \\
\hline
\end{tabular}

1) $\mathrm{C}_{\mathrm{eq}}=\mathrm{C}+1 / 24 \mathrm{Si}+1 / 6 \mathrm{Mn}+1 / 40 \mathrm{Ni}+1 / 5 \mathrm{Cr}+1 / 4 \mathrm{Mo}+1 / 14 \mathrm{~V}(\%) \quad$ 2) Specimen : JIS Z 2202 No. 4

3) For plates over $100 \mathrm{~mm}$ in thickness, deduction of $1 \mathrm{kgf} / \mathrm{mm}^{2}$ from specified value of yield and tensile strengths shall be made for each increase of $25 \mathrm{~mm}$ of specified thickness over $100 \mathrm{~mm}$.

into consideration, heat treatment of these steels stands on the premise of the processes of normalizing $\rightarrow$ PWHT (e.g., PMS 25) or normalizing $\rightarrow$ tempering $\rightarrow$ PWHT (e.g., PMS 30 and 35); therefore, to realize the mechanical properties and weldability specified in Table V.3.3, studies on precipitation hardening by $\mathrm{Mo}, \mathrm{V}$, and $\mathrm{Nb}$ of steel with a ferrite-pearlite structure were actively carried out.

As a result, the synergistic effect on the Y.S. of those alloying elements was revealed and utilized in the development of new steels such as $\mathrm{Nb}-\mathrm{Mo}, \mathrm{Nb}-\mathrm{V}$, and $\mathrm{Nb}-\mathrm{Mo}-\mathrm{V}$ types. For example, as a PMS 35 steel with $75 \mathrm{~mm}$ thickness, $0.17 \mathrm{C}-1.5 \mathrm{Mn}-0.2 \mathrm{Cu}-$ $0.2 \mathrm{Cr}-0.25 \mathrm{Mo}-0.02 \mathrm{Nb}$ and $0.18 \mathrm{C}-1.5 \mathrm{Mn}-0.3 \mathrm{Mo}-$ $0.05 \mathrm{Nb}-0.03 \mathrm{~V}$ have been proposed.

\section{(ii) BS 1501-271B, TÜV WB 36 and BHW 35}

To cope with the cases where European standard steels that were not manufactured in this country had to be used to satisfy the specifications for export boiler, accordingly extra thick plates of reheat crack preventive steels of low V-Ni-Cr-Mo type BS 1501-271B steel, Mo-Ni-Cu-Nb type WB 36 steel, and Mo-NiCr-Nb type BHW 35 steel have been successfully made with favorable properties. It was found then that the accelerated cooling after normalizing was effective for improving the toughness of extra thick BS 1501-271B plates exceeding $100 \mathrm{~mm}$ in thickness.
(3) Steels for High Temperature Pressure Vessels

(i) Steels for Heavy Oil Desulfurization Reactors and for Coal Liquefiers

Under the impact of the two oil crises, development of coal liquefaction and gasification was active promoted in the late $1970 \mathrm{~s}$, and it became clear that coal liquefaction required a huge pressure vessel that could operate under a hostile hydrogenous atmosphere of high temperature and high pressure of such severity which was not experienced in the oil refining. Moreover, while environmental pollution problems were acquiring greater importance, decline in the quality of imported crude oil became inevitable, and on top of those, there was an authoritative recommendation made to the effect that the average $\mathrm{S}$ content of heavy oil should be reduced to $0.55 \%$ maximum by 1978 .

With those as incentive, design studies of and research and development of suitable steel for heavy oil direct desulfurization plants were actively carried out, which led to realization of a reactor of $250 \mathrm{~mm}$ in wall thickness, $3.8 \mathrm{~m}$ in inner diameter, about $35 \mathrm{~m}$ in full length, $19.2 \mathrm{t}$ in gross weight, $180 \mathrm{kgf} / \mathrm{cm}^{2}$ in design pressure, and $450{ }^{\circ} \mathrm{C}$ in design temperature. As for the pressure vessel for coal liquefier, on the other hand, a reactor of $400 \mathrm{~mm}$ in wall thickness, at least $5 \mathrm{~m}$ in inner diameter, $40 \mathrm{~m}$ in full length, $3000 \mathrm{t}$ in gross weight, $260 \mathrm{kgf} / \mathrm{cm}^{2}$ in design pressure, and 
$500^{\circ} \mathrm{C}$ in design temperature was studied. And, to fabricate such a super-large pressure vessel, technical problems such as temper brittleness, hydrogen brittleness, and hydrogen attack of base metal and welded joints of Cr-Mo steel, hydrogen brittleness of weld overlay of stainless steel, homogeneity of strength and toughness in steel thickness direction, raising of strength, and many others have been vigorously tackled and solved.

Since new oil and gas fields were explored coming into the 1980s, investment in coal liquefaction and gasification was postponed to until 1985 or even later, but, for the heavy oil desulfurization reactor, for which a more efficient operation, that is, higher temperature and pressure, is wanted, those studies were continued after 1980 .

\section{(a) Temper Embrittlement Resistant Steels}

In the middle to latter part of 1970 s, the in-service embrittlement of heavy oil desulfurization reactors was discussed in terms of safety upon pressurization testing in the scheduled inspection. For that purpose, embrittlement of the $2 \frac{1}{4} \mathrm{Cr}-1 \mathrm{Mo}$ steel, as evaluated by the step cooling method accelerated embrittlement testing in terms, for example, of $\Delta T T_{40}$, the change in the $40 \mathrm{ft} \cdot 1 \mathrm{~b}$ transition temperature in the $2 \mathrm{~mm} \mathrm{~V}$ notch Charpy test, was required, after embrittlement, to satisfy, for instant, $T T_{40}+1.5 \cdot \Delta T T_{40} \leqq 38{ }^{\circ} \mathrm{C}$, the formula recommended by the SOCAL. As a result of the systematic research on the influences of alloying elements and impurity elements on temper embrittlement, the $J$ factor, which is $\left(\mathrm{Si}_{0} \%+\mathrm{Mn} \%\right) \times$ $(\mathrm{P} \%+\mathrm{Sn} \%) \times 10^{4}$ and the $\bar{X}$ value, $(10 \mathrm{P}+5 \mathrm{Sb}+4 \mathrm{Sn}$ + As) $\mathrm{ppm} \times 10^{-2}$, were recommended and often used as in a proposal that called for $J<250$ and $\bar{X}<20$.

Accordingly, steelmaking technologies for reducing impurities were developed, and clean steels with $\mathrm{P} \leqq 0.01 \%, \mathrm{Sn} \leqq 0.002 \%, \mathrm{Sb} \leqq 0.0007 \%, \mathrm{As} \leqq 0.004$ $\%$, and $\bar{X} \leqq 12$ were commercialized. Previous to this development, on the other hand, a method of attaining an equivalent effect by lowering $\mathrm{Si}$ without reducing the impurities had been developed.

Thus, it may be said that today $\mathrm{Cr}-$ Mo steels that are completely free from temper embrittlement problem are available.

\section{(b) Hydrogen Brittleness and Temper Brittleness}

Since many of the oil refining reactor vessels are used under a high temperature and pressure hydrogen atmosphere for a long time, a large quantity of hydrogen intrudes and gets absorbed in the vessel wall, so that it was pointed out that the loss of toughness due to hydrogen needed be fully considered for safety. Taking the in-service temper embrittlement also into consideration, broad research on the relationship between hydrogen embrittlement and temper embrittlement was carried out for $\mathrm{Cr}-\mathrm{Mo}$ steels. It was shown that, even though no interaction between hydrogen embrittlement and temper embrittlement could be observed for $\frac{1}{2} \mathrm{Mo}, 1 \sim 1 \frac{1}{4} \mathrm{Cr}-\frac{1}{2} \mathrm{Mo}, 5 \mathrm{Cr}-\frac{1}{2} \mathrm{Mo}$, and $9 \mathrm{Cr}-1 \mathrm{Mo}$ steels, for such steels with a strong sensitivity to temper embrittlement as $2 \frac{1}{4} \mathrm{Cr}-1 \mathrm{Mo}$ and $3 \mathrm{Cr}-1 \mathrm{Mo}$ steels, there was a possibility that the tough- ness would decrease appreciably not only by the inservice temper embrittlement but by the hydrogen absorption.

Further, as the hydrogen embrittlement sensitivity tends to manifest itself strongly when the temper embrittlement has progressed to some extent, regulation on temper embrittlement resistance would become called for to improve on the safety and reliability of a pressure vessel. Thus, it was indicated that the quantitative relationship between the degree of temper embrittlement and hydrogen embrittlement sensitivity had to be clarified.

For this, a fact that the $K_{I H}$ would decrease the more, the higher the ${ }_{\mathrm{v}} \mathcal{T}_{\mathrm{rs}}$, namely, working more adversely on the high temper embrittlement sensitivity steels, the larger the grain diameter $d$, namely, the more adversely on the heat affected zone (HAZ) than on the base metal, and the higher the dissolved hydrogen concentration, has been made.

(c) High Temperature and High Pressure Hydrogen Attack

The hydrogen attack occurs when the dissolved hydrogen diffuses through the steel and reacts with unstable carbides, producing methane so as to give rise to decarburization, leading to formation of cracks at the grain boundary. This trouble has become increasingly noticed as higher temperature and higher pressure operation was practiced.

For this problem, it was observed for the $2 \frac{1}{4} \mathrm{Cr}-$ 1 Mo steel that $\mathrm{P}$ and As restrained bubble formation whereas $\mathrm{Sb}$ and $\mathrm{Si}$ promoted it, and that, for the $\mathrm{HAZ}$, the less the heat input and the higher the PWHT temperature, the better the hydrogen attack resistance. Further, it was explained that both lowering of $\mathrm{Si}$ and raising of PWHT contribute to improvement of the hydrogen attack resistance by promoting the formation of respectively $\mathrm{Cr}$-rich carbides and $(\mathrm{CrFe})_{7} \mathrm{C}_{3}$ carbides.

Also, the inappropriateness of the Nelson curve for $\frac{1}{2}$ Mo steel has been recently pointed out and is being reviewed. Moreover, the hydrogen attack resistance of high strength $2 \frac{1}{4} \sim 3 \mathrm{Cr}-1$ Mo steels added $\mathrm{Ti}, \mathrm{B}, \mathrm{V}$, etc. is under vigorous examination.

\section{(d) High Strength Ultra Thickness Steels}

Since both the heavy oil direct desulfurizer and the coal liquefier are of an ultra-large size as mentioned earlier, and require high level manufacturing technologies from the making of a large ingot to hot working and heat treatment, strenuous examination of composition design, manufacturing processes, and many others had been conducted. For example, as the allowable stress, which is the basis of pressure vessel design, is determined mainly by both high temperature tensile strength and creep rupture strength, development of thick steel plate having an excellent high temperature strength was strongly desired.

The MPG of the USA, the institution mentioned earlier, quickly recognized the importance of this issue in the late 1970 s, and investigated the relation between the maximum manufacturable plate thickness of the ASTM steels, such as $2 \frac{1}{4} \mathrm{Cr}-1$ Mo steel and $3 \mathrm{Cr}-$ 
1 Mo steel, and heat treatment conditions of PWHT, and the relation between the relieving of weld residual stress of ultra thick steel and PWHT conditions. The MPC has then proposed the possibility of allowing a higher strength for the ASTM standard composition $2 \frac{1}{4} \mathrm{Cr}-1 \mathrm{Mo}$ steels by relaxing the PWHT conditions, and been carrying out a joint study with Japanese and French steelmakers and fabricators.

In the mean time, studies on strengthening by addition of alloying elements were actively conducted, and effects of $\mathrm{V}, \mathrm{Nb}, \mathrm{Ti}, \mathrm{B}$, and others have been clarified. Based on the results, homogeneuous steel which does not form the proeutectoid ferrite in the center portion of the steel even for a thickness of $500 \mathrm{~mm}$ was developed. Also it was found that raising of the quenching temperature, namely, the high temperature quenching, was effective for increasing the strength of $\mathrm{Cr}-\mathrm{Mo}$ steels of $2 \frac{1}{4} \mathrm{Cr}-1 \mathrm{Mo}$ steel or higher without incurring much decrease in toughness after a long time high temperature tempering. This technology has been applied to practical production.

(ii) Steels for Oil Refining Catalytic Reformer and Fluidized Bed Catalytic Decomposition Reactor

The welded joints of reactor towers, heat exchangers, and piping, made of $1 \sim 1 \frac{1}{4} \mathrm{Cr}-\frac{1}{2} \mathrm{Mo}$ steels, of the catalytic reforming plant that had been constructed after late 1960 in this country, began to frequently develop cracks since late 1970. The cracks were found mostly at those welded joints on the outer vessel surfaces which were subjected to a comparatively strong stress concentration, such as the skirt-root and the nozzle-root of the reactor, starting from the weld toe part and propagating along the grain boundaries in the grain coarsened part of the HAZ. As for the cause of this cracking, it was found in the creep-rupture testing that it was closely related to the creep embrittlement due to notch softening.

With this discovery as a momentum, active studies on the mechanism and prevention of creep embrittlement for $\frac{1}{2} \mathrm{Mo}$ steel $1 \sim 1 \frac{1}{4} \mathrm{Cr}-\frac{1}{2} \mathrm{Mo}$ steel, and moreover $2 \frac{1}{4} \mathrm{Cr}-1 \mathrm{Mo}$ steel were conducted. It turned out that $\mathrm{Sb}, \mathrm{Cu}, \mathrm{P}$, etc. promoted the creep embrittlement in the HAZ coarse grained part, and that high temperature, long time PWHT was effective in suppressing the creep embrittlement. In addition, it was thought that creep cracking sensitivity was strongly affected by the strength difference between the grain interior and its boundary.

In applying the long time, high temperature PWHT to the $1 \sim 1 \frac{1}{4} \mathrm{Cr}-\frac{1}{2} \mathrm{Mo}$ steel to prevent the creep cracking, relations between cooling speed from normalization or PWHT conditions and mechanical properties were systematically investigated. It was then shown that addition of alloying elements such as $\mathrm{V}, \mathrm{Nb}, \mathrm{Ni}$, and $\mathrm{B}$ was necessary in order to guarantee strength and toughness, and the effects of these elements were studied in detail. This led to development of Al-B treated $1{ }_{4}^{1} \mathrm{Cr}-\frac{1}{2} \mathrm{Mo}$ steel, whose base metal properties could be secured even if the PWHT temperature was raised, and which was noted for its excellent creep cracking resistance at the welded joints.

(4) Steels for Low Temperature Pressure Vessels

(i) Steels for LPG Storage Tank

In 1975, the Intergovernment Maritime Consultation Organization (IMCO) has established the "Regulations on Bulk Carrier Structures and Equipment," and accordingly, it became necessary that a welded joint be guaranteed for its having an average absorbing energy value in the $2 \mathrm{~mm} \mathrm{~V}$-notch Charpy test of $2.8 \mathrm{~kg} \cdot \mathrm{m}$ minimum. Thus, studies on improvement of toughness of the Al-killed steel welded joints for LPG storage tanks were come to be promoted. Here, lowering, then extremely lowering, of $\mathrm{C}$ and lowering of $\mathrm{N}$ were aimed at, and for securing strength, application of controlled-rolling was studied. Though the effectiveness of controlled-rolling was duly demonstrated, no conclusion has been reached yet for the problem of safety associated with separation that accompanies the controlled-rolling.

For ultra-low $\mathrm{C}$ Al-killed steel and ultra-low $\mathrm{C}_{-}$ $2 \frac{1}{2} \mathrm{Ni}$ steel, further, it has been shown that the toughness of the base steel and HAZ can be improved by adding $\mathrm{Nb}$, indicating the direction of future development.

\section{(ii) Steels for LNG Storage Tank}

The toughness of both the base and the HAZ of $9 \% \mathrm{Ni}$ steel used for LPG tanks was remarkably improved by lowering $\mathrm{P}$ and $\mathrm{S}$ to an extremity, contributing to the greatly increased reliability of the tank. It was also made clear that addition of $\mathrm{Cr}$ and Mo was also effective in improving the COD property of HAZ. Moreover, the toughness of the joints welded by TIG or MIG using the co-metal filler, i.e., filler made of the base metal, properties of continuously cast steel, and properties of the directly quenched and temperted steels were examined. On the results of those studies, fabrication of a liquefied argon tank by the co-metal filler TIG method without resorting to expensive Ni-base filler, and fabrication of a liquefied nitrogen tank and a liquefied oxygen tank by the pure Ar shielded, co-metal filler MIG method, have successfully been carried out.

\section{3. 3. Machine Parts Steels}

\section{(1) Machine Structural Steels}

(i) Overview

The growth rate of automobiles, the major customer of the special steels, has not increased since the second oil crisis of 1979 as shown in Fig. V.3.2. The demand for machine structural steels and other special steels, except the free-cutting steèl, has not increased or slightly decreased in line with the number of cars manufactured.

Under the strong impact of the oil shock, automobile manufacturers promoted energy-saving measures such as improvement of engine combustion efficiency, cutting-back of specific steel consumption by introducing the front engine, front wheel drive (FF) cars, and decrease in car weight by using high strength 


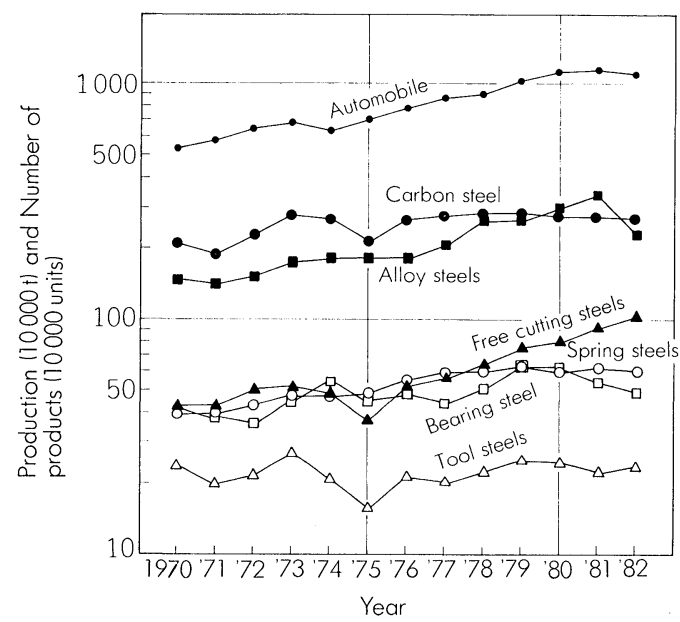

Fig. V.3.2. Production of special steels and of automobiles. Source: MITI: Kikai Tokei Geppo (Machinery Statistic Monthly), 19 (1970), 4 31 (1982), 3.

MITI: Tekko Tokei Geppo (Steel Statistic Monthly), 22 (1970), 4 34 (1982), 3.

steel and light-weight materials such as aluminum and plastics. As regards the processing of parts, conversion from carburizing to induction hardening, adoption of no-chipping cold forging, and employment of Mo-saving steel have been carried out.

To meet those moves, application of continuous casting and control-rolling for special steel, development of ladle refining, vacuum degassing, and other various special refining methods for high strength steels and high quality steels were vigorously pursued on the steelmakers' side.

As for the heat treatment, application of new technologies such as soft nitriding for smaller heat treatment distortion, induction hardening instead of carburize-quenching, and vacuum carburization were positively tried out, and special-purpose steels to be used for these methods were developed.

(ii) Improvement in Steelmaking Technologies and Steel Development

(a) Steel Development Utilizing the Ladle Refining Technology

The ladle refining methods made a remarkable improvement under a strong needs for high-quality steel. Here, what contributed most has been the decrease of nonmetallic inclusions and fine adjustment of chemical composition.

(a)-1. Decrease in Nonmetallic Inclusions

Since nonmetallic inclusions such as oxide and sulfide can become the cause of cracking on cold forging and also decrease strength and toughness, steel manufactures have been intent on decreasing the oxide and sulfide contents.

As a result, technologies which stably ensure $O$ content to $15 \mathrm{ppm}$ or below and S content to $50 \mathrm{ppm}$ or below have been developed using appropriate refractories and fluxes and by improving the degassing techniques, high quality cold forged parts (case hardening steel and carbon steel), high-strength gears (case hardening steel), and high-tension volts (high- toughness steel with tensile strength $120 \mathrm{kgf} / \mathrm{mm}^{2}$ or above) are now available.

(a)-2. Fine Adjustment of Chemical Composition

The most fundamental characteristic of the alloy steel is the hardenability, and good controlling of hardenability is required. For this purpose, a precision control system of hardenability has been developed utilizing the fine chemical composition adjustment function of ladle refining methods in combination with the computer on-line control. In this system, the molten steel composition is rapidly analyzed, and the hardenability is predicted by the computer on that result referring to the standard, and the chemical composition of the steel is finely adjusted.

Here, for the composition-based prediction of hardenability, which is the key technology in this process, a method which directly estimates the whole of the Jominy curve from chemical composition has been developed, contributing greatly to the quality assurance of the hardenability bands for $\mathrm{H}$ steels. These technologies are used to decrease and stabilize heat-treatment distortion of parts having a complicated and precision shape, for example, gears.

Induction hardening instead of carburizing, which takes a long time, is being actively reviewed. For carbon steels adaptable to induction hardening, the problem of stabilization of hardenability will become important in the future.

(b) Steel Development Utilizing the Continuous Casting Technology

For special steels also, application of continuous casting has rapidly progressed for the merit of smaller composition segregation and better quality uniformity of the continuously cast stocks compared with ingotmade stocks. For example, continuously cast steels proved to be quite adept at preventing the occurrence of chevron cracks on forward extrusion of car rear axle shafts made of carbon steel, or at decreasing and stabilizing the distortion of carburize-quenched gears made of case hardening steel.

(c) Steel Development Utilizing the Control Rolling Technology

The control-rolling (CR) and the control-cooling (CG) technologies that were developed originarily for manufacturing of high strength steel plates, are now being applied to bars and rods of special steels, for they are equivalent to the rolled-and-normalized carbon steels and case hardening steels and to the quenchand-tempered carbon steels. Encouraged by the result, omission of annealing or similar process simplification is under positives study for the high-toughness steels.

(iii) Development of New Steels

(a) Energy-saving Steels

The GR and GG technologies have been well adopted to making of various machine parts or structural member steels.

(a)-1. Omission of Normalizing

Through the CR or CC, it is now possible to stably produce steels having as rolled the microstructures and 
qualities that are equivalent to normalized stocks. For example, much of the carbon steels such as $\mathrm{S} 43 \mathrm{C}$ and S48C or case hardening steel such as SCr420 and SCM420 for shafts and gears are now manufactured this way.

(b)-2. Omission of Quench-and-tempering (Nonheat Treated High Toughness Steel)

Many of the connecting rods, crankshafts, and knuckle spindles have been made by quench-and-tempering the carbon steel after hot forging, in which a method that practices hardening by utilizing the heat remaining after forging is already well established as the forge hardening method. The non-heat treated high-toughness steel, has been developed as an extension of this technology by regulating the composition so as to develop mechanical properties that compare favorably to those of quench-and-tempered materials as air-cooled or as blast-cooled after forging.

In consideration of the balance of strength and toughness, steels of 0.3 to $0.5 \% \mathrm{C}$, with 0.05 to $0.15 \%$ $\mathrm{V}$ added for precipitation hardening or about $0.03 \%$ $\mathrm{Nb}$ for grain refinement have been developed.

Presently, those steels are of a tensile strength of 70 to $100 \mathrm{kgf} / \mathrm{mm}^{2}$, and it has been shown that the fatigue strength is the same as that of plain carbon steels heat treated to the same strength. Therefore, their application is widening from connecting rods, crankshafts, etc. to the knuckle spindle that require good toughness. Further, a non-heat treated high-toughness steel that may be directly machined as rolled into rear axle shafts and such has been commercialized by carefully optimizing the rolling conditions and chemical compositions.

The future task is then to develop a non-heat treated steel of more than $100 \mathrm{kgf} / \mathrm{mm}^{2}$ to replace those low alloy steels that are currently used through heat treating to these strength levels.

\section{(iii) Resources-saving Steels}

In view of impending scarcity as well as cost reduction, saving of precious elements, Mo in particular, has been promoted. More recently, however, higher strengths are being demanded of parts for engine and power transmission to cope with the trend toward higher power engines. For this, re-examination of $\mathrm{Ni}$ and Mo is being conducted from the total cost view point, so that in some cases positive addition of those elements may occur.

(a) Mo-saving High Toughness Steel (Boron Steel)

The boron steel has long since been in use to save expensive elements such as $\mathrm{Ni}$ and $\mathrm{Mo}$, so that a standard for it as an automotive steel has already been established as JASO-M106-770. However, application of B steel to machine parts has not advanced too well because of its rather unstable hardenability.

Today, this difficulty has greatly been decreased, and application to machine, parts is on the increase owing to establishment of the control technique of gas elements of $\mathrm{O}, \mathrm{N}$, etc., stabilized addition of effective $\mathrm{B}$ (acid-soluble boron), and the rapid analysis technique of $B$.

\section{(b) Mo-saving Case Hardening Steels}

Mo works to greatly increase the quench hardness and toughness of high $\mathrm{C}$ steels, and also increases the case depth of carburize-quenched stock. Therefore, in order to decrease Mo, overall assessment is necessary, since it will entail a prolongation of carburization time. Yet, there is an example, in which this has been done for every intended part in view of the hardenability and mechanical properties required, and Mo content which was about $0.2 \%$ in the past was decreased to one half. Further for light load duties, no Mo steels such as $\mathrm{Mn}-\mathrm{Cr}$ or $\mathrm{Mn}-$ low $\mathrm{Cr}-\mathrm{B}$ are being examined.

(iv) Improvement in Heat Treatment Technologies and Steel Development

As a promising surface hardening method that produces smaller heat treatment distortion than the conventional carburize-quenching method, salt bath soft nitriding method, gas soft nitriding method, and ion nitriding method have been studied, and improvement of hardwares such as pollution-free salt baths, decrease in gas consumption rate, and development of continuous furnace has been achieved. At the same time, special-purpose steels such as $\mathrm{Cr}-\mathrm{Al}$ and $\mathrm{Cr}-\mathrm{V}$ which can develop a deep case in the soft nitriding treatment have been devised and are now used for crankshaft and transmission parts. Further development of special soft nitriding steels with higher strengths is expected in the future.

The induction hardening method, which features not only energy-saving but the shortness of treatment time that allows ready integration into the process line, appears to keep enlarging its application, replacing the carburize-quenching method. For this, development of high strength steels which are particulary suited for this method is waited for.

Also, for the vacuum carburization method, bright future is expected for its features such as the very short treatment time owing to the high temperature carburization, and no need for a reformer furnace, quick change of furnace atmosphere to make treatment operation versatile.

On the other hand, however, this method has an intrinsic problem in that grain coarsening is in evitable since the treatment temperature is high, for which application of $\mathrm{Nb}$ - or Ti-containing steel is being examined.

\section{(2) Free-cutting Steels}

(i) Overview

The domestic production of free-cutting steels, including stainless free-cutting steels, had doubled in the past decade from about $500000 \mathrm{t}$ in 1972 to about 1 million $t$ in 1982. This is due to the great increase in the automobile production and rapid growth of office automation apparatuses and household electric appliances. In the former application, demand for stronger and higher quality free-cutting steels is becoming all the more severer as much as for other steels, while in the latter, the machinability itself is the object of research and development.

As for the technologies of making of free-cutting 
steels, rapid spreading of continuous casting and ladle refining is to be noted. The continuous casting is now applied to $\mathrm{S}$ and $\mathrm{Pb}$ free-cutting steels contributing greatly to stabilization of quality, while the ladle refining methods, mainly the vacuum degassing, which has been applied only to the base steel in the past, has now come to be applied to making of freecutting steels.

(ii) Free-cutting Steels for Machine Structural Parts Because of the elongated sulfides that work adversely to toughness, the $\mathrm{S}$ free-cutting steel has been restricted in its usage as the automotive and other strength member parts. To alleviate this fault, the so-called sulfide shape-controlled free-cutting steel, in which sulfide is spheroidized by adding $\mathrm{Zr}$ or $\mathrm{Te}$, has been developed. Here, especially Te has an added advantage of being itself a free-cutting agent. They are now used for those parts such as gears which require strength and toughness in the transverse direction also.

Lead free-cutting steel has superior toughness and dectility compared with $\mathrm{S}$ free-cutting steel, and is used as the strength member parts, but its rather short rolling contact life under high surface pressure has been a restraint in its application of gears and bearings. For this problem, low $\mathrm{Pb}$ free-cutting steel with an improved high surface pressure rolling contact life has been developed by controlling the $\mathrm{Pb}$ content to 0.04 to $0.08 \%$ without sacrificing the drill machinability and good chipping of the $\mathrm{Pb}$ free-cutting steel. Further, as the same strength characteristics as the base steel has come to be ensured owing to the lowoxygen refining technology, its uses in the strength member parts are enlarging steadily.

In the free-cutting steel for machine structural parts, too, cold forgeable varieties and non-heat treated steels were developed in the general trend toward no-chip forming and simplification of work procedure. Namely, in the former, the S.Te complex free-cutting steel and the $\mathrm{Pb} \cdot$ low $\mathrm{S}$ free-cutting steel have been developed. In the latter, on the other hand, freecutting version of non-heat treated steel of the precipitation hardening type is available. For the cost reduction, the demand for these free-cutting steels, is expected to increase further in the future.

As for the Ca free-cutting steel, which has been allowed in a JASO, though not standardized yet, as an automotive steel, its consumption is on the increase mostly in the form of combined addition with $\mathrm{S}$ or $\mathrm{S}$ and $\mathrm{Pb}$.

(iii) Free-cutting Steels for General Structural Parts

The production of low $\mathrm{C}$ high $\mathrm{S}$ free-cutting steels and those further containing $\mathrm{Pb}$ or $\mathrm{Te}$ has rapidly increased over the past several years because of the rapid growth in copying machines, computers, and video tape recorders (VTR). As these free-cutting steels are processed in automatic machine tools, meaning that extraordinary long tool life, better surface finish, and finer chipping are required, yet better machinability is being pursued by increasing the amount of $\mathrm{S}, \mathrm{Pb}$, and $\mathrm{Te}$.

\section{(iv) Free-cutting Stainless Steels}

As many stainless steel parts are also processed in automatic machine tools, further improvement of machinability is pursued. An example is a ferritic 20Cr-2Mo steel which has been made free-cutting by adding $\mathrm{S}, \mathrm{Pb}$, and $\mathrm{Te}$. As this steel has the best machinability among stainless steels as well as corrosion resistivity comparable to SUS 303, it is popularly used for small precision parts.

Since $\mathrm{Pb}$ hardly harms the corrosion resistivity of the base steel, various $\mathrm{Pb}$ free-cutting stainless steels are being produced. One fault here is that $\mathrm{Pb}$ greatly deteriorates the hot workability of austenitic stainless steels. This has been overcome by adjusting the main components and by adding $\mathrm{B}$, so that $\mathrm{Pb}$ freecutting austenitic stainless steels are now available.

\section{(v) Free-cutting Tool Steels}

In the tool steel sector too, provision of free-cutting versions are being promoted as witness the development of $\mathrm{Ca}$ free-cutting steel for hot forging die for its superior high temperature strength and toughness and $\mathrm{S}$ free-cutting steel for plastics molding die for its good die machinability.

\section{(vi) Nonmagnetic Free-cutting Steel}

The high $\mathrm{Mn}$ steels such as $0.6 \% \mathrm{C}-14 \% \mathrm{Mn}$ and $0.7 \% \mathrm{C}-15 \% \mathrm{Mn}$ are attracting attention as inexpensive nonmagnetic steel because of the increase in demand with advent of new technologies such as magnetically confined nuclear fusion reactor or magnetic levitation locomotion vehicles. As those high Mn steels are very difficult to machine, however, free-cutting version of those steels has been developed.

\section{(3) Spring Steels}

\section{(i) Overview}

The growth in the past decade of spring steel is about $4 \%$ per annum, reaching to about $600000 \mathrm{t}$ in 1982. The increase in the demand for wire rod was remarkable due to the change from plate springs to coil springs for suspension springs of small-size passenger cars. Here, to aid in the weight reduction of automobile, stronger suspension springs are in demand, and durability under very severe conditions is required. Reviewing of JIS is also being carried out, and SUP 12 (equivalent to SAE 9254) and SUP 13 (equivalent to SAE 4161) were added to the Spring Steel Specification (JIS G4801) in February, 1984.

\section{(ii) Steels for Suspension Springs}

The hot formed coil spring has been shifted from SUP 6 to SUP 7 and SAE 9254 that possess superior sag resistance, and development of one with tensile strength of $200 \mathrm{kgf} / \mathrm{mm}^{2}$ class is well progressed. Here, a method, to improve the sag resistance by adding alloy elements such as $\mathrm{V}$ and $\mathrm{Nb}$, and another to improve the fatigue characteristics by removing harmful nonmetallic inclusions through ladle refining are being tried.

For the cold formed coil springs, heat treated wire rods with a tensile strength of 180 to $200 \mathrm{kgf} / \mathrm{mm}^{2}$ and a diameter up to about $12 \mathrm{~mm}$ can now be formed into spring owing to the recent improvement in the 
cold coiling technology, and are being applied to suspension springs. Further raising of strength by improving the heat treatment is also being attempted.

With the fast popularization of FF cars, the production of tapered coil spring, which has a nonlinear characteristics, has also increased to occupy about $10 \%$ of the coil springs market today, the tapered rod used to be made by peeling, but recently the tensile plastic working method has also come to be employed.

For the plate spring, the tapered leaf spring has been put to practical use by some of the manufacturers for improved driving comfort and weight reduction.

As for the torsion bar springs and stabilizers, demands for weight reduction are strong, for which purpose the induction hardened torsion bar spring and hollow stabilizer, which can withstand a high load, have recently been put to practical use by some of the manufacturers.

\section{(iii) Steels for Valve Springs}

For the steel for valve springs, SWOG-V (equivalent to SAE 9254) are used in Japan and SAE 6150 in the USA. As stable fatigue characteristics are indispensable, requirements against surface flaws and internal defects are becoming the severe, with which the steel manufacturers are coping by practicing full face milling, intensifying the intermediate inspection, and by decreasing oxide and TiN nonmetallic inclusions. VAR or ESR in the double melt process is used to decrease or refine the nonmetallic inclusions, but utilization is limited for special specification cars, such as racers, because of high cost. Manufacturing of ultraclean steel by the degassing method is being tried out on the premise of mass-production and low cost.

\section{(iv) Other Spring Steels}

For heat resisting springs, various materials from carbon steel to superalloy such as Inconel X750 are used. However, as data on performance characteristics are still insufficient to create design standards, accumulation of data is being promoted on a collaborative research basis.

As the austenite stainless steel wire has superior corrosion and heat resistance compared with piano wire, development with emphasion improvement of fatigue strength is making a good progress.

\section{(4) Bearing Steels}

(i) Overview

The production of high C-Cr bearing steel has somewhat decreased since 1979 due probably to the stagnation of automobile production and to the shift to carburized bearing steel centering on small bearings. The production of miniature bearings is increasing owing to the drastic growth of office automation (OA) equipment and VTR.

\section{(ii) High Carbon Chromium Bearing Steels}

The rolling contact life of high C-Cr bearing steel (ex. SUJ 2) has almost doubled in the past decade, owing greatly to advancement in the ladle refining technology such as the ladle furnace plus vacuum degassing treatment. Especially, improvement in the degassing treatment technology is remarkable, and the oxygen content in ordinary steels is now $15 \mathrm{ppm}$ or below. Here, an oxygen content of $10 \mathrm{ppm}$ or less is a common target both for the steel manufacturers and for the bearing markers. The decrease of $\mathrm{Ti}$ (as TiN) is being examined to improve the rolling contact life.

Further, application of the continuous casting to bearing steels is to be noted. Here, continuously cast stocks have already been used for pipes and rods, and application to wire rods will also advance in the future.

Though there is a move to apply the cold forging, but the application will necessarily be limited since high $\mathrm{C}$ is not for cold forging.

\section{(iii) Carburized Bearing Steels}

The carburized bearing steel has been conventionally used when toughness of the core is needed, especially for large bearings, but application to small bearings is rapidly advancing taking advantage of its superior cold forgeability, for which SCr420 and SCM420 are mostly used. The use of carburized bearing steel will increase with progress in improvement of cold forgeability and in prevention of austenite grain growth on carburization.

(iv) Corrosion and Heat Resisting Bearing Steels

As for the corrosion resistive bearing steel, martensitic stainless steels such as SUS $440 \mathrm{C}$ and $420 \mathrm{~J} 2$ are mainly used as before, where for the miniature bearings and such SUS 440G is used and quality improvement with regard to the shape and distribution of carbide is being promoted.

As regards the heat resisting bearing steel, the material for jet engines is now mainly AISI M50, but there is a move to shift to SUS $440 \mathrm{M}$ for its superior heat resistivity. However, as very large carbides are apt to form in this steel, not only manufacture is difficult but the strength is impaired. Improvement is strongly desired.

\section{(5) Tool Steels \\ (i) Overview}

The production of tool steels was about $240000 \mathrm{t}$ in 1982 but the growth rate was lower than those of automobile and household electric appliances. This means that the relative demand has been decreased due to improvement in the tool life, underwriting the performance improvement of the tool and progress of the machining technology. The current breakdown is C tool steel $57 \%$, alloy tool steel $36 \%$, high speed tool steel $6 \%$, and others $1 \%$.

In the field of tool steel, polarization of demands is noted. Namely, high quality steels have become called for with establishment of mass-production systems in automotive, household electric appliances, and other industries, on one hand, the demand for inexpensive tool materials is on the increase in the multiple-products, small-lots production quarter owing to advances of surface treatment and repairing by weld overlay method, on the other. 
In the meantime, the die industry has made a rapid growth with the development of the die forming method, which ensures high productivity production of uniform quality articles. According to the Japan Die and Mold Manufacturers Association, the metal die production in 1983 reached to 141044 t ( $¥ 322.5$ billion), and the weight-wise breakdown was the press die $58 \%$, plastics molding die $20 \%$, forging die $7 \%$, die-casting die $6 \%$, and others $9 \%$, of which the die-casting die and the plastics molding die are growing particularly fast, reflecting the trend toward lighter weight automobiles.

The tasks in die working are to develop measures to be taken in meeting the increase in difficult-to-work articles, complicated shapes, and demand for higher accuracy as well as automation, for which wire electric discharge machining, devising of other new working methods and introduction of CAD/CAM systems are being promoted.

\section{(ii) High Speed Tool Steels}

Accompanying the change from $\mathrm{W}$ type to Mo type in the trend of resources saving, revision of JIS has progressed; steels SKH 4B and 5 have been abolished and high Mo type SKH 58 and 59 were added. On the other hand, for high Mo type high speed tool steels, the problem of carbide refinement was raised, and the study of rod-shaped $\mathrm{M}_{2} \mathrm{G}$ carbide, which is peculiar to those steels, was progressed.

Since the high speed tool steel has a superior resistance to wear and heat, and high strength, application as a high strength, high toughness tool to such plastic working as cold forging and warm forging is increasing. In this field, the matrix steel of SKH 51, which emphasizes toughness, and the $3 \% \mathrm{~V}$ type sintered variety, which emphasizes high, are gaining popularity. Though the sintered high speed tool steels are in possession of good grindability in processing and toughness for tools, with increasing demand for difficult machining and power machining, high performance, high alloy varieties of HRG 70 class are being developed to fill the gap between sintered carbides and high speed tool steels.

\section{(iii) Hot Working Tool Steels}

In the field of hot working, upgrading of die steel made a good progress in accordance with a cycle described by raising of the die performance, prolongation of die life, lowering of the die cost, decrease of the die changes, and improvement of productivity.

For the press die, demand for materials with higher softening resistance than those of SKD 61 and 62 had increased, and SKD 7 and 8 have been added to JIS. In addition, $3 \mathrm{Gr}-\mathrm{Mo}$ type precipitation hardening steel became popular. In the mean time, relative importance of precision forging, which is suited for needs of better accuracy and yield, and difficult-to-forge articles such as turbine blades has increased; for that purpose, matrix type high speed tool steels with a greater high temperature strength than that of conventional hot tool steels and super-heat resisting alloys, for example, Inconel 718, have gained a high evaluation.
For die-casting dies, raising of performance progressed with the vigorous demand for $\mathrm{Al}$ die-cast articles for weight reduction of automobiles and household electric appliances. Here, solving of problems like occurrence of large cracking and early heat check in the die that accompanied the adoption of shower water cooling for improvement of die-casting capability and of large and complex shape dies to cope with the move toward FF cars was given a preference. For this, upgrading of the currently popular SKD 6 in terms of raising of cleanness and uniformizing of structure is being promoted together with development of new steels.

As for the plastics molding die, 8Cr type steels having a high hardness and good wear resistivity were developed for dies for engineering plastics, while improvement of $420 \mathrm{~J} 2$ for high precision plastic articles such as light electric parts and lenses was made for steels for high hardness, mirror finish corrosion resistive dies for plastic injection molding.

In addition, prehardened steels and free-cutting steels for plastics molding die were reviewed, and a die steel system established. Further, the screw cylinders for injection molding machines were improved in the corrosion and wear resistivity to cope with the increasing need of adding the flame retardation agent and the increase in reinforced plastics containing glass fiber, asbestos, etc.

\section{(iv) Cold Working Tool Steels}

The main cold working tool steels are SK 3, SKS 31, and SKD 11, but from the viewpoint of total cost performance in the mass-production system, trend is for higher quality, i.e., SKD 11, for which refinement and improvement of distribution of the eutectic carbide is being made on the basis of theoretical analysis of the solidification structure, and improvement in quality is expected. However, for raising the operation speed, which is the key point of the mass production system, the existing cold working tool steels are all at the technical limit in maintaining the accuracy and preventing the seizure, so that development of new steels that contain as much carbide as in the sintered carbide and of sintered tool steels that contain appropriate lubricant is being promoted.

As for the die working method, as the adoption of the wire electric discharge machining and the PVD coating method progressed, problems of deformation and lowering of hardness due to residual stress and heat became important. For this, need of conducting high temperature tempering became general, so that high temperature tempering conditions (air cooling from 500 to $530{ }^{\circ} \mathrm{C}$ ) were added to JIS SKD 11 Specification. Also, for reduction of die cost or of delivery time, weld overlay repairing, utilization of flame hardenable steels, and cast tools are being reviewed.

\section{(v) Heat Treatment and Surface Treatment}

In the field of heat treatment, vacuum hardening has spread for its merits of improvement in working environment, no pollution, decrease of working manhour, etc. The problem in the vacuum hardening is the lower hardness due to insufficient cooling rate, for 
which development of high pressure gas cooling type furnace with a good cooling capability and highly hardenable tool steels is under way.

As regards surface treatment, development of ion nitriding and methods of coating hard surfacing materials such as $\mathrm{TiN}$ and $\mathrm{TiC}$ has been remarkable, and development of special-purpose steels for those treatment methods is being undertaken.

\section{3. 4. Sheet Steels}

\section{(1) Overview}

The early 1970s were the time when the largescale sheet steel manufacturing technology was established under the increasing world-wide demand. In this period, various technologies of manufacturing steels with uniform quality economically, such as continuous casting, continuous cold rolling, and continuous annealing, had been implemented. After the oil crisis, however, the quantity-intensive manufacturing had to be rationalized or improved into energy- and cost-intensive production. At the same time, to meet the new customer needs that emerged with the oil crisis, various new steels were developed. The high strength sheet steels and the new surface treated sheet steels are only examples that were developed in answer to automotive industry's need of reducing the weight of car body to decrease fuel consumption and to lengthen the life of automobiles in cold countries.

Behind those achievements of the sheet steel sector, there have been three helpful incentives:

(i) the habit of the time that allowed development of new technologies just sprouted out of laboratory right into practice,

(ii) the remarkable progress attained in steelmaking and related sectors, and

(iii) the close cooperation with the customer through which to gain a sure access to customer's needs most quickly.

\section{(2) Hot Rolled Sheet Steels}

To meet the demands for yet higher performance and thicker gauge for the hot rolled high toughness and high strength line pipe steel, the controlled rolling (CR) technology was improved through the study of interrelation of chemical composition and hot rolling conditions. Namely, line pipe steels of grades up to APIX70 with a thickness more than $\frac{1}{2}$ inch have become available, by suppressing the recrystallization of austenite with addition of $\mathrm{Nb}$ or $\mathrm{V}$, and further, by eliminating $\mathrm{S}$ or controlling the sulfide shape with addition of $\mathrm{Ca}$, and by controlling the thermal history and the rolling conditions from slab to coil. Also, line pipe steels of good resistance to hydrogen-induced cracking for sour gas were developed likewise.

In the pursuit of both car safety since late 1960s and weight reduction to decrease the fuel consumption since the first oil crisis, the automotive industry came to want a high strength steel sheet.

The first automotive high strength hot rolled steels were the ferrite-pearlite type ones, solid solution hardened by $\mathrm{Si}$ and $\mathrm{Mn}$ to tensile strengths up to $50 \mathrm{kgf} /$ $\mathrm{mm}^{2}$, or precipitation hardened by $\mathrm{Nb}, \mathrm{Ti}$, or $\mathrm{V}$ from 50 to $80 \mathrm{kgf} / \mathrm{mm}^{2}$; they were all commercially produced on the basis of conventional high strength hot rolled steels. By means of desulfurization and sulfide shape control such formability as bendability and stretchflangeability of those steels was markedly improved compared with that of conventional steel, so that they were used for frames and reinforcements. For application to parts such as wheel disk, however, the drawability was not high enough.

For this new need, the dual-phase steel composed of ferrite and martensite was developed. As this steel did not show the usual yield point elongation on the stress-strain curve, and had such favorable characteristics as low yield ratio, high work hardening exponent, high uniform elongation, and better balance of tensile strength and total elongation compared with that of other steels hardened by different mechanism, it was noticed with a good deal of expectation.

Two methods were developed for manufacturing this type of steel. The first one was to heat-treat the coil hot-rolled in usual manner in a continuous heat treatment equipment.

Though the above mentioned properties were realized, the problems associated with the very use of continuous heat treatment facility and with the increased production cost incurred by adding another process, did not allow production to continue.

Thereupon, to reduce the cost, a second method was developed to obtain the dual-phase structure as hot rolled state. There were two varieties of this method: one, by hot rolling and coiling of a high $\mathrm{Si}-$ Mn steel added with $\mathrm{Gr}$ and Mo in conditions similar to usual hot rolling, and the other, by hot rolling a $\mathrm{Si}-\mathrm{Mn}$ steel with suitable conditions of the finish rolling, rapid cooling at the runout table and coiling at such an extremely low temperature as lower than $300{ }^{\circ} \mathrm{C}$. The latter was put to practical use in two different procedures: in one, the finish rolling was conducted between $A_{1}$ and $A_{3}$ points so as to produce ferrite-austenite two-phase structure, then quenching the steel immediately to below the $M_{\mathrm{s}}$ point of austenite, whereas in the other, the finish rolling was completed at above the $A_{3}$ point, controlling the cooling on the runout table so as to produce ferrite-austenite two-phase structure, then quenching similarly. This new technology of manufacturing dual-phase sheet steel, making the best use of the cooling in the runout table and coiling at an extremely low temperature, is to be highly rated because it made possible the economical manufacture of high strength hot rolled sheet steel with high formability.

Now, the as rolled properties of the dual-phase sheet steel have been elevated to almost the same level as the heat treated type, and those with a $60 \mathrm{kgf} / \mathrm{mm}^{2}$ class tensile strength have been applied to the wheel disk and such. However, the use of this hot rolled dual-phase steel have not come up to the expectation, because the shear-edge stretch-flangeability is not so good as its excellent ductility suggests, the heat affected zone is excessively softened on flash butt welding, and costs are still relatively high. 
To solve these problems, development of new high strength hot rolled sheet steel has been intensively undertaken. As a result, an inexpensive C-Si-Mn type steel is finish rolled at above $A_{3}$ point, and is coiled at an intermediate coiling temperature between $300{ }^{\circ} \mathrm{C}$ to $500{ }^{\circ} \mathrm{C}$, so as to produce a structure composed of ferrite and fine pearlite or bainite, which ensures a tensile strength of 50 to $60 \mathrm{kgf} / \mathrm{mm}^{2}$. As this steel sheet has a ductility which is intermediate between the dual-phase and the precipitation hardened steels, and its shear-edge stretch-flangeability and welding property are satisfactory; it is now used for wheel disks, brackets, and some other parts.

The reasons why various new high strength hot rolled sheet steels have been made successfully are ascribed to the development of technologies of desulfurization and sulfide shape control, use of continuous casting that ensures supply of steels with high uniformity at a low cost, and high performance hot strip mills. In the future, it is expected that development of microstructure controlled steels based on controlled rolling and controlled cooling techniques will be kept advancing.

For ordinary low strength hot rolled steels also, conversion to continuous casting has been an important subject, in which commercialization of continuously castable steel equivalent to rimmed steel merits a special notice. Namely, for hot rolled sheet steels for re-rolling stocks or galvanized plates, rimmed or capped steels were used, but on adoption of continuous casting, Si-killed or Al-killed steels came to be used. However, those killed steels were faced to problems such as relatively higher deformation strength on cold rolling, surface oxidation during annealing, and plating defect on hot dip galvanizing. To solve these problems, a rimmed-equivalent continuously-castable steel was developed by de-oxidizing the degassed metal with a small amount of $\mathrm{Al}$ without $\mathrm{Si}$. This steel is now widely used also for cold rolled sheet and tin plate.

As the CG-HDR process, which directly connects continuous casting with hot rolling, has been realized, further, the optimum thermal histories both for the Al-killed steel for cold rolling and for the precipitation hardening steel have been studied. In the future, new low cost steels are expected to emerge out of this process.

\section{(3) Cold Rolled Sheet Steels}

With the remarkable development of the automobile industry, the demand for cold rolled sheet steel expanded greatly since about 1965 . In the mean time, the cold rolled sheet steel for automobiles had progressed from the core-killed steel and the decarburization-annealed rimmed steel with good anti-aging and low yield stress, through the Ti-stabilized or the double cold reduced extra-deep drawing steels, and the continuously cast Al-killed deep drawing steel, to the today's continuously annealed deep drawing steel.

In developing a continuous annealing process for deep drawing sheet steel, there was a problem in applying the conventional continuous annealing process for tin plate. The annealed cold rolled steel was fine grained and was left with much solid solution of $\mathrm{C}$ due to short time annealing and fast-cooling cycle, it finished to be hard and poor in the anti-aging property. This problem has been solved by adopting the high temperature coiling in hot rolling and by devising a heat cycle combining rapid cooling after soaking and subsequent overaging.

The purpose of high temperature coiling is to have the ferrite grains grown and the carbide particles agglomerated in hot rolled sheet so as to ensure, through cold rolling and short time annealing, the ferrite grain growth and the $\{111\}$ recrystallization texture development. As a result, a low yield strength and a high deep drawability will be achieved simultaneously. On the other hand, the rapid cooling from soaking followed by overaging in the continuous annealing, is to quickly precipitate carbide from solute $\mathrm{C}$ dissolved in the course of recrystallization annealing so as to improve the anti-aging property. For this purpose, first, the gas jet cooling methods $\left(5 \sim 50^{\circ} \mathrm{C} / \mathrm{sec}\right)$ and the water quenching method $\left(>1000^{\circ} \mathrm{C} / \mathrm{sec}\right)$, then the roll cooling and the mist cooling methods (both $100 \sim 400{ }^{\circ} \mathrm{C} / \mathrm{sec}$ ) were put to practical use.

Furthermore, as might be seen in Fig. V.3.3, to manufacture a deep drawing sheet steels by continuous annealing, optimization of all stages from steelmaking to temper-rolling as a total system is necessary. As material for continuous annealing, low $\mathrm{G}$ capped steel was mainly used at first, but low G Al-killed steel, low $\mathrm{C}$ low $\mathrm{Al}$ rimmed-equivalent steel and low C B-bearing steel became popular to improve the antiaging property and to increase the proportion of continuous casting. Further, owing to development of the combination blowing process and the vacuum de-

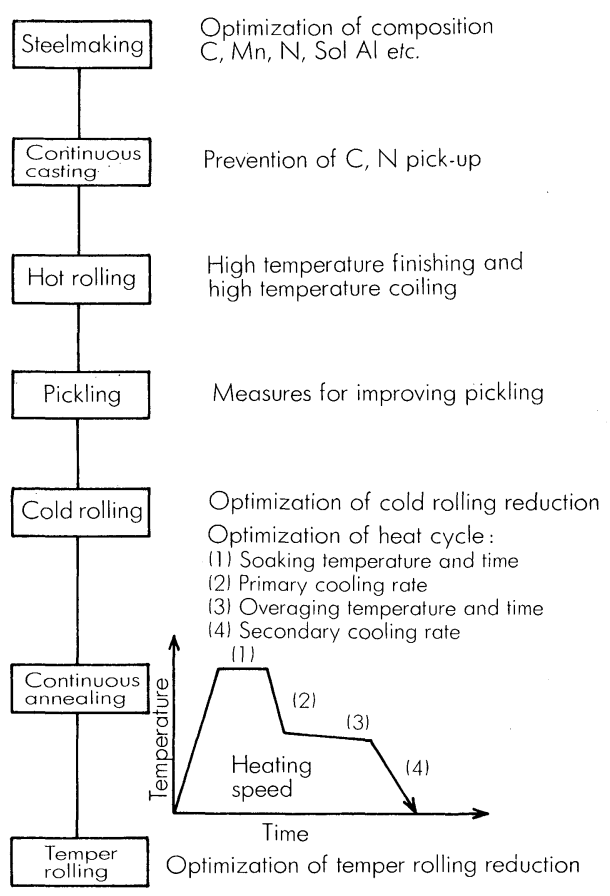

Fig. V.3.3. Total process of manufacturing deep drawing quality cold rolled sheet steel based on continuous annealing method. 
gassing technologies, optimization of $\mathrm{C}, \mathrm{Mn}$, and $\mathrm{N}$ balance has been made progress. Further, the manufacture of deep drawing steels became possible by using extra-low carbon steel of less than $0.01 \% \mathrm{C}$ and steels added with $\mathrm{B}, \mathrm{Ti}$, or $\mathrm{Nb}$ to it. With such improvements in the quality, the ratio of continuously annealed steel in the total production of the cold rolled sheet steels has been increasing year after year. The expectation imposed on the continuous annealing in constructing the concatenation and rationalization of iron- and steel-making process has become so great that optimization of continuous annealing conditions to yet improve the stability of quality and to yet reduce the production cost will be pursued further.

As for the box annealing method, the continuously cast steel such as the Al-killed steel and the reband steel deoxidized with $\mathrm{Si}$ and $\mathrm{Al}$ was the mainstream, but the low $\mathrm{Al}$ steel having the characteristics equivalent to rimmed steel has come to take their places. There are two varieties to this steel, with sol.Al less than $0.010 \%$, and with sol.Al 0.01 to $0.02 \%$, and neither can develop as good drawability as the usual Al-killed steel. On the other hand, they have an excellent ductility and low production cost, so that a large amount of this steel is being manufactured.

As for the high strength cold rolled sheet steel for automotive application, the most popular one is the P-bearing Al-killed steel with 35 to $40 \mathrm{kgf} / \mathrm{mm}^{2}$ class tensile strength, which is manufactured by adding $\mathrm{P}$ less than $0.10 \%$ to Al-killed deep drawing steel of about $0.05 \% \mathrm{C}$ and by subjecting to box annealing. As the $\bar{r}$ value of this steel is over 1.5, meaning as good deep drawability as that of conventional low strength deep drawing sheet steel for car body outer plates, application to outer panels was soon materialized.

Here, for such outer panels as the door outer, high strength steels of $40 \mathrm{kgf} / \mathrm{mm}^{2}$ class were used to assure sufficient dent resistance, but according to models it was sometimes necessary to reduce the strength slightly to avoid the occurrence of such shape defect as surface deflection. To satisfy the dent resistance and the shape-fixability simultaneously, a bake-hardening deep-drawing grade sheet steel having a pressformability as good as that of P-bearing Al-killed steel sheet, a tensile strength of $35 \mathrm{kgf} / \mathrm{mm}^{2}$, and bake hardenability of 3 to $5 \mathrm{kgf} / \mathrm{mm}^{2}$ was required. To meet this demand, improvement on the box annealed Pbearing Al-killed steel for better bake hardenability, was attempted and duly commercialized either by using faster cooling rate in the open coil annealing or by decreasing the $\mathrm{G}$ content to about $0.01 \%$.

Since it is easy to give rise to the bake hardenability by continuous annealing, bake-hardenable deep drawing sheet steel of a quality as good as the box annealed ones has been commercially produced by continuous annealing. Here, two methods are available: one is the so-called solid solution strengthened type, comprising the $\mathrm{P}$-bearing or the $\mathrm{P}$ and $\mathrm{B}$ bearing lower $\mathrm{G}(0.02 \%)$ steels, and the other is the dual-phase steel with martensite as the second phase. The latter is manufactured by subjecting the high temperature coiled hot band for the drawing grade steel to the water quenching type continuous annealing. Since they contain only a small amount of $\mathrm{Mn}$ and $\mathrm{P}$, they are advantageous in spot welding and in scrap recycling, so that they are gaining reputation as sheet steel for the outer panels, replacing the box annealed steel.

As the extra-deep drawing steel which has better press-formability than that of the P-bearing Al-killed steel, new varieties were designed, modifying the extra-low $\mathrm{C}$, Ti- or Nb-bearing interstitial-free steel by addition of solid solution hardening elements such as $\mathrm{Si}, \mathrm{Mn}$, or P. This steel features a high $\vec{r}$-value of over 1.8 , low yield ratio, non-aging property and the convenience of attaining those mechanical properties equally well by either box annealing or continuous annealing. However, its cost is high, and, being a solid solution-hardened steel, the tensile strength is limited from 35 to $45 \mathrm{kgf} / \mathrm{mm}^{2}$ level.

The dual-phase sheet steel, composed of hard martensite dispersed in soft ferrite matrix, which is manufactured by heating a cold rolled steel to between $A_{1}$ to $A_{3}$ transformation points and cooling at an appropriate rate, is attracting attention as an epochmaking high strength steel sheet for press-forming because of its good anti-aging property at room temperature and high bake hardenability together with those favorable properties mentioned above.

There is another feature in the dual phase steel; diverse characteristics can be achieved by varying the cooling method of continuous annealing in combination with chemical composition. These methods can be roughly divided into two types: one is for low $\mathrm{Mn}$ steels, which are cooled rapidly by water quenching from the two-phase region, and then tempered to ameliorate the thermal instability due to the excessive supersaturation of solute $\mathrm{G}$, while the other is for steels containing more than $1.5 \% \mathrm{Mn}$, which are cooled at comparatively slow rate as that of gas jet, from the two-phase region. The former, i.e., the quench-andtempering of low Mn steel, was developed mainly for cost saving whereas the latter, i.e., the slow cooling of high Mn steel, for better formability.

The features of those two varieties are as follows: firstly, both show superior ductility compared with that of the conventional high strength steel of the same strength level. Since the former, i.e., the rapid cooling type, can leave more $\mathrm{C}$ in solid solution, it develops a high bake hardenability of $10 \mathrm{kgf} / \mathrm{mm}^{2}$ or so. The ductility of the latter, i.e., the slow cooling type, is better; even though the bake hardenability is low, and it has as low a yield ratio as 0.5 and a sufficiently high work hardening exponent $n$. Whereas the yield ratio of the former is usually about 0.7 , it can be lowered to 0.6 or below by controlling the microstructure through appropriately changing the thermal cycle. Further, owing to the development of the roll cooling and the mist cooling methods, dualphase steel sheets having properties intermediate between those two are available today. One other feature of those dual-phase steels is that, even if the 
solute carbon is excessive, the yield point elongation scarcely reappears on room temperature aging for long period due to the presence of martensite.

There remain still two problems with the dualphase steel. One is its inferior deep drawability and the other is the rather poor shear-edge stretch-flangeability compared with its high ductility. To improve the deep drawability, two methods have been proposed. One is to produce the dual-phase structure in a high Mn Al-killed steel, which is capable of controlling the recrystallization texture by precipitation of AlN during box annealing, while the other is to convert a box annealed deep drawing steel into the dual phase structure by continuous annealing. As for the method using only continuous annealing, a technology that produces the dual-phase structure in a high temperature hot-coiled low Mn steel by applying the water quenching type continuous annealing has been developed.

With regard to the shear-edge stretch-flangeability, on which the hard martensite is considered to have a negative effect, a method to control the hardness of martensite are being tried out by tempering, or by substituting martensite with bainite.

All in all, by combining the process conditions from steelmaking to continuous annealing variously, manufacture of the dual phase sheet steels with widely varying properties and tensile strengths of 35 to $80 \mathrm{kgf} /$ $\mathrm{mm}^{2}$ has become possible. Accordingly, the usage has also been extended from the outer panels to inner panels, structural members, and further to reinforcing members of automobiles.

In the mean time, the ultra-high strength sheet steel with a tensile strength of $100 \mathrm{kgf} / \mathrm{mm}^{2}$ or above, being used for such reinforcing members as the impact beam, have come to be stably manufactured by continuous annealing. Here, in the first method, the $\mathrm{C}-\mathrm{Mn}$ steel is water quenched from the ferriteaustenite two-phase region so as to introduce martensite about $60 \%$ in volume fraction. In the second method, the high Mn steel is cooled by gas jet from the austenite single-phase region to produce a ferritebainite structure. In the third method, the $2.0 \% \mathrm{Mn}$ steel, added with $\mathrm{Ti}$ to raise the recrystallization temperature to the ferrite-austenite two-phases region, is heated to just below the recrystallization temperature, then gas-jet cooled so that the structure be unrecrystallized ferrite, fine $\mathrm{TiC}$, and martensite. Thus desired strength is obtained by combining work hardening, precipitation hardening, and transformation hardening. All the steels feature a good strength to ductility balance with a total elongation of more than $10 \%$ for a tensile strength of $100 \mathrm{kgf} / \mathrm{mm}^{2}$ level. Further, by extending those methods, a single-phase martensitic steel having an ultra-high tensile strength of $150 \mathrm{kgf} / \mathrm{mm}^{2}$ class was developed on a commercial basis.

The relationship between the total elongation and the tensile strength of those high strength cold rolled sheet steels discussed heretofore is shown in Fig. V. 3.4 .

Other examples of remarkable development in the

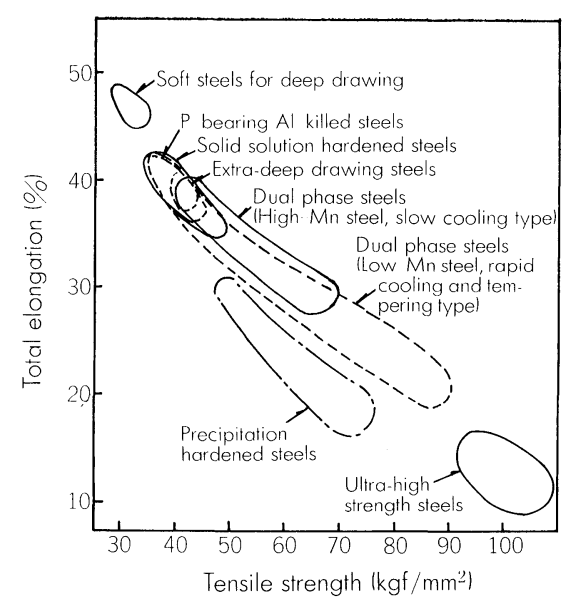

Fig. V.3.4. The tensile strength-total elongation balance of various high strength sheet steels.

field of cold rolled steel is the enamelling steel, which has been discussed in Sec. IV.6.3.(4), and the shadow-mask plate of the cathode-ray tube for a color TV. For this thin gage plate, to be innumerably perforated by the photoetching processing, decarburization-annealed rimmed steel has been used, but the rather poor press formability and liability to etching defects because of inclusions were the problems. These problems have been solved completely by developing a decarburization-annealed Al-killed steel.

\section{3. 5. Tubular Goods}

\section{(1) Overview}

The advances in the manufacturing technology of tubular products in the past decade have indeed been remarkable. As for the raw materials, in the first place, clean and uniform steels have come to be consistently available by virtue of the ladle refining and continuous casting process, contributing not only to the improvement in the quality of the commercial tubes and pipes but also to the manufacturing of high grade steel pipes and tubes that can withstand the very stringent environments. Secondly, as it happened to be also the time of equipment renewal, various advanced pipe-making facilities of seamless and welded pipes and tubes went into operation. For example, in the Mannesmann plug mill, the press piercing process and combined roll angle piercing methods have been applied to improve the big problems involved in the old piercing process. As for the electric resistance welding (ERW) process, the maximum outer diameter has been increased from 20 to $26^{\prime \prime}$, and owing to the improvement in the quality of hot coil, the introduction of automatic welding control technologies, and the improvement in post heat treatment of welded joint, mass production of line pipes up to API X70 became readily possible. In the UO process, distinct improvements have been made in the forming of heavy wall thickness and welding with better quality even the high speed.

As regards the progress in the quality and the performance of steel tubular products, in developing the 
line pipes of high toughness, high strength, heavy wall thickness for submarine pipeline in the North Sea, or the materials resistant to the hydrogen induced cracking (HIG) for pipelines of Middle East or other regions, Japan has led the world, greatly contributing to securing energy resources.

In the boiler and heat exchanger tube, the trend to increase the capacity of power plants has required the boiler tubes for the higher temperature and high pressure service, that makes alloy steel boiler tubes much popular with the above requirements.

Regarding the applications to the petrochemical industry, high strength, corrosion resistant steel tubes have been developed with the growing need for operational conditions of higher temperature and pressure by the introduction of larger capacity equipments and new processes.

In the tubular goods for mechanical use, the production has been increased and the quality improved in the past decade in response to the rapid growth of automobile production. The pipe manufacturers have faithfully followed out the VA (value analysis) activity that has been positively promoted in the automotive industry, contributing to the improvement in automobile performance through supplying the mechanical parts produced with the mother tubes of good formability, machinability, and heat treatability, not to mention the ever higher strength. These improvements in tube properties as a raw material also stimulated the introduction of numerical control lathes and robots. The regular adoption of FF (forward engine, forward driving) system to small automobiles has added the steel tubes for drive shafts to the inventory of automotive steel tubes, quantitatively as well, replacing the propeller shafts.

As for the oil country tubular goods (OCTG), coping with the increase in the development of oil and gas fields with corrosive environment, and deep wells, high $\mathrm{Cr}$ tubes and stainless steel tubes have come to be manufactured in addition to conventional low alloy steel tubes. These alloyed oil country tubular goods show an excellent corrosion resistance in the environments of hydrogen sulfide and carbon dioxide with chloride exist in mixture at an elevated temperature.

Regarding the coating for steel pipes, bitumen used conventionally for corrosion protection of their external surface has almost become out of use and been replaced by polyethylene and epoxy resin, as discussed in Sec. IV.6.3.

\section{(2) Piping Pipes (Line Pipes)}

In the 1970 s and coming into the 1980 s, the development of natural gas resources has been conducted on a worldwide scale, and the regions have come to be extended to the arctic area and to deeper waters. Transportation projects of the produced resources to consuming countries have successively been put to execution, for which ever higher strength, higher toughness line pipes with larger diameter and heavy wall thickness became demanded. Furthermore, the production at sour oil and gas fields containing corrosive fluids have come to be carried out, requiring the line pipes resistant to corrosive environment. As for large scale projects in the arctic area, the extremely long pipeline of $4500 \mathrm{~km}$, transmitting natural gas from West Siberia over to Europe is a good example. This is a typical pipeline that aims at transporting the gas efficiently and in a great quantity. In this project, enormous tonnage of $56^{\prime \prime}$ line pipes of API grade X70 with high toughness were used, a portion of which was exported from Japan. It is reported that Russians are planning to raise the transporting pressure from $75 \mathrm{~atm}$ up to $100 \mathrm{~atm}$ for high efficient operation, using pipes of X80 equivalent or even stronger ones.

In the meantime, submarine pipelines have been installed in succession in North Sea, Mediterranean Sea, Middle East, offshore of Thailand, offshore of India, and northwest part of Australia, and with the depth becoming greater, pipes with a higher strength and a larger $T / D$ (the ratio of wall thickness to diameter) have come to be utilized. For example, where the $T / D$ was between 0.02 and 0.03 in the case of the North Sea project (water depth: $150 \mathrm{~m}$ ), that for the project of Norway offshore $(300 \mathrm{~m})$ was 0.035 and that for Sicilian Channel 0.05 (diameter 20", wallthickness $1.000^{\prime \prime}$ ), and in every case, X65 line pipes with heavy wall thickness have been employed. Furthermore, a pipeline to be constructed at a depth of $2000 \mathrm{~m}$ is now being planned, exemplifying the current trend, which will call for progressively increasing $T / D$ ratio.

With the advancement in the technology of enhanced oil recovery, injection of high pressure sea water, $\mathrm{CO}_{2}$, or natural gas has come to be practiced, and for the transportation of these fluids, high strength, high toughness line pipes with heavy wall thickness are also frequently used: in the Alaskan sea water injection project, the $\mathrm{X} 70$ pipes with a wall thickness of 1.375 " were used.

Table V.3.4 summarizes changes in the fracture toughness requirement for the steel pipes to be used in cold regions. It may be seen that the requirements have become particularly stringent since 1975, especially on natural gas lines. This is because, aside from the lowering of fracture transition temperature for prevention of brittle fracture, it has become known that there are problems of unstable shear fracture propagation in a large diameter at the high pressure gas trankline as discussed in Sec. V.2.2.

In order to meet these severe requirements, Japanese pipe manufacturers have expended strenuous efforts in improving all aspects of mill facilities, steel quality, pipe-manufacturing technology, fundamental research, and application techniques, and have been playing the role of the supply source of line pipes for the world.

First, there has been the development of line pipes resistant to corrosion environment, which originated from the failure caused by crude oil containing $\mathrm{H}_{2} \mathrm{~S}$ of Arabian Sea pipeline in 1972. It was made clear that the inclusion of water in natural gas (or oil) contained $\mathrm{H}_{2} \mathrm{~S}$ or $\mathrm{CO}_{2}$ would allow hydrogen to be absorbed in steel, causing $\mathrm{HIC}$ (hydrogen induced 
Table V.3.4. Changes in the fracture toughness requirement for various pipelines (transversed direction).

\begin{tabular}{|c|c|c|c|c|c|c|c|c|}
\hline \multirow[b]{2}{*}{ Year } & \multirow{2}{*}{$\begin{array}{l}\text { Place of service } \\
\text { (transmission fluid) }\end{array}$} & \multirow[b]{2}{*}{ Pipe grade } & \multicolumn{2}{|c|}{$\begin{array}{l}\text { Charpy requirements } \\
\text { of base metal }\end{array}$} & \multirow{2}{*}{$\begin{array}{l}\text { Charpy testing } \\
\text { required for }\end{array}$} & \multicolumn{2}{|c|}{ DWTT } & \multirow[b]{2}{*}{ Remarks } \\
\hline & & & $\begin{array}{l}\text { Testing } \\
\text { temp. } \\
\left({ }^{\circ} \mathrm{C}\right)\end{array}$ & $\begin{array}{l}\text { Absorption } \\
\text { energy }(\mathrm{J})\end{array}$ & & $\begin{array}{l}\text { Testing } \\
\text { temp. } \\
\left({ }^{\circ} \mathrm{C}\right)\end{array}$ & $\begin{array}{c}\text { Ductile } \\
\text { fracture } \\
\text { ratio }(\%)\end{array}$ & \\
\hline 1970 & Alaska (oil) & $\begin{array}{l}\mathrm{X} 65 \\
(\mathrm{X} 60, \mathrm{X} 70)\end{array}$ & -10 & 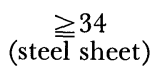 & HAZ, Weld & - & - & SAW pipes \\
\hline 1972 & North Sea (oil) & $\mathrm{X} 65$ & -10 & $\geqq 61$ & HAZ, Weld & - & - & $\#$ \\
\hline 1973 & North Sea (oil) & $\mathrm{X} 65$ & -10 & $\geqq 61$ & HAZ, Weld & 0 & $\geqq 75$ & $"$ \\
\hline 1975 & Alaska (natural gas) & $\mathrm{X} 65$ & -24 & $\geqq 68$ & HAZ, Weld & -24 & $\geqq 75$ & $"$ \\
\hline 1977 & USSR (natural gas) & $\mathrm{X} 70$ & -20 & $\geqq 63$ & Weld & -20 & $\geqq 85$ & $"$ \\
\hline 1978 & Canada (natural gas) & $\mathrm{X} 70$ & Cv 100 & $\geqq 68$ & HAZ, Weld & -20 & $\geqq 60$ & Not realized \\
\hline 1980 & North sea (natural gas) & $\mathrm{X} 65$ & -10 & $\geqq 109$ & HAZ, Weld & -10 & $\geqq 65$ & SAW pipes \\
\hline 1983 & USA $\left(\mathrm{CO}_{2}\right.$ gas $)$ & $\mathrm{X} 70$ & -18 & $\geqq 88$ & HAZ, Weld & - & - & ERW pipes \\
\hline 1984 & Alaska (oil) & $\mathrm{X} 65$ & -46 & $\geqq 27$ & Weld & 0 & $\geqq 40$ & $"$ \\
\hline
\end{tabular}

cracking) or SSCG (sulfide stress corrosion cracking). This has led to the studies on the analysis of the phenomena, evaluation of anti-corrosive materials and preventive methods from the view of both fundamental and manufacturing aspects. As for the evaluation of HIC, the BP testing method (standardized later as NACE TM-02-84) is popular, and NAGE solution is employed for severe environments. For the prevention of $\mathrm{HIC}, \mathrm{Cu}$ addition is effective for inhibiting hydrogen absorption $(\mathrm{pH}>4)$, on the other hand, it was clarified that removal of crack initiation point of HIG such as MnS type inclusion, and homogenization of micro-structure in steel are necessary to increase the resistance against HIC.

Among the principal achievements of manufacturing technologies, there have been the establishment of the control method of inclusion shape by $\mathrm{Ca}$ treatment, advance in refining process to obtain low $\mathrm{C}$, low $\mathrm{P}$, low $\mathrm{S}$, and low $\mathrm{O}$ steels and stabilization of quality of continuous-cast slabs, contributing greatly to the development of high corrosion resistance and high toughness to the line pipes.

In the rolling technologies, there is the development of the thermo-mechanical controlled rolling process, and for plates, in particular, low temperature heating at 900 to $1000{ }^{\circ} \mathrm{C}$, intensification of the two-phase region rolling, and accelerated cooling after controlled rolling have been developed, enabling the manufacture of high strength materials up to Grade X80 by producing uniform micro-structure composed of fine ferrite-pearlite or ferrite structure with some bainite or martensite. Of those, the accelerated cooling appears to be especially effective to lower the carbon equivalent and to improve the toughness. In the hot strip mill, line pipe steels with high strength and toughness up to $\mathrm{X} 80$ have come to be available owing to such improvements as heating with low temperature, increase in finishing roll reduction, lowering of finishing temperature, improvement of water cooling, and lowering of coiling temperature, as well as modernization of the mill.

In the pipe manufacturing, improvements in electric resistance welded (ERW) pipes have been re- markable. Namely, by the virtue of the improvements in forming, welding, heat treatment of weld area, and NDI together with the advancements in the steel quality and rolling techniques of hot coils, the ERW pipes have covered the market of line pipes with high toughness, corrosion resistance and their service in Alaska has just started as shown in Table V. 3.4. In the case of UOE pipes, Grade X70 line pipe with a heavy wall thickness of $1.500 "$ have come to be manufactured through modernizing the facilities and enlarging the size ranges. In addition, improvement of welding efficiency has been achieved through adoption of multi-electrode welding, and improvement of weld toughness by introduction of MIG welding process, multi-pass welding, and improvement of welding materials. As for the seamless tubes, omission of heat treatment by adoption of direct quenching process and improvement in hardenability are noted.

In the aspects of materials, although attempts to lower $\mathrm{C}$, carbon equivalent, and $\mathrm{P}_{\mathrm{cm}}$ have been made in that order to cope with the demands for higher weldability and higher toughness, steels containing those basically precipitation hardening elements as $\mathrm{Nb}, \mathrm{V}$, and $\mathrm{Ti}$, have become popular. However, in recent years, extra-low carbon bainitic steel which takes advantage of hardenability of boron has been developed, attracting attention for its high strength and high toughness covering Grades X65 to X80 even with a low $\mathrm{G}$ content of $0.02 \%$, and also for its good weldability.

As for the collaborative research activities of Japanese steel industry, a series of large scale burst tests on unstable shear fracture propagation have been undertaken on actual line pipes using air (Kamaishi) and a two-phase gas (contracted to the BGG) by HLP Committee (High Strength Line Pipe Comm.), organized by 5 Japanese steel manufacturers. By determining the absorbed energy of notched specimen necessary to arrest the propagating crack, it has been proved that the separation believed by some to be deleterious, is in fact harmless. Further, to establish more rational $\mathrm{HIC}$ evaluation for line pipes resistant 
to corrosion environment, an exposure test of actual pipes is being performed as two year project starting from 1984.

\section{(3) Boiler and Heat Exchanger Tubes}

\section{(i) Boiler Tubes}

Regarding the steam generators in power plant, the trend to larger capacity has toned down since reaching the peak of $1000 \mathrm{MW}$ around 1975, and instead, new technical improvements such as the environment protection and the intermediate load operation have been highlighted. Therefore, no radical change can be observed in the materials, other than that a high-Mn type high strength steel tube has been standardized in JIS as STB 52 (1978) and come to be widely used, and the $\mathrm{Cr}-\mathrm{Mo}$ type low alloyed steel ERW tubes were also standardized in JIS in a series up to STBA 22 (1978). As for 9Cr type steels, various grades are being studied for early commercialization. The notable ones are the $9 \mathrm{Cr}-2 \mathrm{Mo}$ steel, which is a modification of the STBA 26 (9Cr-1Mo), and the high strength steel of 1 to $2 \%$ Mo with an addition of $\mathrm{Nb}, \mathrm{V}$, or $\mathrm{N}$, which has a markedly higher allowable tensile strength than that of the $2 \frac{1}{4} \mathrm{Cr}-1 \mathrm{Mo}$ steel, enabling economical design of boilers. Of these, the $9 \mathrm{Cr}-2 \mathrm{Mo}$ steel is being mainly used as the reheater tubes for boilers, being standardized in the Thermal Power Technical Standards regulated by the Ministry of International Trade and Industry as STBA 27 and STPA 27 (1983). These materials are being studied also for application to heat exchangers of the FBR (Fast Breeder Reactor).

As for the stainless steel tubes for superheater, oxidation by steam on the inside surfaces of tubes and high temperature alkaline and vanadium attack on the external surfaces have become a problem. For the countermeasures against steam oxidation, adoption of fine grained $347 \mathrm{H}$ steel and the shot blasting of inside surface of the tube have been carried out, while against high temperature corrosion, the $347 \mathrm{H}$ steel is popular for its fairly good corrosion resistance among the standardized materials. In addition, practical application of various steel tubes with treated surfaces are also being contemplated. The addition of very small amount of $\mathrm{Nb}$ or $\mathrm{V}$ are applied to strengthen the stainless steels and the improvements of the $25 \mathrm{Cr}-$ $20 \mathrm{Ni}$ and the $32 \mathrm{Ni}-22 \mathrm{Cr}$ are being tried to make them higher strength and better corrosion resistance. Especially, in the trend toward supercritical high pressure boilers for yet efficient utilization of energy by raising the temperature level from 567 to $593 \sim 649{ }^{\circ} \mathrm{C}$ and the pressure level from 246 to $316 \sim 350 \mathrm{~atm}$, a situation that is sure to entail severe corrosion environments, development of high-Cr alloy steels, co-extruded composite tubes and surface treated tubes are being conducted. In addition, as for the piping, adoption of high strength high-Gr steels or stainless steels in place of conventional $2 \frac{1}{4} \mathrm{Cr}-1 \mathrm{Mo}$ steel is being studied.

Regarding the fuels for boiler, it is forecast that the utilization of coal will substantially expand. This will create the problems of ash erosion and corrosion, and though they will have to be solved mostly by the design, behaviors of materials under ash are also being studied, and the countermeasures including protecting materials are being investigated. In the special boiler tubes, the ERW rifle tubes, with inner surface spirally grooved for raising the thermal efficiency as the water wall tube, and the co-extruded composite clad tubes have been developed.

\section{(ii) Tubular Products for Nuclear Applications}

For stainless steel pipes for BWR (Boling Water Reactor), 304 stainless steel was initially used, but the IGSGG (intergranular stress corrosion cracking) mainly around the weld heat-affected zone became a serious problem. To overcome those phenomena, in addition to the improvement of welding method and chemical control for water, the development of materials has been proceeded. An extra-low-C 316 stainless steel with $\mathrm{C} \leqq 0.02 \%$ to prevent sensitization due to grain boundary carbide precipitation of carbide, and $\mathrm{N}$ raised to $\leqq 0.12 \%(\mathrm{C}+\mathrm{N} \leqq 0.13 \%)$ to offset the decrease of strength due to decrease in $\mathrm{C}$, has been developed and been actually used in the BWRs of this country. In the steam generator tubes for PWR (Pressurized Water Reactor), on the other hand, the susceptivity of the NGF 600 TB (the Alloy 600) of $72 \% \mathrm{Ni}$ has been further improved by optimizing the heat treatment conditions, particularly those of the final heat treatment, and the chemical compositions resulting in the development of Alloy TT 600, which is now used in the operating PWRs.

As for the heat exchanger tubes for FBR (Fast Breeder Reactor), nuclear power reactor of the next generation, the $9 \mathrm{Cr}$ steels and the Alloy 800 are being studied as prospective materials.

Furthermore, as the tubular products in special shapes for nuclear applications, the integrated tubejoint member to decrease the welding portions, the roll-formed low-fin tubes, various stainless steel tubes as the fuel cladding tubes and duct tubes for the fuel bundle have been developed.

\section{(iii) Heat Exchanger Tubes for Chemical Industry}

For materials used in the petrochemical and oil refinery industries, various stainless steels, besides those well applied steels for heat resistance and anti-corrosion service (for instant, SUS 321 and modified SUS 347 as polythionic acid resistant steel, have been developed for heat exchangers using sea water or recycled water. They are austenitic, duplex, or ferritic, and in the austenitic stainless steels, the improvement of resistance to crevice corrosion has been researched with adding Mo (4 to $6 \%$ ), Si, N, and several other elements. In the ferritic stainless steels, for which there are the 25 to $30 \%$ Cr type added $\mathrm{Mo}$ and $\mathrm{Ni}$ and the $19 \% \mathrm{Cr}$ type added with $\mathrm{Mo}, \mathrm{Nb}$, and $\mathrm{Ti}$, the toughness has been raised greatly by reducing $\mathrm{C}$ and $\mathrm{N}$ to the extremely low contents in the improved vacuum ladle refining processes such as VOD. Those steels are called the high purity ferritic stainless steel. Further, expansion of their applications is well expected. 
(4) Tubular Goods for Mechanical Use

(i) Tubular Products for Automobiles

The demand for steel tubular products has expanded during the past decade with the increase in automobile production, though the specific consumption of steel tubular products has been showing a declining tendency in the general weight reduction and the recent rapid increase of the $\mathrm{FF}$ cars. Here, a typical example of weight reduction is the promotion of hollow tubes for various shafts (steering shafts, valve rocker arm shafts, and cam shafts) for conventional rods and bars. Another example is the constant velocity joints, drive shafts, and the like that have been developed specifically for development of the FF system, of which the hollow drive shaft, necessitated from the view point of the improvement of automobile performance and realized by the steel pipe, is representative. At present, those drive shafts made of steel pipe are fabricated by caulking, friction welding, or one-piece forming, and these fabrications affected the pipe manufacturing technology depending on the fabricating requirements, for example, steel tubes applied to the one-piece forming are provided with not only static strength but also formability, machinability, hardenability, and are required with good fatigue strength. Since, tubular products made of high toughness steel or case hardening steel have come to be sought in the VA (value analysis) studies in the automotive industry, further expansion of demand for steel pipes may be expected for, if the forming method and the pipe-making technology are properly improved.

The improvement in quality such as wear resistance, shock resistance, etc. of bearing steels which are in use not only for automobiles but also for various machine parts, have been promoted to prolong the service life, and a remarkable progress has been made in the manufacturing of clean steel. Therefore, with a further progress in improvement of the dimensional accuracy of steel tubes, which will be appreciated in the VA, as, for instance, reduction of allowable lower limit marginal thickness, further growth of demand for tubular products including what is to replace the bars and rods, may be expected.

(ii) Tubular Products for Construction Machines and Industrial Machines

In the trend toward larger construction machines, light weight and high strength steel pipes (80 to $100 \mathrm{kgf} / \mathrm{mm}^{2}$ ) are widely employed for booms or stems, while for the crawler belt bush, for which $\mathrm{Cr}-\mathrm{Mo}$ steel has principally been used in the past, change over to the $\mathrm{Cr}$ steel, Mn steel, or boron-added steel is in progress. Furthermore, switching from seamless tubes to ERW tubes has come to be studied.

The mainstream for the hydraulic or pneumatic cylinder tube for construction machines and industrial machines is still the honing finish of the cold drawn seamless tube or the cold drawn ERW tube, but in recent years, roller varnishing or ball sizing of hot rolled seamless or ERW tubes is being applied. Also, adoption of $\mathrm{Al}$ alloys to the pneumatic cylinder, and in parallel with this, application of nonferrous metals (light weight and high corrosion resistance) to lower pressure hydraulic lines, have become noted. Further, there is a move to employ nonmagnetic stainless steel tubes in the built-in micro computer controlled NG machine tools equipped with precision servomechanisms.

For reduction of machining hours and improvement of metal yield, the replacement of round bars by tubes has become popular in the making of light duty rolls, and the printing rolls with comparatively thin wall thickness has been considered as a subject of VA in switching from seamless to ERW tubes and in adoption of one piece forming.

As a new field of application, VA for the extra-high pressure cylinder of the plastics injection molder is expected by switching from the round bar machined to the hollow to the extra-heavy wall thickness tube for the purpose of reducing machining hours and the improvement of yield.

\section{(5) Oil Country Tubular Goods (OCTG)}

The last decade has seen a great change in the trend of oil country tubular goods (OGTG). The demand not only for API standard products but also for non-API products for special purposes have been increasing, and the research on the quality design, manufacturing, evaluation test methods are being vigorously conducted. The recent trends of oil well development are shown in Fig. V.3.5.

\section{(i) High Strength OCTG}

In concert with the exploration of deep wells which exceed $15000 \mathrm{ft}$ deep, casing and tubing with a minimum yield point of $125 \mathrm{ksi}\left(87.9 \mathrm{kgf} / \mathrm{mm}^{2}\right)$ or $150 \mathrm{ksi}$ $\left(105.4 \mathrm{kgf} / \mathrm{mm}^{2}\right)$ have become to be employed. These products are manufactured by quenching and tempered low alloy steels of a $\mathrm{Cr}-\mathrm{Mo}-\mathrm{V}$ type so as not to lower the toughness nor to cause the delayed rupture by hydrogen induced to the steel.

(ii) High Collapse Casing

In the places where complicated formation such as
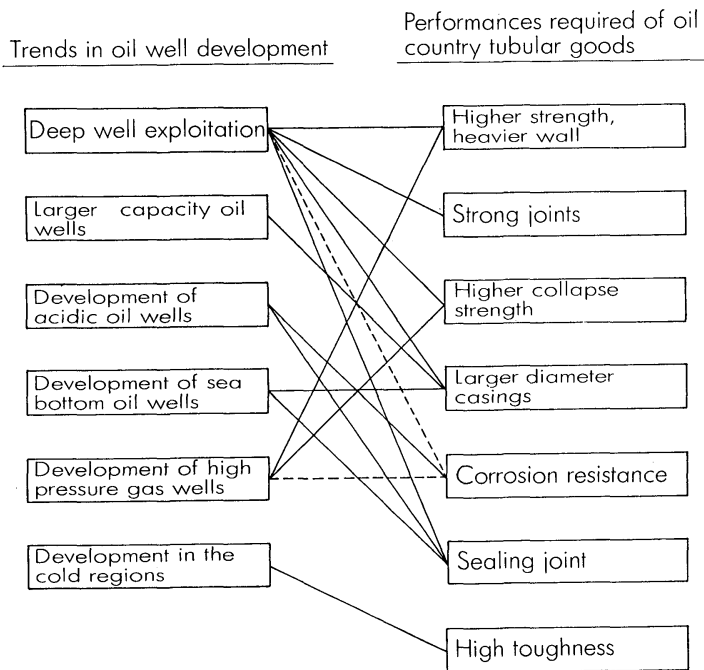

Fig. V.3.5. Recent trends in oil well development and the performance required of oil country tubular goods. 
salt zone exist, strong casings against collapse under a high formation pressure are required, and the casing having higher collapse value than that specified in API standard are being employed. In order to raise the collapse value, casings of high dimensional precision, such as less in the ovality, non-uniform thickness and eccentricity, and less in the fractuation of yield point and the low level of elastic zone are being manufactured by intensifying the control over the residual stress.

\section{(iii) OCTG for Sour Gas Service}

In an environment where wet $\mathrm{H}_{2} \mathrm{~S}$ gas is involved, SSCG (sulfied stress corrosion cracking) becomes a problem. The SSCG used to be appeared in high strength materials, and is also influenced by the microstructure. The pipe is generally produced with a chemical composition of AISI 4130 type, by quenching and tempering process preferably with high tempering temperature to control hardness strictly to Rockwell G 22 to 25. Because the wall thickness can be as much as $2^{\prime \prime}$, it is necessary to minimize the variation of the hardness at the cross section of OCTG and to select a material having good hardenability and cleanliness of micro structure by the chemical contents of low $\mathrm{S}$ and $\mathrm{P}$.

As for the evaluation methods of SSCG susceptibility, the NACE tensile test type, the bent beam method (the Shell method), the DCB, the $\mathrm{C}$ ring test method, and others are available. Besides these laboratory acceleration tests, some customers have come to insist on the actual pipe SSCG test to simulate the real service conditions.

\section{(iv) OCTG for $\mathrm{CO}_{2}$ Gas Environment}

Under the environment of wet $\mathrm{CO}_{2}$ gas, there is a possibility of the occurrence of violent corrosion when chlorine ions $\left(\mathrm{Cl}^{-}\right)$coexist. The corrosion forms are the general corrosion, pitting corrosion and crevice corrosion, and depending on the load conditions of gas temperature and pressure, CSCC (chlorides stress corrosion cracking) is appeared. Though the $\mathrm{CO}_{2}$ corrosion can be prevented by using an inhibitor, whose effect is aggravated at elevated temperatures, or it takes a big cost in the treatment, so that solution is often sought in the steel. Here, as the effectiveness of $\mathrm{Cr}$ is well known for $\mathrm{CO}_{2}$ corrosion, $9 \mathrm{Cr}-1 \mathrm{Mo}$ steel, $13 \mathrm{Cr}$ steel (AISI 420 type), and 22 25 $\mathrm{Cr}$ steel (duplex stainless steel) are being applied. Since the more popular $9 \mathrm{Cr}-1 \mathrm{Mo}$ steel and $13 \mathrm{Cr}$ steel are not sufficiently resistive to $\mathrm{SSCC}$, they should not be used in the wells containing $\mathrm{H}_{2} \mathrm{~S}$ in principle. In reality, however, as a certain amount of $\mathrm{H}_{2} \mathrm{~S}$ will always be contained in actual wells, OCTG for $\mathrm{CO}_{2}$ gas environment is produced by conducting quenching and tempering process so as to finish their steel in a uniform tempered martensite structure with the maximum Rockwell G (HRG) hardness controlled in the range from 22 to 24 in order to improve on the resistance to SSGG as much as possible. On the other hand, the duplex stainless steel, whose typical chemical composition is $22 \sim 25 \% \mathrm{Cr}, 5.5 \sim 7.0 \% \mathrm{Ni}, 2.5 \sim$ $3.5 \%$ Mo, is used in a comparatively high tempera- ture environment or in the case where a small amount of $\mathrm{H}_{2} \mathrm{~S}$ coexists. However, as the sufficient strength to the high grade OCTG cannot be expected only by heat treatment, they are used as cold deform (cold drawn or cold rolled) so that the yield point be 110 to $140 \mathrm{ksi}\left(71.3\right.$ to $\left.98.4 \mathrm{kgf} / \mathrm{mm}^{2}\right)$ at the minimum. Evaluation tests for corrosion resistance are conducted by variously combining the $\mathrm{CO}_{2}$ and $\mathrm{Cl}^{-}$concentrations, temperature, and pressure.

(v) OGTG Resistant to the Corrosion by $\mathrm{H}_{2} \mathrm{~S}, \mathrm{CO}_{2}$, and $\mathrm{Cl}^{-}$

In environments involving $\mathrm{H}_{2} \mathrm{~S}, \mathrm{CO}_{2}$, and $\mathrm{Cl}^{-}$, high $\mathrm{Ni}$ alloys containing a large amount of $\mathrm{Ni}, \mathrm{Cr}$, and Mo are applied. The representative is the Hastelloy C276, but for economical reasons, alloys with Cr normally $18 \sim 20 \%$ or more, Ni $20 \sim 25 \%$ or more, and Mo $3 \%$ or more such that the sum of those three is $50 \sim 80 \%$, and are made by applying modern ladle refining method or special melting method have recently been highlighted. Because of the single-phase structure, these materials have high resistance to the deformation at high temperature; therefore, products are principally manufactured by extruction. Further, in the case of the duplex stainless steel, they are used as cold forming, becuase the strength required to the OCTG for deep well are not obtained only by heat treatment. More recently, however, the materials based on these types of alloys have been developed by adding the element of $\mathrm{Nb}$ or $\mathrm{Ti}$ to utilize the precipitation hardening in order to obtain the necessary strength only by heat treatment (aging process). The strength level of those high $\mathrm{Ni}$ alloys is generally 95 to $150 \mathrm{ksi}\left(66.8\right.$ to $105.4 \mathrm{kgf} / \mathrm{mm}^{2}$ ) by the minimum yield strength.

The corrosion tests are conducted by simulation test method using auto-clave to create a near actual environments. However, besides these laboratory tests, full scale tests using actual pipes are also being desired. Because of the complexity of the corrosion behaviors due to mutually influencing effects of the concentrations of $\mathrm{H}_{2} \mathrm{~S}, \mathrm{CO}_{2}$ and $\mathrm{Cl}^{-}$, temperature, and $\mathrm{pH}$, then, an evaluation system to correlate the test data to the performance results in actual wells will have to be established.

\section{(vi) Drill Pipes}

In most cases, drill pipes are used with tool joints welded on at the both ends. High strength and corrosion resistance have come to be required of some of the drill pipes as well as casings and tubings. Because corrosion fatigue can be a problem in view of its nature of usage, investigations on the behavior of not only the materials of drill pipes but also the parts of friction welding, and their vicinity are being conducted by varying $\mathrm{pH}$, salt concentration, and temperature of mud as the service environments, Also, drill pipes whose inside surface is coated with epoxy or phenol-derived resin to prolong the service life or to provide smoother mud flow are increasing.

Finally, as another important property of OGTG, the sealing of thread connection resistance to galling, and corrosion resistance of the joints should be noted. 
meaning that special OCTGs are often applied with premium joints. In generally speaking, there have been a great progress in steelmaking and rolling technologies, improvement of heat treatment techniques, and advances in the finishing process equipment, in the method of upsetting, in particular, owing to which, as well as to the intensification of quality assurance, attainment of higher level quality is being achieved. It is forecast that in future the demand of special products will progressively increase, and that manufacture of larger-diameter, heavier wall products will become necessary. Furthermore, to the development of enhanced oil recovery, geothermal well development, and of oil sand and oil shale, these novel technologies are keenly expected.

\section{(6) Coated Pipes}

There has been a remarkable progress in the field of coated steel pipes, such as the polyethylene coated, the epoxy powder coated, and the polyethylene powder lined pipes. Those have been discussed in Sec. IV.6.3.

\section{3. 6. Wire Rods and Wire Products}

\section{(1) Overview}

Wire products are extensively used for various purposes, as automobile parts, which occupy a greater portion, and as parts for construction machines, industrial machines, household appliances, business machines, and also for products closely related with daily life, for example, nails, wires and wire nets. For this reason, wire rods are well diversified according to steel types, working process, and their required quality as compared with other steels.

However, after the oil crisis, the demand for wire rods has continued to be sluggish, while customer's demands for higher-grade products those new products that would rationalize or simplify their own working processes are getting stronger. It may be said that the wire rods sector is now facing a great transition.

\section{(2) Low Carbon Steel Wire Rods}

Low carbon steel wire rods have traditionally been manufactured mainly out of ingot rimmed or capped steel, but as described in Sec. III.3.7 and elsewhere, a rimmed-substitute steel was developed and is now being used.

As this rimmed-substitute steel is quite uniform in terms both of the chemical composition and of the mechanical properties, and is of a favorable drawability, its application is steadily expanding.

\section{(3) High Carbon Steel Wire Rods \\ (i) Wire Rods for Prestressed Concrete Wire}

The wires for prestressed concrete (PG) are manufactured first by drawing, then stranding if required, the patented high carbon wire rods (the piano wire rods), then by bluing or hot stretching it to reduce the relaxation values. For those PC wires, JIS provides two classes by the strength, the $175 \mathrm{kgf} / \mathrm{mm}^{2}$ $(250 \mathrm{ksi})$ class and the $190 \mathrm{kgf} / \mathrm{mm}^{2}(270 \mathrm{ksi})$ class, but with the recent needs for larger size and lighter weight, there is a demand for higher strength PG steel wires that exceed $190 \mathrm{kgf} / \mathrm{mm}^{2}$. Research and development of such wires is currently under way from both the chemical composition of the steel and wire processing technology viewpoints.

Further, in order to omit lead patenting, various rolling patenting methods have been developed and put to practical use. Some wire-makers are actually beginning to use these methods to produce PC wires by drawing the piano wire rods that are directly patented in wire rod rolling process.

(ii) Wire Rods for ACSR Core Wire

The ACSR is a steel cored aluminum strand wire, shown in Fig. V.3.6, and is utilized as aerial power transmission cable. This steel core wire for ACSR is produced by drawing the patented hard steel wire rods before galvanizing or aluminum plating, then by stranding. With the capacity increase in the recent aerial power transmission, large-section cables on small-section steel core wire have become needed. To meet this call, studies have been made on all processes from composition designing, drawing, to plating, and a high strength galvanized steel core wire of $190 \mathrm{kgf} / \mathrm{mm}^{2}$ class has been developed and is being put to actual use by some cablemakers.

(iii) Steel Wire Rods for Long and Large Suspension Bridges

With the coming of the long and large suspension bridge era in Japan, which was triggered by the Kanmon Bridge, full scale construction of the HonshuShikoku Connecting Bridges has now begun. The main cables for large suspension bridges are the most important component to sustain the suspension structure, in which parallel wire-strands are used. They are manufactured using about $100 \mathrm{Zn}$-coated $5 \mathrm{~mm}$ diameter piano wires, having a tensile strength of $160 \mathrm{kgf} / \mathrm{mm}^{2}$ class, by piling them in parallel into a tight bundle as shown in Fig. V.3.7. Since the cable is subjected to constantly repeating stresses, each element wire must be of uniform and superior mechanical and surface properties all along its entire length. Therefore, the wire rod suppliers and the wire drawing, galvanizing, and stranding manufacturers have established an integrated fabrication system of highly co-operative and interactive quality control, through which steady manufacture of these main cables have become possible.

(iv) Wire Rods for Steel Cords for Automotive Tires Development of expressways has prompted the spread and expansion of radial tires, especially steel radial tires illustrated in Fig. V.3.8 both at home

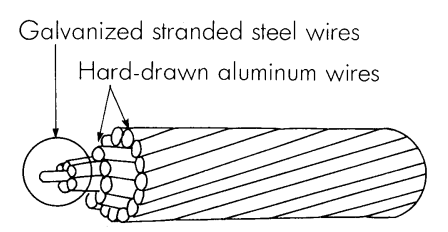

Fig. V.3.6. A cutaway view of the ACSR aerial power transmission cable. 
(a)
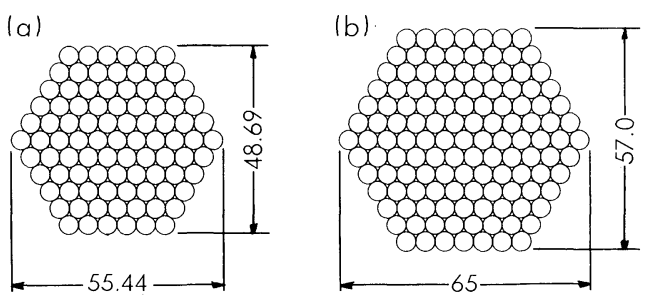

(a) Kanmon suspension bridge: $5.04 \times 91$ wires

(b) Honshu-Shikoku suspension bridge: 5.00 $\times 127$ wires

Fig. V.3.7. Examples of parallel wire strand.

Source: Kobe Steel PWS Catalogue.

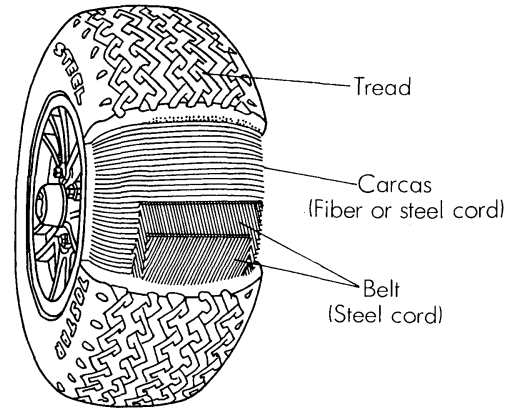

Fig. V.3.8. Structure of steel radial tire and usage of steel cords.

Source: Iwata: The Special Steel, 32 (1981), No. 3, 38.

and in abroad, giving a sure expectation to the growth in production of these tires in the years to come. Thus, the demand for steel cords, which are employed as reinforcement member for radial tires, has remarkably increased, and the production is already over $10000 \mathrm{t} /$ month in Japan today.

Steel cords are made first by repeating the drawing and patenting of a high carbon steel wire rods with a carbon content of 0.65 to $0.75 \%$, then brassplating after the final heat treatment so as to finish in a very fine wire of $0.15 \sim 0.4 \mathrm{~mm} \phi$, and lastly by stranding into cords with diversified structures. Therefore, the wire rods for the steel cord must be able to take a high speed $(1000 \mathrm{~m} / \mathrm{min})$ and high reduction ratio $(96 \%)$ drawing. Furthermore, the bunching process in stranding has been replacing the tubular process in recent years, the processing conditions have become even severer. Here, as breaking of wires, especially during drawing and stranding, exerts a serious influence upon productivity and quality of steel cords, it has become the most important subject.

Since the breaking of wire is greatly influenced by nonductile inclusions and center segregation, as may be seen in Fig. V.3.9, which shows the relation between the amount of inclusions and the frequency of wire breakage, the steelmakers are taking various measures in the steelmaking processes, from raw material selection to casting, to prevent the formation of the alumina-based inclusions, or to make them ductile, and to alleviate the center segregation by applying electromagnetic stirring to continuous casting. As

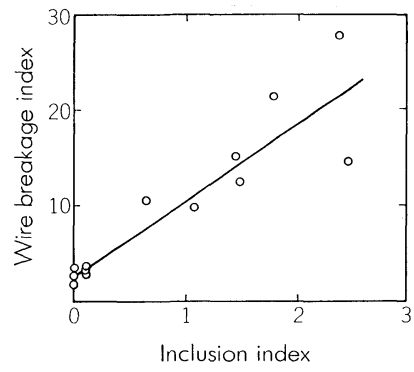

Fig. V.3.9. Relationship between the amount of inclusions and the frequency of wire breakage in drawing and stranding.

Source: Saito et al.: Kobe Steel Engineering Report, 34 (1984), No. 2, 98.

a result, billets having good cleanliness and homogeneity have come to be produced, and the frequency of wire breakage has been remarkably reduced.

The recent needs for reducing the weight of tire raised a demand for refining the diameter of steel cords, and high strength steel cords, whose tensile strength has been improved by 10 to $20 \%$, has been developed based on those steelmaking technologies. They have already been put to actual uses for buses and trucks.

\section{(4) Special Steel Wire Rods}

(i) Wire Rods for Cold Heading and Cold Forging

The cold forging of steel, which rapidly came into wide use after 1960, is now an indispensable parts forming method for automotive, screw-making, and many other machine industries. Therefore, the demand for cold forging wire rods has remarkably increased in the past decade.

The cold forging wire rods may be either plain carbon steel or low alloy steel, both of which are required to be low in the deformation resistance and high in the formability so as to be malleable. Since these characteristics are largely influenced by inclusions in addition to chemical compositions, structure, and surface flaws, each steelmaker has established their own integrated manufacturing and quality control system from steelmaking, rolling to delivery to obtain cold forging wire rods of high quality with very little harmful constituents such as sulfur, inclusions, segregation, and surface flaws. Figure V.3.10 shows improvement in the cold forgeability by decreasing sulfur. Recently, there has been a demand for nondefect placed by the automobile manufacturers, and wires without flaws over the full length have been begun to put to actual uses.

In the meantime, for rationalization of the working process and for cost reduction, $\mathrm{B}$ steel for cold forming to save the costly Mo, wire rods for non-heat treated bolts to omit a heat treatment process such as quenching and spheroidizing, and low work hardening wire rods made by controlled rolling and controlled cooling, precision-rolled wire rods to omit the redrawing, ultra-large diameter wire rods from 8 to $50 \mathrm{~mm} \phi$ to improve the metal yield, and steels that combine cold forgeability and machinability, the two 


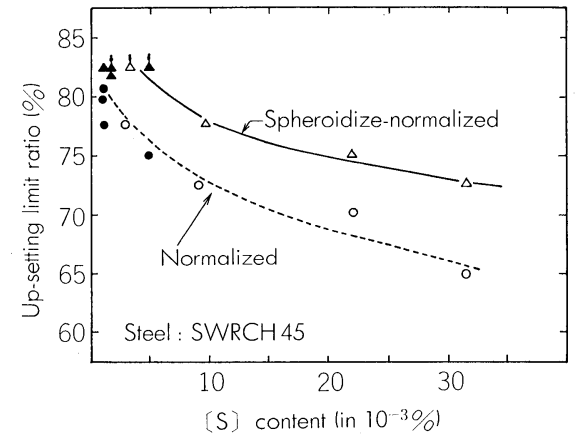

Fig. V.3.10. Improvement of cold forgeability for decreasing the sulfur content.

Source: Onishi et al.: Kobe Steel Engineering Report, 31 (1981), No. 3, 55.

mutually contradicting properties, have been developed and gradually put to actual use. Figure V. 3.11 shows an example of the size tolerance of the precision-rolled wire rods.

(ii) Wire Rods for Valve Springs

As the service conditions for valve springs are one of the severest, oil tempered steel wires and piano wires that are of carbon steel, $\mathrm{Cr}-\mathrm{V}$ steel, or $\mathrm{Si}-\mathrm{Cr}$ steel are used for the valve spring material. With recent high performance such as high output and high revolution of automobile engines, valve springs of higher performance are required, and the trends are for the oil tempered wires which are made of a high carbon alloy steel like $\mathrm{Cr}-\mathrm{V}$ steel and $\mathrm{Si}-\mathrm{Cr}$ steel and are excellent in fatigue resistance, relaxation resistance, and heat resistance. Further, as the service conditions became severer, the notch sensitivity became a problem, and decrease of sub-surface inclusions as well as such surface defects as surface flaws and decarburized layer have become very important. Therefore, especially in the steelmaking process, decrease of oxide-based inclusions is promoted by optimizing the raw material selection and operation conditions of the ladle refining to improve further and stabilize the fatigue resistance.

Further, because of the high hardenability of these high carbon alloy steels, the wire rods are liable to develop a supercooled structure such as martensite and bainite even during rolling, so that the high carbon alloy steel wire rods are usually annealed before submitting to drawing. Here, wire rods that can dispense with annealing has been made by adopting the controlled rolling and cooling technology to get fine and homogeneous structure, and have now been put to actual use.

(iii) Wire Rods for Suspension Springs

The suspension springs of passenger cars have been shifted from the leaf spring to the coil spring to improve the riding comfort and to reduce the weight, and active improvement and development of these springs are currently under way as described in Sec. V.3.3.(3).

(5) Wire Rods for Welding Wire

The coated arc welding electrodes have tradition-

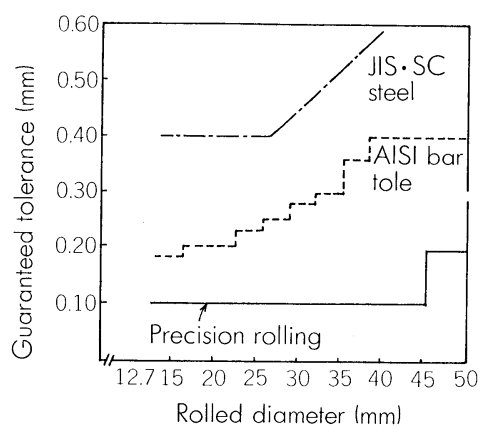

Fig. V.3.11. An example of dimensional tolerance attainable by precision rolling.

Source: Nagai: The 98-99th Nishiyama Memorial Seminar, ISIJ, (1984), 18.

ally held a central position of welding materials, but gas shield welding wires have greatly increased in recent years due to ease of automation and high effciency of this welding method. For $\mathrm{CO}_{2}$ welding wires, which account for the majority of the gas shield welding wires, great emphasis has been laid on the need to lower prices and ease of use. As regards MIG welding wires, which are replacing the coated arc welding wires in fabricating the chemical process facilities and the offshore structures, demands for improving the quality of welded joints, for example, mechanical properties and resistance to cracking is intensifying. To meet these needs, various improvements and development have been conducted for the steel for these welding wires.

As for the $\mathrm{CO}_{2}$ welding wire, optimization of composition design and development of such a steel that develops superior wire drawability and descaling ability without impairing its own welding functions, and for which heat treatment can be omitted, by utilizing the controlled rolling and cooling technology is being promoted to decrease the production cost. Also studies are being made into the possibility of continuous casting such steels.

For the MIG wires, on the other hand, to improve the quality of the welded joints, there is a demand for cleanliness and homogeneity like in the case of steel plates, for which those modern steelmaking processes such as the ladle refining and degassing are being utilized freely to positively decrease the impurity elements such as $\mathrm{P}$ and $\mathrm{N}$, and to narrow up the allowable range of alloying element addition.

Thus, welding wires to produce welded joints having a quality equal to or even better than that of the base metal and also having an excellent low temperature toughness and weld cracking resistance are being commercialized.

\section{(6) Future Prospects}

The future prospects of wire rods may be summarized as follows:

(1) Owing to the advancement of steelmaking centering on the ladle refining method, manufacture of very clean wire rods will become possible, and drawability of the wire rods and fatigue resistance of 
the wires will be improved greatly.

(2) The desire of weight reduction on the customers' side will prompt further the strengthening of the steel for wire rods.

(3) Owing to the advancement of technologies such as the controlled rolling and cooling and precision-rolling, development of steels which can eliminate the wire processing. (e.g., annealing and wire drawing) will be accelerated and the use of these steels expanded.

(4) Owing to the advancement of manufacturing and inspection technologies, manufacturing of wire rods and wires without surface defects and inclusions will become possible.

\section{3. 7. Stainless Steels and Heat Resisting Steels}

\section{(1) Ferritic Stainless Steels}

The reduction of $\mathrm{G}$ and $\mathrm{N}$ contents of stainless steels has come to be economically and easily attainable by means of the AOD or the VOD process, which have become the mainstream refining process of stainless steels since the 1970 s, achieving a clear improvement in toughness and resistance to intergranular corrosion, especially of ferritic stainless steel. It followed that the ferritic stainless steel became highlighted as a corrosion resisting material, which has given impetus to the research and wider application of this steel. Newly developed grades, in general, contain $0.04 \%$ or less $\mathrm{C}+\mathrm{N}$, and in most cases a small amount of $\mathrm{Nb}$ or $\mathrm{Ti}$, which forms stable compounds with $\mathrm{C}$ or $\mathrm{N}$, is added. Of those steels, $12 \mathrm{Cr}$ (SUS $410 \mathrm{~L}$ ), $17 \mathrm{Cr}$ (430 LX), $17 \mathrm{Cr}-1 \mathrm{Mo}$ (436 L), 18Cr-2Mo (444), 26Cr-1Mo (XM 27), and 30Cr-2Mo (447 J1) steels have newly been standardized when JIS was revised in 1981. To develop those steels further, researches were conducted in detail of the effects of various alloying elements on corrosion resistance, toughness, and weldability; the essential points of the optimum chemical composition, of working, and of application of these steels have been elucidated.

Besides those standardized steels, $12 \mathrm{Cr}-1.5 \mathrm{Mn}-$ $0.4 \mathrm{Cu}$ steel in the low $\mathrm{C}$-low $\mathrm{N}-13 \mathrm{Cr}$ series and $17 \mathrm{Cr}-$ $1.5 \mathrm{Mn}-\mathrm{Ti}$ steel in the low $\mathrm{G}-17 \mathrm{Cr}$ series have emerged as the steels for welded structure in which the properties of welded joint are improved. For further improvement of ferritic stainless steel, attention was paid to adding $\mathrm{Al}$ in combination with $\mathrm{Nb}$ or $\mathrm{Ti}$. Moreover, a ridging effect which is not like the one that occurs in SUS 430 was found in Ti-added low G-17Cr steels.

In the meantime, ferritic stainless steels that have a resistance to corrosion equivalent to that of SUS 304, an excellent formability and weldability, and, in addition, contain less or even no Mo, an expensive but highly effective corrosion-resistance improving element, have been developed by various companies. Their chemical compositions, which are shown in Table V.3.5, are basically low C-low N-17 19\% Cr, $0.4 \sim 0.5 \% \mathrm{Cu}$, and $0 \sim 0.5 \% \mathrm{Mo}$ with addition of $\mathrm{Nb}$
Table V.3.5. Mo-saved ferritic stainless steel with good atmospheric corrosion resistance. (\%)

\begin{tabular}{l|rcccl}
\hline Symbol & G & Cr & Mo & Cu & Others \\
\hline $430 \mathrm{M}$ & $\leqq 0.02$ & $19 \sim 21$ & - & $0.3 \sim 0.6$ & $\mathrm{Nb}$ \\
$442 \mathrm{M} 3$ & 0.017 & 19.16 & - & 0.50 & $\mathrm{Nb}$ \\
$\mathrm{U}-4$ & $\leqq 0.025$ & $17.5 \sim 19.5$ & $0.4 \sim 0.7$ & - & $\mathrm{Nb}$ \\
160 & 0.015 & 16.75 & - & 0.38 & $\mathrm{Nb}$ \\
$430 \mathrm{ML}$ & 0.014 & 17.27 & 0.33 & 0.51 & $\mathrm{Nb}, \mathrm{Ti}$
\end{tabular}

or Ti. These steels are being considered for the outer lace of automobiles or for other many applications in place of SUS 434 with $1 \%$ Mo.

Because of its eminence of resistivity to corrosion in hot water, especially that to stress corrosion cracking (SCG) and crevice corrosion, SUS 444 (18Cr$2 \mathrm{Mo}$ ) has come to be employed for the heat absorber plate of natural convection type solar water heater, hot water tanks as well as heat exchanger tubes. Researches of energy absorbing properties in relation to these applications and of improvement in toughness as the plate steel have been conducted, leading to elucidation of optimum chemical composition for plates that are excellent in toughness. Moreover, as a welding material for this steel, SUS $316 \mathrm{~L}$ type steels have been adopted, but in view of susceptibility to SGG, the co-metal (i.e., SUS 444 itself) welding electrode has been developed. In addition, $21 \mathrm{Cr}-$ 0.7 Mo steels, a Mo-saving type of SUS 444, have been proposed.

As for highly corrosion resisting ferritic stainless steels, $28 \mathrm{Cr}-2 \mathrm{Mo}, 26 \mathrm{Cr}-4 \mathrm{Mo}$, and $25 \mathrm{Cr}-3 \mathrm{Mo}-4 \mathrm{Ni}$ steels have been studied in this country for services in sea water besides the $26 \mathrm{Cr}-1 \mathrm{Mo}$ and the $30 \mathrm{Cr}-2 \mathrm{Mo}$ mentioned earlier. However, commercialization of high $\mathrm{Cr}$-high Mo type ferritic stainless steels will be left to the future.

Further, improvement of manufacturing method of conventional SUS 430 for alleviation of ridging has continually been conducted, and in addition, influences of addition of less than about $0.1 \% \mathrm{Al}$ on the quality and optimum manufacturing conditions were studied. It was then seen that the improvement in formability and the reduction in the post-hot rolling annealing time were gained.

\section{(2) Austenitic Stainless Steels}

As for the austenitic stainless steels, not only the corrosion resistance but also strength, deep drawability, and machinability have been investigated, and numerous new grades have been presented.

In the aspect of corrosion resistance, the effect of $\mathrm{N}$ as an alloying element attracted special attention. Namely, $\mathrm{N}$ has long been used as an alloying element in austenitic stainless steels to raise the yield strength and as a substituting element of $\mathrm{Ni}$ for its austenite forming capability, but later, as its effect on improving resistance to pitting corrosion was revealed, nitrogen has been brought to light as a valuable alloying element. For example, N-modified steels of the 
$25 \mathrm{Cr}-12 \mathrm{Ni}$ type added with $0.8 \sim 25 \%$ Mo had already been in use in this country also, yet, more recently, $\mathrm{N}$ addition became to be applied to the existing high Mo austenitic stainless steels, which have a superior resistivity to general corrosion and to pitting corrosion, leading to development of $\mathrm{N}$-added low $\mathrm{C}$ 20 $\mathrm{Cr}-22 \sim 25 \mathrm{Ni}-4.5 \sim 6 \mathrm{Mo}$ steels.

Furthermore, studies to decrease Mo in the SUS 316 , which is a well established general purpose corrosion resisting stainless steel, without impairing its corrosion resistivity have been made, through which ones of the 316 type but containing Mo only less than $1 \%$, and those of $18 \mathrm{Cr}-8 \mathrm{Ni}$ type added with $2 \sim 3 \%$ $\mathrm{Cu}$ have been developed. Also, to improve the pitting corrosion resistivity, addition of $\mathrm{N}$ and reduction of $\mathrm{Mn}$ and $\mathrm{S}$ are being practiced.

In the meanwhile, the effect of $\mathrm{Cu}$ was again noticed as an alloying element for improving the resistance to SCG in a neutral environment containing chlorides, and a new steel has been presented. In addition, to correct for the inferiority of stainless steel against concentrated nitric acid, $17 \mathrm{Cr}-14 \mathrm{Ni}-4 \mathrm{Si}$ steel, of which the large addition of $\mathrm{Si}$ is the feature, and low $\mathrm{C}-25 \mathrm{Cr}-20 \mathrm{Ni}$ steel, in which the raised $\mathrm{Cr}$ content is the point, have been developed. In addition to these, $11 \mathrm{Cr}-16.5 \mathrm{Ni}-6 \mathrm{Si}-\mathrm{Zr}-\mathrm{Ti}$ steel, in which the amount of $\mathrm{Si}$ has been increased and, in contrast, $\mathrm{Cr}$ content has been reduced, has also been presented.

Besides, steels in which the $\mathrm{C}$ content is kept to below 0.02 to $0.03 \%$ to improve the corrosion resistance of the weldment and the resulting reduction of strength has been offset by the addition of $\mathrm{N}$ have been developed. They are low $\mathrm{C}-17 \mathrm{Cr}-7 \mathrm{Ni}-\mathrm{N}$ and low $\mathrm{C}-17 \mathrm{Cr}-7 \mathrm{Ni}-\mathrm{N}-\mathrm{Nb}$ steels, which are the modification of SUS 301 and the steels which are the modification of SUS 201 with C reduced, as stainless steels for railway car, on one hand, and $18 \mathrm{Cr}-8 \mathrm{Ni}$ and $17 \mathrm{Cr}-12 \mathrm{Ni}-2 \mathrm{Mo}$ steels, the ones in which $\mathrm{G}$ is kept to less than $0.02 \%$, with $0.12 \% \mathrm{~N}$ added so as to prevent the intergranular stress corrosion cracking (IG$\mathrm{SCG}$ ) of the welded zone of pipes for boiling water reactor piping, on the other. It has been noted especially that Mo-bearing steels display good resistance to 1 GSCG in high temperature water. Also, a modified version of SUS 347 in which $\mathrm{G}$ and $\mathrm{Si}$ are reduced to improve the weldability has been developed for the same application. Furthermore, to improve the resistance of $\mathrm{Ni}-15 \mathrm{Cr}-8 \mathrm{Fe}$ alloys to IGSCG in high temperature water, effects of various alloying elements and heat treatment were studied in detail, and alloys with improved IGSCG resistance at the welded zone have been found.

In the aspect of enhancement of the strength of austenitic stainless steel, addition of $\mathrm{N}$ has long been practiced for raising yield strength as discussed previously. Later, combined addition of $\mathrm{Nb}$ or $\mathrm{V}$ together with $\mathrm{N}$ was investigated, having been utilized in practical materials. Thus, 5 classes of steels with more than $0.1 \% \mathrm{~N}$ added to conventional austenitic stainless steels, namely, SUS 304 N1, 304 N2, 304 LN, $316 \mathrm{~N}$, and $316 \mathrm{LN}$ have been newly incorporated in JIS in 1981.

Extensive researches for improvement of formability have continuingly been conducted, especially focusing on conventional $18 \mathrm{Cr}-8 \mathrm{Ni}$ stainless steels, and effects of chemical composition, forming lubricant, environment, and aging on the season cracking after forming have been investigated in detail. In addition, steels which are the modification of $17 \mathrm{Cr}-7 \mathrm{Ni}$ steels with $2 \% \mathrm{Gu}$ added and further with $\mathrm{G}$ reduced for improvement of deep drawability and season cracking resistance have been developed. Table V. 3.6 shows chemical compositions of these steels.

Regarding the improvement in machinability, attention was paid to the development of free-cutting corrosion resistive steels, and several types of steels including S-bearing $18 \mathrm{Cr}-8 \mathrm{Ni}$ steels added with 0.25 to $1 \%$ Mo or $\mathrm{Cu}$ have been presented. In addition, it was indicated that the reduction of the Mn content so as to make the $\mathrm{Mn} / \mathrm{S}$ ratio smaller would be effective to improve the corrosion resistance. Furthermore, ones containing $\mathrm{Pb}, \mathrm{Pb}+\mathrm{Te}$, etc. as alloying elements for further improvement in machinability have been developed.

\section{(3) Duplex Stainless Steels}

As for the so-called duplex stainless steels consisting of 2 phases of austenite and ferrite, SUS $329 \mathrm{~J} 1$ of the $25 \mathrm{Cr}-5 \mathrm{Ni}-1.5 \mathrm{Mo}$ type has already been standardized in JIS and been practically applied to marine condensers, stack gas resulfurization plants, urea manufacturing plants, and other chemical plants. Furthermore, researches have been made to improve the resistance to sea water corrosion and the hot workability, bringing forth duplex stainless steels in which Mo content is increased for better resistance. These steels are all based on the $\mathrm{Fe}-25 \mathrm{Cr}-6 \sim 7 \mathrm{Ni}-$ $2 \sim 3 \mathrm{Mo}$ added with $0.1 \%$ or more $\mathrm{N}$, and there are some that contain a small amount of $\mathrm{Cu}$ or $\mathrm{W}$. The $0.2 \%$ strain yield strength of these steels is high,

Table V.3.6. Cu-added austenitic stainless steel for deep-drawing. (\%)

\begin{tabular}{|c|c|c|c|c|c|c|c|}
\hline Symbol & $\mathrm{C}$ & $\mathrm{Si}$ & $\mathrm{Mn}$ & $\mathrm{Ni}$ & $\mathrm{Cr}$ & $\mathrm{Cu}$ & Mo \\
\hline 304 UD & 0.12 & 0.51 & 1.08 & 7.23 & 14.05 & 2.00 & Addition \\
\hline $27 \mathrm{~A}$ & 0.06 & 0.70 & 1.50 & 6.50 & 17.60 & 2.00 & - \\
\hline 304 M 2 & 0.018 & 1.45 & 1.88 & 7.59 & 16.45 & 1.86 & - \\
\hline D-6 & $\leqq 0.03$ & $\leqq 1$ & $\leqq 2$ & $6 \sim 9$ & $15 \sim 16$ & $1.5 \sim 3$ & $0.15 \sim 0.3$ \\
\hline 304 LA & 0.022 & 0.48 & 2.35 & 7.50 & 16.40 & 1.98 & 0.19 \\
\hline $8 \mathrm{MK}$ & 0.025 & 0.56 & 3.58 & 6.81 & 16.39 & 1.58 & 0.19 \\
\hline
\end{tabular}


$50 \mathrm{kgf} / \mathrm{mm}^{2}$ or more, and these steels are used for various chemical plants as well as the rotating barrel of a centrifugal separator. Because these steels can withstand, depending on condition, the high temperature environment containing $\mathrm{CO}_{2}, \mathrm{H}_{2} \mathrm{~S}$, and $\mathrm{Cl}^{-}$, they are being studied for application to oil or gas field. For the same usage, $22 \mathrm{Cr}-5 \mathrm{Ni}-3 \mathrm{Mo}$ steel, namely with less $\mathrm{Gr}$ content than that of these duplex stainless steels, has come to be manufactured.

With the development of these duplex stainless steels, researches on the formation of $\sigma$ phase upon heat treatment, the change in corrosion resistance by the changes in the distribution of various alloying elements between austenite and ferrite phases and in the phase ratio, as well as the effect of cold working on the corrosion resistance were conducted. This has led to the interesting finding of a phenomenon that cold working would actually give rise to the alleviation of corrosion in sulfuric acid.

(4) Other Stainless Steels

In the field of martensitic high strength steels, the SUS 420 type high $\mathrm{C}-13 \mathrm{Cr}$ steels but with $\mathrm{C}+\mathrm{N}$ reduced to improve the hardenability, and ones further added with 1.5 Mn have been developed. In addition, development of low $\mathrm{G}-12.5 \mathrm{Cr}-4 \mathrm{Ni}-\mathrm{Ti}$ steel as a high strength stainless steel with good weldability, research of improvement of various properties of $13 \mathrm{Cr}-$ Ni type casting and forging steels, and development of $17 \mathrm{Cr}-5 \mathrm{Ni}-1.5 \mathrm{Mo}$ steel as a hydraulic turbine runner material with good corrosion resistance and corrosion fatigue strength have been conducted. Further, as for precipitation hardening stainless steels, $15 \mathrm{Cr}-7 \mathrm{Ni}-1.5 \mathrm{Si}-0.7 \mathrm{Cu}-0.4 \mathrm{Ti}$ steels as a high strength spring steel and $13 \mathrm{Cr}-4.5 \mathrm{Ni}-4 \mathrm{Cu}-4 \mathrm{Mo}-4 \mathrm{Co}$ steel as a good corrosion resistant die material for plastics molding have been developed.

Besides these studies, research of obtaining stainless steels that have properties unavailable by the conventional method of melting-solidification-working by utilizing rapid solidification, especially, amorphous alloys of $\mathrm{Fe}-\mathrm{Cr}$ type containing a great deal of $\mathrm{B}$ or $\mathrm{P}$ or both, was conducted, confirming that excellent corrosion resistance may be had even with a low $\mathrm{Cr}$ content.

Because Gr resource is unevenly distributed in the world, researches have long been performed, especially in the USA, of corrosion and oxidation resistant austenitic stainless steels that contain no or less $\mathrm{Cr}$; in Japan also, studies of $\mathrm{Fe}-\mathrm{Mn}-\mathrm{Al}$ system as austenitic stainless steels containing no $\mathrm{Cr}$ have been undertaken.

(5) Ferritic and Austenitic Heat Resisting Steels

(i) Heat Resisting Steels for Boiler

Since the oil crisis took place in 1973, it has been strongly required of fossil-fired power plants in our country, where energy cost is especially high, to increase thermal efficiency by utilizing high temperature, high pressure steam. As the first step, a coalfired ultra-supercritical plant of a $316 \mathrm{kgf} / \mathrm{cm}^{2}$ and $593{ }^{\circ} \mathrm{C}$ class is targeted for realization sometime in 1990 . In line with this aim, a development has been carried out to create high strength ferritic heat resisting steels for superheater and reheater tubes that would provide higher performance than that expected of conventional $2 \frac{1}{4} \mathrm{Cr}-1 \mathrm{Mo}$ steel (JIS, STBA 24) or $9 \mathrm{Cr}-1$ Mo steel (STBA 26) and would substitute Type 18-8 austenitic stainless steel. As a result, 9Cr$2 \mathrm{Mo}, 9 \mathrm{Cr}-1 \mathrm{Mo}-\mathrm{Nb}-\mathrm{V}$, and (9 to 10$) \mathrm{Cr}-2 \mathrm{Mo}-\mathrm{V}-$ $\mathrm{Nb}$ steels, as are shown in Table V.3.7, have been proposed in succession since 1975, and some of them have achieved favorable results in a long-duration test in an actual boiler. As for Type 18-8 stainless steels, fine-grained $18-8 \mathrm{Nb}$ steel (SUS $347 \mathrm{H}$ ) has been recognized for excellence not only in corrosion resistance on the inside and outside surface of the tube but also in high temperature strength from the longterm use in an actual boiler, whereas 18-8 Ti Nb stainless steel with its strength effectively enhanced by adding a small amount of $\mathrm{Ti}$ and $\mathrm{Nb}$ in combination has been also put to practical application. In addition, 18-8 Ti stainless steel tubes (SUS 321HTB) with the inside surface which are processed by shot blasting and grain-refining treatment for the improvement of resistance to steam oxidation are being used.

In order to cope with the trend of steam toward higher temperature and higher pressure, the application of $17-14 \mathrm{Cu}$ Mo and Alloy $800 \mathrm{H}$ (NGF $800 \mathrm{H}$ ) can be also considered; whereas, the research and development of the modification of Alloy $800 \mathrm{H}$ or others are being vigorously conducted. On the other hand, the boiler tubes in a cladding type in which Inconel 671 excellent in corrosion resistance to coal ashes are employed as outside tubes, are being tested in an actual boiler.

In the field of these heat resisting steels for boiler tube use, numerous researches have especially been

Table V.3.7. Typical chemical composition of high strength ferritic heat-resisting steel. (wt $\%$ )

\begin{tabular}{l|cccccccccc} 
& G & Si & Mn & Ni & Cr & Mo & Nb & V & W & B \\
\hline STBA 26 & 0.1 & 0.4 & 0.5 & - & 9.0 & 1.0 & - & - & - \\
HCM 9M & 0.06 & 0.3 & 0.5 & - & 9.0 & 2.0 & - & - & - \\
TEMPALOY F9 & 0.06 & 0.5 & 0.6 & - & 9.0 & 1.0 & 0.4 & 0.25 & - & 0.005 \\
E 12 & 0.12 & 0.3 & 1.0 & - & 9.0 & 2.0 & 0.4 & 0.3 & - & - \\
Modified 9Cr-1Mo & 0.1 & 0.2 & 0.5 & - & 9.0 & 1.0 & 0.08 & 0.2 & - & - \\
HT-9 & 0.2 & 0.3 & 0.5 & 0.5 & 12.0 & 1.0 & - & 0.3 & $(0.5)$ & - \\
NSCR 9 & 0.07 & 0.2 & 0.8 & - & 9.0 & 2.0 & 0.05 & 0.13 & - & - \\
Modified TAF & 0.05 & 0.5 & 0.5 & - & 10.0 & 2.0 & 0.05 & 0.1 & - & - \\
\hline
\end{tabular}


conducted of the relationship between manufacturing parameters and the consequent properties such as microstructure and strength. The longer-term creep and creep-rupture data on a wide range of homemanufactured materials which have been collected principally by the National Research Institute for Metals, are highly evaluated inside and outside our country.

\section{(ii) Heat Resisting Steels for Steam Turbine}

As the materials for high- and intermediate-pressure rotors of a steam turbine, $1 \mathrm{Cr}-\mathrm{Mo}-\mathrm{V}$ steels have conventionally been employed; however, with the trend toward the higher efficiency of a large-size fossil-fired power plant, $12 \mathrm{Cr}-\mathrm{Mo}-\mathrm{V}-\mathrm{Nb}-\mathrm{N}$ steels came to be used, and the improvement of high temperature strength properties has been achieved by the adjustment of chemical composition and by the optimization of heat treatment conditions meeting the requirements of an actual rotor. Further improvement in the performance of $\mathrm{Cr}-\mathrm{Mo}-\mathrm{V}$ steels is being pursued as well.

Besides, in recent years there is a move worthy of mentioning that the development of a monoblock rotor is being carried out. The low-pressure rotors of middle- or small-size turbines have been conventionally made in a single-cylinder type; however, when it came to a large-size turbine, the rotors were manufactured in a shrunk-on type because the ingot weight exceeded $500 \mathrm{t}$, impeding an attempt toward a monoblock structure which had been required for improvement in reliability. However, owing to the advancements in steelmaking technology including refining and forging techniques, the production of extra-large size monoblock low-pressure rotors made from an ingot with a weight exceeding 500 t has been made possible, allowing their gradual usage in actual turbines (principally turbines for nuclear power plants). In the case of a compact, small-size turbine, it is more economical for high-, intermediate-, and low-pressure rotors used on the wide temperature range to be manufactured in a single-cylinder type, but the rotor is required for 2 contradictory properties, i.e., increased creep rupture strength in high temperature region and enough toughness in low temperature region. This has thus led to the realization of manufacturing single-cylinder rotors with excellent properties over both temperature regions by virtue of the adjustment in minor elements and the improvement in heat treatment.

\section{(iii) Heat Resisting Steels for Nuclear Reactor}

The nuclear power generation in our country is evolving smoothly and has grown up to be able to supply more than $20 \%$ of the total power supply. However, one of the problems associated with materials is stress corrosion cracking (SCG) induced by high temperature high pressure water in a steam generator or others, which has stimulated the development of materials excellent in resistance to SGG. For instance, in the case of boiling water reactors (BWR), nuclear grade 316 stainless steel with $\mathrm{C}$ and $\mathrm{N}$ contents balanced and with the grain-size adjusted has been put to practical use by substituting 304 stainless steel which caused numerous SGG failures. On the other hand, advanced countries have been vigorously performing the researches of materials for the steam generator tube of a fast breeder reactor (FBR). Also in Japan, $2 \frac{1}{4} \mathrm{Gr}-1 \mathrm{Mo}-\mathrm{Nb}$ steels, expected to substitute the current $2 \frac{1}{4} \mathrm{Cr}-1 \mathrm{Mo}$ steel, various (9 to 12$) \mathrm{Cr}$ ferritic steels shown in Table V.3.7, and Alloy 800 have been proposed for selection to be used in the demonstration reactor scheduled for construction in 1990s.

The second problem is the swelling of a fuel cladding tube for FBR which is irradiated by fast, high density neutrons. Gurrently, cold worked 18-8 Mo stainless steel is employed for this tube in our country. However, for the future demonstration reactor or commercial reactors, the emergence of materials further superior in the resistance to swelling and in creep strength are anticipated, and modified 316 stainless steels, (9 to 12) Cr ferritic steels, and $\gamma^{\prime}$ strengthened $\mathrm{Cr}-\mathrm{Ni}-\mathrm{Mo}$ alloys are being studied.

\section{(iv) Heat Resisting Steels for Automobile}

In order to clear the automobile exhaust gas regulations enforced in succession over the period from 1975 to 1978 , the developments have been vigorously performed of materials for a purifier which resist to severe cyclic oxidation in exhaust gas and are excellent in high temperature strength, workability, weldability, and productivity. In the thermal reactor system at the beginning, SUS 310 S was principally used in the parts at elevated temperature, followed by inexpensive SUS XM15Jl (18Cr-13Ni-3.5Si steel) which, making use of the compound effect of $\mathrm{Si}$ and rare earth metals on oxidation resistance, has been widely applied. However, catalytic converters later became the main-stream of the purifiers, and the related-materials have recently shifted to $12 \mathrm{Cr}$ ferritic steels such as SUH 409. The researches that have been carried out for purification of exhaust gas have in turn promoted the development of heat resisting ferritic stainless steels, which have been favorably employed for room heating appliances.

In relation to exhaust valves, those made of $\mathrm{Ni}$ base alloys such as Inconel 751 and Nimonic 80A with the omission of the overlay of Co-base alloys with the recent sharp rise of Co price have partly been used for practical application, and on the other hand, the research and development of economical $\mathrm{Fe}-\mathrm{Ni}$ base alloys are also being conducted. Whereas, for countermeasures against the abnormal wear of valve seats which is caused by $\mathrm{Pb}$-free gasoline, sintered alloys good in lubricating properties have come to be dominantly used. Besides, among the materials for turbo-charger impellers which rotate at a high speed in exhaust gas, high creep strength Ni-base alloys produced by investment casting such as Alloy 713C find their wider applications.

\section{(v) Heat Resisting Steels for Chemical Industry}

As the reformers or cracking tubes in the chemical industry, centrifugally cast products of $\mathrm{HK} 40$ have normally been used. However, in meeting the trend toward higher operating temperatures in various re- 
cent plants, HP type alloys, IN-519 (24Cr-24Ni-Nb steel), and their modified steels which are superior in resistance to carburization, in strength, and in ductility have come to be employed. In recent years, for cracking tubes for ethylene production, a damage by carburization associated with the trend toward higher temperature operation has become a problem, and the attention is being focused upon the increase in contents of $\mathrm{Ni}$ and $\mathrm{Si}$ for decreasing the solid solution range of carbon and upon the barrier effect of compact, adhesive oxide film against carburizing atmosphere.

(6) Heat Resisting Alloys

(i) Heat Resisting Alloys for High Temperature Gas-cooled Reactor

In view of the importance of environmental effect in nuclear reactors, the researches have been accumulated on Hastelloy X and Inconel 617 of their material properties within a special atmosphere of low oxidizing potential containing an extremely small quantity of impurity, which is known as He in a high temperature gas-cooled reactor (HTGR), and these researches have provided numerous findings. Hastelloy $\mathrm{XR}$, a modified Hastelloy $\mathrm{X}$, is regarded as the best among the proposed structural materials because of the reason that it is excellent in resistance to corrosion in $\mathrm{He}$ gas simulated to that of actual HTGR, is possessed of appropriate creep rupture properties, and is supported by abundant industrial backup data.

On the other hand, in relation to the research and development of the " Nuclear Steelmaking ", a largescale project sponsored by the Agency of Industrial Science and Technology $(1973 \sim 1980)$, a study was carried out on the potentiality of developing superalloys, from which a long seamless tube can be manufactured, that provide $5 \times 10^{4} \mathrm{~h}$ creep rupture strength of more than $1 \mathrm{kgf} / \mathrm{mm}^{2}$ in $\mathrm{He}$ at a temperature of $1000{ }^{\circ} \mathrm{C}$ as heat exchanger tubes for the intermediate heat exchanger. As a result, several kinds of promising $\mathrm{Ni}-\mathrm{Cr}-\mathrm{W}$ and $\mathrm{Ni}-\mathrm{Cr}-\mathrm{W}-\mathrm{Mo}$ solid solution hardened alloys have been developed and its achievement was highly evaluated.

\section{(ii) Alloy Design and Manufacturing and Working Process}

Since the latter half of the 1960s when PHACOMP was developed in the USA as a method of achieving phase stabilization by predicting the precipitation of what is known as TCP phases such as $\sigma$ phase, several methods have been proposed of designing heat resisting alloys in Japan, with the aim of developing nove] gas turbine blades, using theoretical analyses and computation, and obtained anticipated results. These methods have also been applied in the "Research and Development of High Efficiency Gas Turbine" sponsored by the Agency of Industrial Science and Technology (from 1978), leading to the development of Ni-base heat resisting alloys for the turbine blades with a performance surpassing the existing alloys.

Recently, in the area of Ni-base superalloys associated principally with turbine blades, numerous high strength casting alloys containing 7 to $8 \mathrm{wt} \%$ of
$\mathrm{Al}+\mathrm{Ti}$ and 60 to $65 \mathrm{vol} \%$ of $\gamma^{\prime}$ phase have been developed by virtue of the progress of melting and casting techniques and of alloy design methods. However, alloy development works merely by controlling principal constituents has been gradually drawing to the limit, bringing about a contradiction that giving priority to strength would result in degradation in the properties of castability and ductility. It was the addition of Hf that broke this limit from the standpoint of ductility, and furthermore, it was the high-performance structure-controlled alloy that has brought forth an epoch-making advancement in the aspect of strength which will be discussed in the following:

On perceiving the fact that the grain boundaries which are perpendicular to the principal stress axis would tend to develop as initiating points of fracture, directionally-solidified (DS) columnar-crystal alloy obtained by solidifying in columnar structure parallel with the principal stress axis was developed. It possesses excellent thermal fatigue properties due to the lower elastic modulus of [100] which is the preferential growth orientation of grains. The exclusive alloys for gas turbine blades of an aircraft engine such as Mar$\mathrm{M} 200+\mathrm{Hf}$ (PWA 1422) have become to be widely used in this area since the early part of the 1970s. In contrast to the alloys mentioned above, single crystal alloys do not need grain boundary strengthening elements such as $\mathrm{G}, \mathrm{B}, \mathrm{Zr}$, Hf, etc. And high solid solution temperatures can be adopted by decreasing these elements mentioned above. This fact produced a concept that creep strength would be improved by increasing the amount of finely dispersed $\gamma^{\prime}$ which is brought about by the adoption of higher solid solution temperatures, and directionally-solidified singlecrystal (SG) blades thus manufactured have come to be spotlighted. For instance, Alloy 454 (PWA 1480) which is superior to the above mentioned DS MarM 200+Hf alloy in strength and corrosion resistance, is practically employed at present as SC exclusive alloy. Furthermore, a directionally-solidified eutectic alloy (DSE), so-called in situ composite, in which eutectic alloy is directionally solidified with lamellar or fibrous strengthening phase aligned parallel to the direction of solidification, is characterized by the merit of stability of the interface between fibers and matrix at an elevated temperature and the practical application is anticipated to the systems of $\gamma / \gamma^{\prime}-\alpha, \mathrm{Ni}-\mathrm{TaC}$, etc. Figure V.3.12 compares the service temperatures of these structure-controlled turbine blade materials.

The advances in powder manufacturing technology such as contamination-free atomization and super rapid solidification process (RSR) and in high densification technology such as Gatorizing process (isothermal forging utilizing super-plastic deformation) and HIP (hot isostatic press) method, have brought about conspicuous developments in the powder metallurgy of superalloy components including principally gas turbine disks and blades, resulting in the realization not only of reduction in segregation, but also of grain size control, of enlargement of the freedom of alloy design, and of improvement in yield. In the 


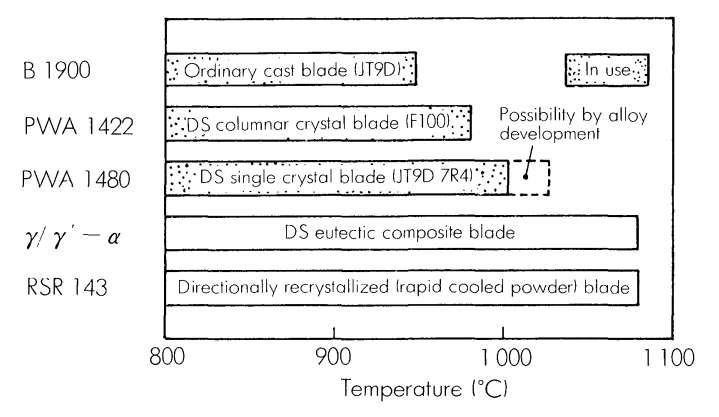

Fig. V.3.12. Comparison of service temperatures of jet engine turbine blade materials made by the recent structure control process.

area of oxide dispersion strengthened (ODS) alloys, mechanical alloying (MA) method in which the cold bonding of raw material powders is positively carried out in a high energy ball mill has been developed. MA $6000 \mathrm{E}$ for the use of turbine blade manufactured by this method is higher in creep rupture strength at the higher temperature range compared with those of DS and SC alloys mentioned above. Regarding the manufacturing and working techniques discussed previously, the researches are briskly conducted overseas, but some of them have been adopted in the subjects of the "Research and Development Project of Basic Technology for Future Industries" sponsored by the Agency of Industrial Science and Technology in our country as well.

\section{(iii) High Temperature Protective Coating}

In the area of Ni-base high-strength superalloys, composition balance has been taken into consideration so as to reconcile strength and hot corrosion resistance to a possible extent; however, for the materials that are used in extremity such as the turbine blade, it is extremely difficult to carry out composition adjustment that would satisfy both requirements at the same time. Moreover, high $\mathrm{Ni}$ concentration in the materials will, in essence, act adversely toward hot corrosion resistance, and under a hot corrosive environment, the preferential intergranular attack that has been enhanced by a stress will tend to degrade the high temperature strength. Therefore, the protective coating has now been generally used as an inevitable process, and it is no exaggeration to say that the quality of coating will control an overall service life.

In the age of the 1960s, the diffusion coating using $\mathrm{Al}, \mathrm{Cr}$, and $\mathrm{Cr}-\mathrm{Al}$ was widely employed because of its good adhesion between the substrate and the coating layer due to the effect of diffusion layer, and $\mathrm{Cr}$ diffusion coating has substantial records of performance used in industrial gas turbine blades in our country. However, these methods, in which the elements for coating are limited, came to fail to accommodate to the corrosive environment which became severer with increasing temperature, especially in the gas turbines of an aircraft engine. It followed that $\mathrm{Cr}-\mathrm{Al}$ diffusion coating using Pt pre-plating and electron-beam vapor-deposition of MCrAlY alloy were developed in the first half of the 1970s, and low pressure plasma spraying of MCrAlX type alloy group and cladding of MCrAlY alloy thin sheet were consecutively developed in the latter half of the 1970s. Whereas, the composition of the alloys for coating, represented by MCrAlY, have been optimized depending on their respective purposes, evolving toward more complicated alloys such as NiCoCrAlYHfSi. On the other hand, thermal barrier coating (TBC) has been developed in which the ceramics mainly consisting of $\mathrm{ZrO}_{2}$ is sprayed on the hot section components of a gas turbine using MCrAlY alloys as a bonding layer.

\section{3. 8. Magnetic Materials}

\section{(1) Electrical Steel Sheets}

At present, Japan is supplying about one quarter of the entire world's annual demand (about 4 million $t$ ) for electrical steel sheets. Expanding industrialization and home electrification in Japan, which started in the decade beginning in 1955, created the conditions which led to a large increase in demand for electrical steel sheets. At first, the manufacturing method of grain-oriented Si steel was that of ARMCO of the USA but, after 1965, several kinds of grain-oriented Si steel sheets with high permeability were developed and produced independently in Japan, the technologies of which were finally sold to various companies in Europe and so on.

As regards the progress made in the last decade, in order to meet the worldwide need for energy saving since the oil crisis, extensive research and development works have been carried on in the field of electrical steel sheets to attain ever lower iron loss, and substantial progress was accomplished with both grainoriented and non-oriented electrical steels.

(i) Progress in Grain-oriented Electrical Steel Sheets

As an improvement of the conventional Goss process which had been believed to be the ultimate for more than a quarter of a century, two new products differing in the manufacturing method, one of which is the so called single stage heavy cold rolling method, with $\mathrm{AlN}$ and $\mathrm{MnS}$ as the inhibitors, and the other, the two-stage cold rolling and two-step box anneal method, with $\mathrm{MnSe}$ and $\mathrm{Sb}$ as the inhibitors, were successively developed and produced in Japan late in the 1960s and early in the 1970s, respectively. In these methods, the mean deviation of the easy magnetization axis along with the rolling direction is reduced to about $3 \mathrm{deg}$ compared with about $7 \mathrm{deg}$, in the conventional grain-oriented sheet (manufactured by the Goss process, employing $\mathrm{MnS}$ as the inhibitor). By development of these new products, performance of the grain-oriented $\mathrm{Si}$ steels has been remarkably improved as shown in Fig. V.3.13. Novel technologies established during the last decade are detailed in the following.

(a) Development of Light Gauge and High Si Steel Sheets for Lower Iron Loss

According to the statistical data for fiscal 1982, 6 


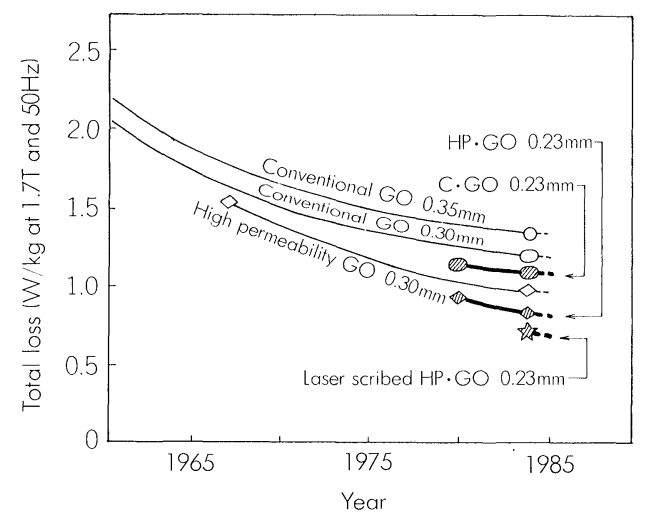

Fig. V.3.13. Improvements in core loss of commercial grades of grain-oriented electrical steels in Japan.

billion $\mathrm{kWh}$, enough to meet the demand of 2.5 million households, was wasted in the transformers used in power transmission and distribution systems out of the total annual electric power of 480 billion $\mathrm{kWh}$ supplied in Japan. A strong stimulus for improved quality to save energy has promoted the production of 9 mil gauge with the iron loss about $10 \%$ lower than the conventional products (Fig. V.3.13). In general, the eddy current loss $W_{e}$ which accounts for the greater part of the iron loss $\left(W_{T}\right)$ than the hysteresis loss $\left(W_{h}\right)$, can be expressed as $W_{e} \propto 2 L d^{2} / \rho$, where $d$ is the thickness, $\rho$ the specific resistance and $2 L$ the magnetic domain width of the material. Therefore, the iron loss $\left(W_{T}\right)$ can be reduced by decrease in the sheet thickness $(d)$ and increase in the Si content which results in increased specific resistance $(\rho)$. However, because of the problems of operational handling by users, brittleness in the production and difficulties in perfect secondary recrystallization in the light gauge materials, the sheet gauge was limited to $0.35 \mathrm{~mm}$ or $0.30 \mathrm{~mm}$ for Japanese domestic use and $0.27 \mathrm{~mm}$ for export and the Si content between 2.9 and $3.2 \%$. As a consequence of extensive studies on the processing variables and the microalloying with such as $\mathrm{Sn}, \mathrm{Cu}$, and Mo, sheets with a gauge of 8 and 9 mil and a Si content of as high as $3.5 \%$ have been successfully produced to give lower losses and better grain orientation.

\section{(b) Refinement of Magnetic Domains}

Laser beam irradiation of the surface of products (Fig. V.3.13) has been developed for further improvements of losses. As is evident from the abovementioned formula for the eddy current loss $\left(W_{e}\right)$, refinement of magnetic domains reduces the iron losses, because a higher energy is required for movement of domain walls in a larger domain in reversed magnetization with alternating current. When laser beams are irradiated on a sheet surface in arrays nearly perpendicular to the rolling direction with a spacing of between $5 \mathrm{~mm}$ and $10 \mathrm{~mm}$, as shown in Photo. V.3.1, clusters of dislocations which are generated in the subsurface of the sheet reduce the width of domains due to the strain field and as a consequence the iron loss is decreased by more than $10 \%$. The prod-

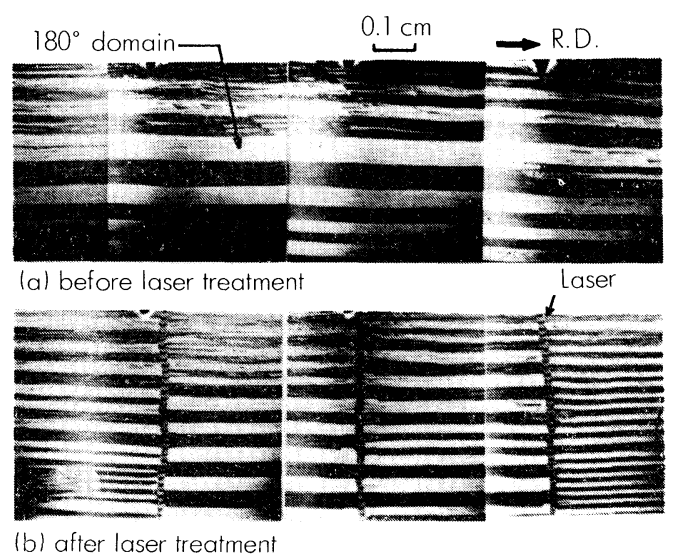

Photo. V.3.1. Domain structures before and after laser scribing.

ucts are commercially available for stacked lamination cores. Improvement of the iron loss by laser irradiation is more pronounced in the material with a higher permeability and a lighter gauge and laser irradiated material is expected to be a candidate to compete with amorphous materials.

(ii) Progress in Non-oriented Electrical Steel Sheets

The decade beginning in 1955 saw a sharp increase in demand for non-oriented electrical sheets, which are used for the cores of motors in home appliances such as fans and refrigerators as well as in industrial motors. Therefore, aside from the magnetic properties, efficiency of punching and welding by users was important in the development of the materials at that time. However, cemented carbide dies have substantially eliminated the problems in punching.

Thus the steel companies have concentrated their efforts on the development of sheets with high performance and low cost on the basis of high purification techniques of steel and integrated processing in the last decade.

(a) Development of Highest Grades of Non-oriented Electrical Steel Sheets

The highest grade of non-oriented electrical steel sheets specified in JIS is S-9. However, as shown in Fig. V.3.14, non-oriented electrical steel sheets of higher grades have been developed during the last decade in Japan, such as S-8 equivalent and subsequently an S-7 equivalent; S-6 equivalent is near to production. These highest grades are used in hydroelectric generators and turbine generators, replacing the grain-oriented sheets to reduce costs. The rapid upgrading can be attributed to the progress of purification of steels together with the texture control by optimization of cold rolling and annealing process. Reduction of both $\mathrm{S}$ and $\mathrm{N}$ to as low as $10 \mathrm{ppm}$ in molten steel has enabled extensive grain growth in the final annealing and easy motion of the domain walls in the product.

Furthermore, reduction of $\mathrm{C}$ in molten steel allows the omission of decarburization in annealing and consequently the prevention of oxide formation on the sheet surface, resulting in an improved iron loss at high induction. Technologies of purification of 


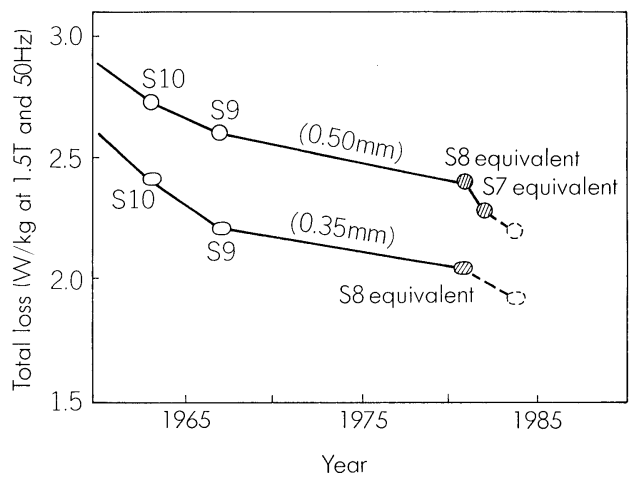

Fig. V.3.14. Improvements in core loss of commercial higher grades of non-oriented electrical steels in Japan.

steel also bring about the possibility of favorable texture control in cold rolling and annealing.

(b) Development of Non-oriented Electrical Steels for High Efficiency Motors

Non-oriented electrical steel sheets of the grades S30 and lower with low Si content were widely used for the electric appliances after World War II. The low grade materials have advantage of low cost and high induction in spite of the disadvantage of relatively larger core loss. However, with the impact of the oil crisis, there occurred the need for energy saving in refrigerators and coolers which account for a substantial part of electricity consumption. Requirements for high efficiency motors to save $10 \%$ of energy consumption in the USA have stimulated the development of high quality materials for export. For domestic use, in order to meet the Moonlight project (started in 1978) and the regulations for rationalization of energy consumption (1979), high efficiency core materials are available as equivalents of grades S-18 to -14 in terms of iron loss with the content of $\mathrm{Si}$ as low as that of grade S-30. Highly purified steels have contributed to production of these high efficiency materials. Also microalloying of $\mathrm{Sb}$ or $\mathrm{Mn}$ is effective for improvement of permeability through the texture control. Demands for high performance is extending to the grade $\mathrm{S}-12$, which will be realized by efforts in research and development for further refining of steels and more sophisticated texture control.

\section{(2) Materials for Permanent Magnets}

The permanent magnet materials are used as a part or a composite with iron yoke in the design of magnetic circuit for generation of the static magnetic field. A permanent magnet which is equivalent to an electromagnet as an element in static device for magnetic circuit, requires no electric source and also have an advantage free from the fluctuations in use. Therefore, the permanent magnets are favorably used in loudspeakers, electric motor, generators, attraction magnets, sector magnets of charged particles, etc. With the growth of the electronics industry, the output of permanent magnets has been increasing year by year, with quite a high rate of growth. At present, the respective shares of the total output in the free world are $40 \%$ for Japan, $35 \%$ for the USA and $25 \%$ for Europe; the production in Japan amounted to 60000 t or $¥ 70$ billion during the calender year 1983 (according to statistics complied by the Japan Electronic Materials Manufacturers Association). Large scale industrial production of permanent magnetic materials began in 1917 that marks the invention of $\mathrm{KS}$ steel ( $36 \%$ Co steel). Alinico alloy, as a modification the $\mathrm{MK}$ steel ( $\mathrm{Fe}-\mathrm{Ni}-\mathrm{Al})$ invented in 1931 and the NKS steel ( $\mathrm{Fe}-\mathrm{Ni}-\mathrm{Co}-\mathrm{Ti})$ invented in 1934, had been the main product of permanent magnets until 1970. In contrast with various other industrial materials, the innovation of these permanent magnetic materials was largely made in Japan. The ceramic (ferrite) magnet also entered the market with rapid growth, although the magnetite $\left(\mathrm{FeO} \cdot \mathrm{Fe}_{2} \mathrm{O}_{3}\right)$ was known in prehistoric times, OP magnets $((\mathrm{Fe} \cdot$ $\mathrm{Co}) \mathrm{O} \cdot \mathrm{Fe}_{2} \mathrm{O}_{3}$ ) were invented in 1933 , and hexagonal ferrite magnets $\left(\mathrm{BaO} \cdot 6 \mathrm{Fe}_{2} \mathrm{O}_{3}\right.$ or $\left.\mathrm{SrO} \cdot 6 \mathrm{Fe}_{2} \mathrm{O}_{3}\right)$ were developed in 1952. Since these ferrite magnets are advantageous with respect to resourses as well as cost, they have come to account for $95 \%$ of the present production of magnets, having progressively replacing Alnicos after the oil crisis in the late 1970s, despite their some drawbacks with respect to permanent magnet properties. Consideration of international standards for properties of materials for permanent magnets has also been undertaking by IEG TG-68 (Magnetic Alloys and Steels) since 1975, and the definition, classification and designation of materials are in the process of being specified; however, one cannot deny that standardization is lagging behind the progress of material development, which will be described later. In Japan, only materials equivalent to the $\mathrm{RI}$ (Alnico magnets) and S1 (ferrite magnets) of the IEC have been standardized in JIS-2502 (1973). The Japan Electronic Materials Manufacturers Association has standardized the permanent magnetic materials in EMAS-7001 (1975), increasing the items covered to the extent that the standards are more useful for practical dealings. The main purpose of permanent magnetic materials is for preservation of the greatest possible magnetic field energy in the air gap of instrument, and in order to fulfill this purpose, efforts are being devoted to increasing the magnetic field energy storage per unit volume. Now, let the magnetic properties of a magnetic material be expressed by the formula $B=J+\mu_{0} H$. Here, $B$ is the magnetic flux density $\left(\right.$ tesla $\left.=\mathrm{V} \cdot \mathrm{s} / \mathrm{m}^{2}\right), J$ the magnetic polarization (related to magnetization $M$ by $\left.M(\mathrm{~A} / \mathrm{m})=J / \mu_{0}\right), \mu_{0}$ the permeability of the vacuum $\left(4 \pi \times 10^{-7} \mathrm{H} / \mathrm{m}\right)$, and $H$ the magnetic field strength $(\mathrm{A} / \mathrm{m})$. Regarding $J$ as a function of $H$ and seeking the maximum value of the product $B \times H$ in the second quadrant of the $B v s$. $H$ curve, one obtains

$$
(B H)_{\max }=\left(J^{2} / \mu_{0}\right)\left\{1-\left(J^{\prime} / \mu_{0}\right)\right\} /\left\{2-\left(J^{\prime} / \mu_{0}\right)\right\}^{2} .
$$

Thus, substances with the higher residual magnetism $J_{r}\left(=B_{r}\right)$ and $J^{\prime}=0$ invariably constitute ideal permanent magnetic materials.

Improvements of the hexagonal ferrite magnets has progressed providing maximum $B H$ values as high 


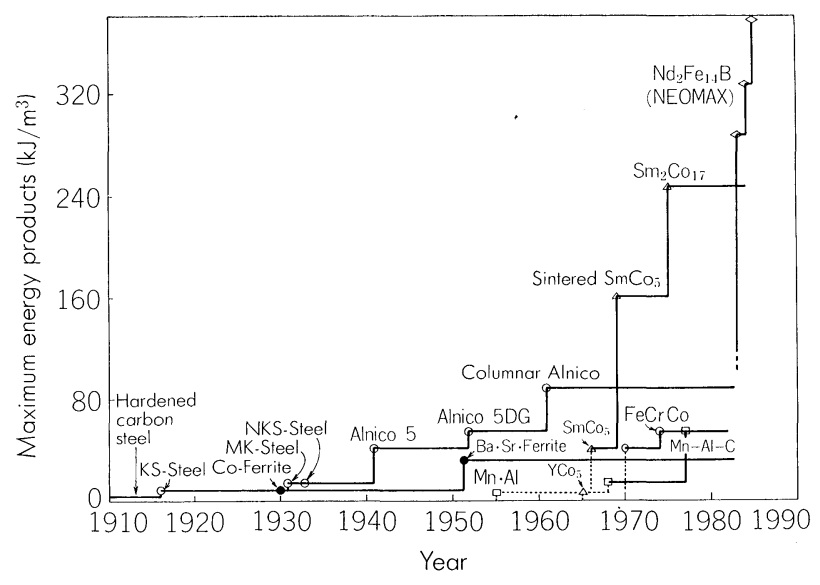

Fig. V.3.15. Increase in value of $(B H)_{\max }$ for permanent magnet materials in the 20th century.

as $40 \mathrm{~kJ} / \mathrm{m}^{3}$ has been developed in $\mathrm{SrO} \cdot 6 \mathrm{Fe}_{2} \mathrm{O}_{3}$ rather than $\mathrm{BaO} \cdot 6 \mathrm{Fe}_{2} \mathrm{O}_{3}$. Although Alnico family with a higher $(B H)_{\max }$ had already been developed, the above-mentioned material is actually equivalent to a $58.3 \mathrm{~kJ} / \mathrm{m}^{3}$ Alnicos material, since the specific gravities of the materials are to be taken into account when the cost per unit of $(B H)_{\max }$ is considered. This also constitutes a factor in the present ascendancy attained by the hexagonal ferrites.

In 1965, the high magneto-crystalline anisotropy was discovered in $\mathrm{YCo}_{5}$ intermetallic compounds. In the mid-1970s sintered rare earth magnets, represented by $\mathrm{SmCo}_{5}$ have come in commercial practice reaching $160 \mathrm{~kJ} / \mathrm{m}^{3}$. In 1980, a $240 \mathrm{~kJ} / \mathrm{m}^{3}$ material (an $\mathrm{Sm}_{2} \mathrm{Co}_{17}$ type intermetallic compound) was developed.

As shown in Fig. V.3.15, since the turn of the century, a conspicuous progress has been made in raising the value of $(B H)_{\max }$ in permanent magnetic materials. Ever since magnetic materials originating from hardened carbon steels appeared early in the 20th century, a development of magnetic materials not containing Co and more recently rare earth magnets containing neither Co nor Sm, had been regarded as a dream. $\mathrm{Nd}-\mathrm{Fe}-\mathrm{B}$ magnets, with the intermetallic compound $\mathrm{Nd}_{2} \mathrm{Fe}_{14} \mathrm{~B}$ as the principal constituent has attained the $(B H)_{\max }$ value of $280 \mathrm{~kJ} / \mathrm{mm}^{3}$ or more in 1982, and the amazing value of $360 \mathrm{~kJ} / \mathrm{m}^{3}$ in the laboratory. Also, from the aspect of resourses, $\mathrm{Nd}-\mathrm{Fe}-\mathrm{B}$ magnets are regarded as promising candidates for the magnets of the 21st century, since they contain approximately two thirds of iron with the background of natural resourses in which $\mathrm{Nd}$ content can be expected one digit greater than that of Sm.

\section{3. 9. Sintered Alloys}

\section{(1) Overview}

Sintered alloys are being used to a highly diversified purposes such as sintered tools, friction material, contact points, and porous material, of which the sintered tools are of the greater concern.

With regard to the sintered tools, the cemented carbides were the mainstream in the 1960s. Diamond and CBN superhigh pressure sintered tools made their appearance coming into the 1970s. However, the mainstream cutting tool of this age was the coated cemented carbides, and their applications were greatly advanced. In the latter part of the 1970s, the kinds of coating increased and the synergistic effect of the composite layer coating was discovered; and the machining became faster and more efficient, assisted by the progress in tool design and upgrading of machine tools (adoption of numerical control), while the tool life was extended remarkably, that is, 3 to 5 times that of non-coated cemented carbide tools.

On the other hand, a main topic in the 1980s has been the industrial applications of superhigh pressure sintered tools. It should not be overlooked, however, that the properties of cermets, which had been hidden overshadowed by the coated cemented carbides, were greatly improved as they were evolved from $\mathrm{TiC}_{-}$ Ni-Mo-type to TiG-TiN-Ni-Mo-type. Thus the reliability of cermet tools was enhanced, and great progress was made in their applications following the coated cemented carbide tools.

Recently, further research into ceramic tools became active, and their variety increased, thus a whole range of cemented carbides, coated cemented carbides, cermets, ceramics, and superhigh pressure sintered tools has become available.

In the meantime, the upgrading of machine tools progressed further and $\mathrm{NG}$ tooling became widely used, promoting labor saving, automation, and unattended operation in machining on one hand, and intensifying the demands for further improvement in the reliability of cutting tools on the other. It was also noteworthy that practical use of advanced high-speed tools such as the sintered highspeed tools and coated high-speed tools made a good progress during the 1970 s into the 1980 s.

Another important field of sintered alloys is the applications of the sintered machine structural parts; on this aspect, reference should be made to Sec. IV.4.2.

\section{(2) Sintered Tools}

In the technical innovation of cutting tools, an important event was the development of the CVD coating technology of cemented carbides. In the 1970s, both domestic and overseas cemented carbide tool makers made efforts to develop GVD coating techniques, and the types of coated layers became diverse; for example, TiG, TiN, TiGN, TiGO, $\mathrm{HfN}, \mathrm{Al}_{2} \mathrm{O}_{3}$, and their combinations (multilayer coats). The features of GVD coating are that owing to the reaction at a high temperature of $1000^{\circ} \mathrm{C}$, diffusion between the coating and the substrate progresses, until a high bonding strength and a coated layer of good crystallinity are obtained, and excellent uniformity in coating is achieved to permit coating of articles with small apertures and complicated shapes. Further, it has been indubitably shown that GVD coating is well suited for mass production.

Here, it has been found that in coating TiC using the GVD method, carbon diffuses from the base to the coated layer and, as a result, a brittle layer (sev- 
eral $\mu \mathrm{m}$ thick), where the $\eta$ phase $\left(\mathrm{Co}_{3} \mathrm{~W}_{3} \mathrm{G}\right)$ is precipitated, is formed just beneath the coating, bringing about lowering of cutting performance, particularly toughness. However, through some special treatment for improving the toughness of the cemented carbide surface layer ( $\beta$ phase removal), it has become possible to overcome the adverse effects of such embrittlement. Further, the coating techniques of alumina, which has excellent chemical stability among hard substances, were developed by GE of the USA and by BMI Research Center in Geneva, and alumina was found to have a remarkable crater wear resistance among the coatings. However, as direct coating of alumina on the cemented carbide poses a bonding strength problem, the usual practice is to employ a composite coating, in which the substrate is first coated with a layer with excellent flank wear resistance consisting of any of carbide, carbonitride, or oxycarbide of $\mathrm{Ti}$, then alumina coating is applied. With appearance of such coating techniques which permit formation of coatings in any desired combination of layers, the GVD coating seemed to have been brought to a fair perfection.

Besides the GVD method, there is also another coating method which is a physical vapor deposition (PVD) technique (ion plating) developed by Mattox in 1963. After several improvements by Bunsha and others, this method was put to commercial use. Here, a high-energy glow discharge in a high vacuum is utilized to cause reactive deposition of hard substances on the base body, obtaining a considerable bonding strength. As the PVD method has a great advantage over the GVD method in that coating is possible at a far lower temperature, although somewhat inferior in mass productivity, this method has come to be used as a high speed steel coating technique in the latter part of the 1970s, because evaporation deposition can be conducted at a temperature $\left(500\right.$ to $550{ }^{\circ} \mathrm{C}$ ) below the quench-and-tempering temperature of the high speed steel. Here, TiN is usually selected as the coating substance because of its excellent resistance to wear, oxidation, and seizing.

Subsequently, it has been found that there are advantages in applying the PVD coating of TiN, TiC, or TiGN, which have a fine and dense structure, at a low temperature on the cemented carbide. Namely, as against the GVD coating, whose strength is inevitably reduced as the coating thickness increases, making it unsuitable for machining in which strong impact force is applied as in milling, in the PVD coating of TiN, such a conspicuous reduction in strength is not only forestalled, but, by selecting a coating of good thermal cracking resistivity, it is always possible to give to the coating the properties to withstand the above-mentioned milling operation. Thus the PVD coating on the cemented carbide has become commercialized.

As regards the cermet tools, which actually started off with the development of TiC-Ni-Mo-type by Hamenik et al. in the latter half of the 1950s, did not become very popular through the 1960s. It was because they lacked reliability, in that they were liable to tool failure due to insufficient toughness and to thermal deformation and cracking in the tool edge, and in spite of their excellent resistance to oxidation, seizing, and wear, they were used only in the limited field of high-speed finish machining of steel.

Since the first half of the 1970s, when Kieffer proposed the TiN-bearing cermets and Rudy discovered improvement in wear resistivity due to grain refining by thermal decomposition of ( $\mathrm{Ti}, \mathrm{Mo}) \mathrm{CN}$ phase, the TiN-bearing cermets have become actively studied also in Japan, and the image of cermet tools has completely changed. The problem with $\mathrm{TiC}-\mathrm{N}-\mathrm{Mo}$ cermet tools was that the TiG particles, which are the hard phase, take on a cored structure, forming a TiC core with (Ti, Mo) $\mathrm{C}$ double carbide rim containing a great deal of Mo. As the rim is not only of insufficient hardness but is brittle, its growth brings about considerable brittleness of the cermet.

Here, TiN, which has a better oxidation resistance and resistance against affinity with steel than TiC has, came in use. Namely, when TiN is added to TiG-Ni-Mo, the hard phase core structure undergoes a great change and becomes a structure having a core of TiCN and a peripheral phase (rim) of (Ti, Mo) CN. What is noteworthy is that the concentration of Mo contained in the rim is greatly decreased, and the grain growth due to dissolution-reprecipitation is greatly suppressed, thereby improving strength, toughness, thermal deformation resistance, and thermal impact resistance, as a result of refined structure, thermal stabilization, improvement in thermal and chemical characteristics due to the changes from the carbide to the carbonitride, and improvement in heat resistance due to increase in Mo concentration in the binder phase.

Later on, further, $\mathrm{WC}$ and $\mathrm{TaC}$ were added to improve the machining performance, and as a result, the strength and toughness have become nearly equal to those of cemented carbides. Thus, they are now stably used in both high-speed rough and finish machining, so that, the growth of the production in this country of cermet inserts is next only to that of coated cemented carbides.

With respect to $\mathrm{CBN}$ and diamond superhigh pressure sintered tools, it is well known that the latter is not suitable for machining steels because of the reaction with ferrous metals and easy oxidation in the air at a comparatively low temperature, and therefore is used for machining nonferrous metals such as Al-Si alloys and copper alloys, or carbon, plastics, and cemented carbide. Whereas the former, the GBN tools, have less reactivity with iron and have a high hardness, high thermal conductivity, and high oxidation resistance, and demonstrate their worth in machining high hardness materials such as chilled cast steels and quenched steels.

In recent years, the superhigh pressure sintering techniques have come to be actively studied in Japan, and detailed research has been conducted on the effects of using ceramics such as TiN, TiCN, and $\mathrm{Al}_{2} \mathrm{O}_{3}$ as the binder phase in place of conventional metallic Co, and the machining performance, particularly 
toughness, is being steadily improved. However, the true nature of the strength and toughness increase, is left with many unknown points, which need be clarified in the future.

Finally, regarding the ceramic tools, the alumina tools, which have been used since some time, did not gain much popularity as they were too brittle to be a reliable tool. Coming into the 1960s, however, their characteristics were greatly improved by increased structural consistency and crystalline grain refinement owing to the use of the hot press and by the enhancement of thermal cracking resistance due to compounding with TiG (tools made of alumina alone are called the "white ceramic" tools, and those made by compounding with TiC are called the "black ceramic" tools); the strength, too, was increased to $40 \sim 50 \mathrm{kgf} /$ $\mathrm{mm}^{2}$ for the white ceramic and $80 \sim 100 \mathrm{kgf} / \mathrm{mm}^{2}$ for the black.

On entering the 1970s, further, HIP, which was more suitable for mass production, has come to be applied instead of the hot press, and it seemed as if the alumina-based ceramic had approached perfection as the ceramic tool. In the latter half of the 1970 s, however, Clausen showed the possibility of achieving a high toughness (enhancement of $K_{\mathrm{IC}}$ ) of ceramic by dispersing zirconia in it. This concept utilized the phase changes of zirconia, and was immediately adopted for improving the toughness of alumina tools and its effectiveness was confirmed.

Besides those mentioned above, the $\mathrm{Si}_{3} \mathrm{~N}_{4}$-based ceramic, which was developed as a heat resistant material for aircraft engine parts (blade material), is also attracting attention as a machining tool, and is considered promising for machining heat-resistant alloys such as nickel-based superalloys.

\section{3. 10. Nuclear Structural Materials}

\section{(1) Overview}

Japanese nuclear power generation, now all of the two decades old since the commencement of the operation of the Japan Power Demonstration Reactor (JPDR) of Japan Atomic Energy Research Institute (JAERI), has become the nucleus of power supply source, technically and economically. The total number and power output of the nuclear power plants in commercial operation in this country as of the end of August, 1983 reach 24 plants and 17177 MW, respectively, and if those plants that are either under construction or in preparation for construction are counted in, the sum total amounts to 44 plants and 36134 MW, respectively. Regarding the types of the reactors, all of them, except one gas-cooled type which was imported early in the development, are the light water reactors, comprising the boiling water reactor (BWR) and the pressurized water reactor (PWR).

The technology of the light water reactor has been steadily improved from the initial stage of dependency on the foreign technologies so that the operation rate of the light water reactor has recently reached a worldwide highest level of $71 \%$, while the domestic produc- tion of the components is now almost $100 \%$. In addition, comprehensive program of standardization for improvement of light water reactors was inaugurated in 1975 under the guidance of the Ministry of International Trading and Industry (MITI) aiming at improving the reliability and operation rate of the light water reactor, and decreasing the radiation exposure of operators by means of the Japanese own technology. Presently, the third stage program to develop a new advanced light water reactor is being promoted.

On the other hand, research and development of advanced reactors are also under way. Namely, as for the fast breeder reactor, the Power Reactor and Nuclear Fuel Development Corporation (PNG) takes the lead in development. The experimental reactor "Joyo" has been successfully operated since it was brought to critical in April 1977. On the basis of the technology acquired in operating "Joyo", the prototype reactor "Monju" which is scheduled to go on critical in 1990 is under construction. Furthermore, in parallel with this project, study of the construction program of a demonstration reactor has also been instituted.

As regards the multi-purpose high temperature gascooled reactor, JAERI is carrying out the detailed designing of an experimental reactor for commissioning sometime in 1990. In the nuclear fusion reactor, further, the JAERI, universities, national research laboratories, and private corporations are working together with particular emphasis on the construction of a critical plasma testing facility (JT-60) of the Tokamak type so as to start the heating test in 1986.

\section{(2) Materials for Light Water Reactor}

\section{(a) Reactor Pressure Vessel Steels}

Steels for the light water reactor pressure vessel are required to be free of internal defects and be excellent in fracture toughness, neutron irradiation embrittlement resistance, fatigue strength, and weldability. Principal materials which have been employed are the ASME SA 533 B Cl.1 (JIS SQV 2A) plate steel and the SA 508 Gl.2 (JIS SFVQ 2A) forged steel, of which the latter is being replaced by SA $508 \mathrm{Cl} .3$ (JIS SFVQ 1A) from the standpoint of preventing under-clad cracking and of shortening the time needed for in-service inspection (ISI). This steel has been adopted for the first time in the beltline region of reactor vessel of the Tsuruga No. 2 of Japan Atomic Power Company (JAPGO).

The technical criteria for the materials for components including reactor pressure vessels have been steadily established. In this connection, the fracture mechanics analysis method, in particular, is well employed in many fields concerned. And, to meet those very stringent requirements for the reactor pressure vessel steels, various research and development have been vigorously conducted.

First, in the steelmaking technologies, the reduction of impurities and segregation by adopting electric furnace melting plus ladle refining and vacuum treating and by resorting to basic oxygen converter 
melting plus hollow-ingot making, and enhancement of forging effect by improving the quality of the ingot, on the other hand, are noted. Secondly, in the fabrication technologies, there have been the development of narrow-gap MIG welding for pressure vessel, that of weld overlay by electroslag method to the inner surface of pressure vessel, and the research of countermeasures against under-clad cracking. Lastly, in the field of quality, studies on various types of fracture toughness of heavy section steels and welded joints, on thermal shock of the nozzle, and on the fatigue crack growth properties in elevated temperature water have attracted international attention. Thus, the manufacturing technologies of steels and nuclear reactor pressure vessels in Japan are evaluated as being on the highest level in the world.

Regarding the neutron irradiation embrittlement of nuclear reactor pressure vessel steels, it has been demonstrated in the IAEA co-ordinated research program (Phase II) started in 1977 that the steels and welded joints containing low $\mathrm{Cu}$ and $\mathrm{P}$ presented from Japan were less susceptible to the irradiation embrittlement. Now, this fact has been brought to notice in recent years in association with the subject of pressurized thermal shock. Namely, in the PWRs of this country, the integrity of reactor pressure vessels is considered fully ensured against occurrence of pressurized thermal shock since the early ones, owing to the low irradiation sensitivity due to the low impurity elements such as $\mathrm{Cu}$ and $\mathrm{P}$. Nonetheless, in order to further improve the reliability of nuclear power generation, the MITI is promoting the project of pressurized thermal shock demonstration tests on a six-year scheme from 1983.

In addition to these, establishment of elastic-plastic fracture mechanics analysis method and review of fracture toughness, fatigue crack growth rate, and irradiation embrittlement susceptibility design diagram are the issues of an international importance in the future, to which contribution by Japan is expected.

\section{(b) Materials for Steam Generator Tubes}

For the steam generator tubes of PWR, the resistance to stress corrosion cracking, general corrosion, and pitting corrosion is most important. Of the researches made on the quality of steam generator tube materials, the study of influences of heat treatment on the stress corrosion cracking susceptibility, that of the behavior of Alloy 600 in the solution of sodium phosphate at an elevated temperature or under the condition of all volatile treatment (AVT), and the "Steam Generator Reliability Demonstration Tests" that was carried out in 1975 to 1981 under MITI sponsorship are noted. While in the manufacturing technologies, improvement in cleanliness by the introduction of rotation ingot making method and the improvement in resistance to stress corrosion cracking by reducing residual stress, by converting it to compression stress, or by applying special heat treatment are internationally well known.

As for materials for steam generator tubes, Alloy 600 has been used widely, but the so-called TT Alloy
600 , which is subjected to a special heat treatment for sensitization recovery based on these researches, has come to be widely adopted. Furthermore, for the advanced PWR, Alloy 690 with even better resistance to stress corrosion cracking is being studied as a strong candidate.

\section{(c) Materials for Piping}

As the materials for pipes for BWR, austenitic stainless steels (types 304 and 316) and carbon steels have been used for their good resistance to corrosion and toughness, but damages due to intergranular stress corrosion cracking took place in succession at the welded joints of the austenitic stainless steel piping, in Japan and abroad, which stimulated researches for countermeasures.

Of those, the study of susceptibility to stress corrosion cracking of various austenitic stainless steel pipes and welded joints, development of stainless piping steels, and the "Stainless Steel Piping Weldments Reliability Demonstration Tests" sponsored by MITI have gained a high international fame.

Based on the achievements of these studies, nuclear grade 304 and 316 type stainless steels (low C, Nadded, and fine grained) have been developed. In addition, as methods for preventing the stress corrosion cracking, welding with the inner surface water cooled, high frequency induction heating stress improvement method, and weld overlaying of inner surface have been developed.

(d) Steels for Containment Vessel

Regarding the containment vessels of PWR and BWR, in the trend of enlargement and in the standardization for improvement, studies of fracture toughness and weldability have been conducted.

Namely, for the PWR containment vessels, which have conventionally been a cylindrical vessel made of JIS SGV 49 steel plate with a thickness of $38 \mathrm{~mm}$, the upper limit that does not require postweld heat treatment, the possibility of extending the plate thickness up to $44.5 \mathrm{~mm}$ without applying postweld heat treatment has been investigated, duly proving the safety of its practical use. In addition to this, application of prestressed concrete containment vessel (PCCV) was studied for four-loop plant of $1100 \mathrm{MW}$ class, and realized for the first time in the Tsuruga No. 2 of JAPGO.

On the other hand, BWR containment vessels have conventionally been constructed with the same SGV 49 steel, but, with the development of the modified design, adoption of JIS SPV 50 steel with improved strength and toughness was examined, leading to the practical application to the components or parts requiring strength or thinner thickness.

\section{(3) Materials for Fast Breeder Reactor}

Because a fast breeder reactor (FBR) utilizes liquid $\mathrm{Na}$ as coolant, the structural materials are especially required to be compatible with $\mathrm{Na}$, so that corrosion resistance in liquid $\mathrm{Na}$, strength in $\mathrm{Na}$ environment, and tribology in $\mathrm{Na}$ are important. As for $\mathrm{Na}$ corrosion, long-term immersion testing in flowing $\mathrm{Na}$ of austenitic stainless steels (304, 316, and 321) and $2 \frac{1}{4} \mathrm{Cr}-$ 
1 Mo steel, studies of behavior ofdecarburization and carburization of those two in a bi-metallic loop consisted of those two different steels, and a study on the effects of heat treatment (microstructure) on $2 \frac{1}{4} \mathrm{Cr}$ $1 \mathrm{Mo}$ steel for FBR have attracted international attention. Secondary, as for the material strength in a $\mathrm{Na}$ environment, creep rupture, low cycle fatigue, and interaction between creep and fatigue in $\mathrm{Na}$ at an elevated temperature were investigated. Lastly, in the welding technology, development of austenitic welding electrodes to ensure a good creep ductility, studies on strength and deformation evaluation method of the welded joints, applicability of electron beam welding, and methods of repair welding of $\mathrm{Na}$ piping were conducted.

The results obtained from those researches have led to the selection in the prototype "Monju" steam generator, which was drawing quite an attention, of 321 stainless steel for the superheater tubing and of $2 \frac{1}{4}$ $\mathrm{Cr}-1 \mathrm{Mo}$ steel for the evaporator tubing. In addition, the criteria associated with $\mathrm{Na}$ environment effect and the creep fatigue evaluation criteria based on linear cumulative damage rule were established in 1981 .

Furthermore, for the demonstration reactor, whose construction is scheduled to commence sometime in $1990 \mathrm{~s}, 9 \mathrm{Cr}-1 \mathrm{Mo}-\mathrm{V}-\mathrm{Nb}, 9 \mathrm{Cr}-2 \mathrm{Mo}$, and $12 \mathrm{Cr}-1 \mathrm{Mo}-$ $\mathrm{V}$ steels, and Alloy 800 have been proposed as candidates for the steam generator tubing, and they are being investigated from various angles.

(4) Materials for Multi-purpose High Temperature Gas-cooled Reactor

As the multi-purpose high temperature gas-cooled reactor (HTGR) uses $\mathrm{He}$ as coolant, and because the heat exchanger metal temperature is designed to become as high as $950 \sim 1000{ }^{\circ} \mathrm{C}$ so as to take out the nuclear heat directly to the process, particularly good compatibility with high temperature He environment is required for the structural materials. During the past decade, various research and development have been carried out in line with this point, as described in Sec. V.3.7.(6).

The subjects left to future investigation include improvement in corrosion resistance and low cycle fatigue under severer conditions, the preventive measures of carburization and penetration of tritium, and establishment of the evaluation method of durability taking into consideration the effects of impurities in $\mathrm{He}$ gas atmosphere.

As for pressure vessel materials, on the other hand, neutron irradiation embrittlement, thermal aging, fracture toughness, and fatigue crack propagation are being studied for $2 \frac{1}{4} \mathrm{Cr}-1 \mathrm{Mo}$ steel and its welded joints. Here, establishment of the fatigue design curve and the permissible damage factor for interaction between creep and fatigue are the subjects of future study.

\section{(5) Materials for Nuclear Fusion Reactor}

As for the nuclear fusion reactor, Japanese first Tokamak test facility JT-60, is scheduled to be completed in 1984. Here, in a Tokamak reactor which comprises the main structure such as the blanket ves- sel, the primary shield wall, diverter plates, and pipings, the structural materials for the primary shield wall is of special concern. Namely, as it is subjected to an extremely high neutron dosage, the materials need be of a high resistivity to irradiation damages such as blistering, embrittlement, and fatigue, an excellent resistance to stress corrosion cracking in cooling water, and a good weldability.

For this, the Fusion Reactor Material Research Subcommittee within the No. 122 Comm., the Japan Society for the Promotion of Science undertook investigations of candidates such as 316 stainless steel, superalloys, ferritic steels, refractory metals (Mo, Nb, and $\mathrm{V}$ ), and Ti alloys, and also experiments on the thermal fatigue properties of 316 stainless steel and Ni-base alloys, and on mechanical properties of Mo and Mo alloys. Then recommendations were made JAERI to the effect that a database which will provide accurate prediction of the endurance limits of the materials be prepared, and development of new materials to enlarge the endurance limits be instituted.

Complying with this proposals, JAERI organized the Fusion Reactor Material Research Committee, and under its auspices researches on fatigue, structural stability, weldability, compatibility with cooling water, and irradiation test of the blanket structural materials are being conducted. With a modified 316 stainless steel containing a small amount of $\mathrm{Ti}$, as the primary candidate alloy, irradiation tests including fatigue behavior and study of stress corrosion cracking in cooling water environment for welded joints as well as on base metal will commence soon. Further, studies on weldability and irradiation embrittlement of Mo alloys as the materials for diverter or limiter, the sputtering, evaporation, and blistering of the primary shield wall as the interaction with plasma, and the hydrogen attack or embrittlement due to diffusion or penetration of deutrium and tritium into the materials have been initiated.

\section{3. 11. Topics}

\section{(1) Clad Steel}

In Japan, the stainless clad steel has been developed as economical and corrosion resistive thick steel plate principally for boilers, pressure vessels, etc. In the second half of the 1970s and coming into 1980s, however, clad steels other than stainless steel clad, those clad with such non-ferrous alloys as $\mathrm{Cu}$ alloy, $\mathrm{Ni}$ alloy, $\mathrm{Ti}$ alloy, or $\mathrm{Al}$ alloy have been developed in answer to the diversification taken place in the corrosion environment of the pressure vessels and storage tanks, which are the principal subject of application, and also to the enlargement of application to pollution prevention devices, desalination plants, and offshore structures. As an example of potential utilization of clad steels in industry, Fig. V.3.16 classifies major application fields in terms of type of cladding materials. The important progress of clad steel in the past decade is as follows: 


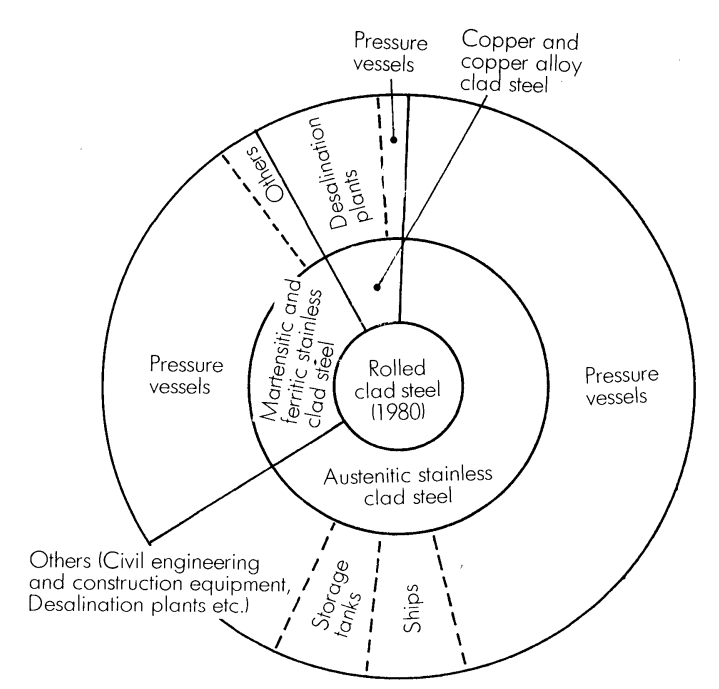

Fig. V.3.16. Classifications of clad steels according to application. (Examples of rolled clad steel)

(1) In the past, as most of the technical standards regarding clad steel were those established by private organizations, they were very complicated. The Clad Steel Research Committee, High Pressure Institute of Japan, examined these standards from various angles to unify them into JIS and to adjust them to international standards. As a result, JIS specifications for clad steels have been established in $1977 \sim 1980$.

(2) Research to develop technology for the manufacture of higher quality clad steel more economically has been vigorously promoted, resulting in diversified manufacturing methods, and contributing to improving the quality of clad steel.

(3) In the past, clad steel plate was mostly of a thickness of $8 \mathrm{~mm}$ or more, but recently, thin clad steel of $0.5 \sim 4 \mathrm{~mm}$ and very thin clad steel strips have been developed, and besides the general applications such as to cooking wares, hot water boilers, and architecture materials, clad steels have been gradually diffusing in the electric and electronic industry, for example, as the IG lead frame material, because of their ability for variety of physical properties peculiar to a composite material.

(4) Attention is being paid to clad steel in the plant piping and pipeline fields because of its low cost and high functional ability, and application as a piping element to fill the gap between $\mathrm{G}$ steel pipes and the high corrosion resistant high alloy pipes has now begun.

(2) Laminate-type Vibration-damping Sheet Steel

Laminate-type vibration-damping sheet steel, in which a thin resin layer is deposited between two steel sheets, has been developed and put to practical use. This sheet steel demonstrates it vibration-damping effect by converting vibration energy into lower-order thermal energy as a result of shearing slippage caused during bending deformation. The loss factor, which indicates vibration-damping performance, of the laminate-type vibration-damping sheet steel has been improved by 3 digits from the value of common sheet

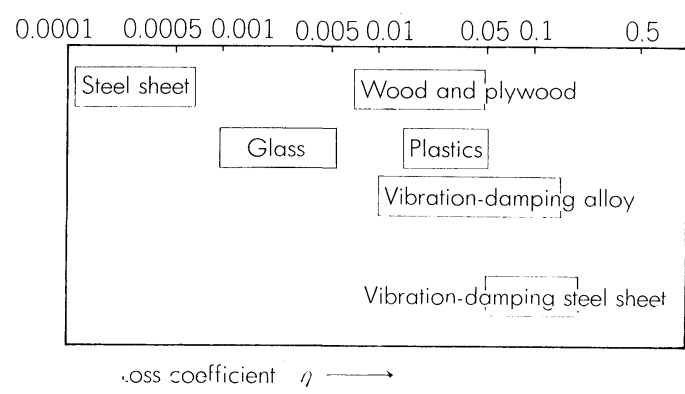

Fig. V.3.17. Vibration-damping performances of various materials.

steel, thereby making it a better material than wood in terms of vibration-damping property. (Fig. V. 3.17).

The automobile field is where the need for vibration-damping sheet steel is the highest at present. In the automotive industry where efforts have been made to make the body thinner and the output higher through the use of high strength sheet steel, it is necessary to solve the problem of coping with the Secondstage Accelerated Driving Noise Control since 1957 following the first-stage control in 1954. In addition, the automotive industry does not want to change its current production system just to cope with the problem. In view of such needs, the laminate-type vibration-damping sheet steel has been made capable of being deep-drawn as in the conventional sheet steel and also capable of being welded.

Vibration-damping sheet steel was developed first in Sweden and in the USA, and has been put to practical use as oil pans of automobiles, particularly in Sweden. In Japan, its application development was started several years ago in the fields of bridges, ships, motor covers, etc. As its need has grown in the field of automobiles, all steel makers began to participate in its production, and at present vibration-damping sheet steel has entered the practical use with the manufacture of oil pans for trucks as the first step. (Photo. V.3.2). Beside the above, needs for this type of steel are found as material for steel staircases and roofs in the construction material industry. In the field of furniture and household fittings, future expansion of demand for vibration-damping sheet steel is expected to improve the "feeling", of steel sheets to match high-class finishing of the furniture.

From the manufacturing technique established by vibration-damping sheet steel, it has become possible to manufacture various types of laminated sheet steels, for instance, a lightweight laminated sheet steel in which a thick, hard resin layer is used as a core sheet, instead of a vibration-damping viscoelastic resin, to increase the rigidity of the steel sheet and consequently to make the sheet thinner, or what may be called the "multifunctional sheet steel", in which one of the skin sheets is made of stainless steel to improve corrosion resistance and external appearance, and the resin gives the vibration-damping and lightweight properties. In view of the above, it can be said that 


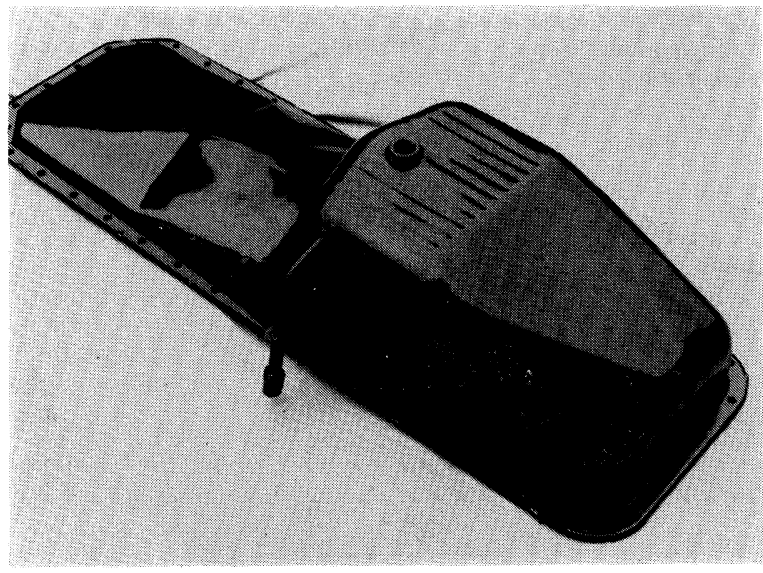

Photo. V.3.2. Oil pan manufactured with vibration-damping sheet steel.

the laminate-type sheet steel has practically eliminated the defects inherent in conventional sheet steel, namely, resonance, heavy weight, easy rusting, and a cold and hard touch, through the composite structure with high polymer materials. It can also be taken as the embodiment of a technique for developing a new demand by appealing to people's emotions to the steel sheets which have been mainly supporting the functional side of our daily life.

\section{(3) High Damping Alloy}

It is a common observation that the industrial structure is gradually changing from the age of heavy, thick, long and large centering on the steel industry and heavy and chemical industries to the age of light, thin, short and small centering on the high technology industries. In these circumstances, technology in such aspects as high speed, high performance, low cost and low energy consumption have extremely advanced, and along with this, vibration control techniques are now becoming increasingly important. In response to this, various materials are being newly developed and trial and error tests are being carried out with the aim of their practical utilization. The number of patent application concerning high damping alloy already exceeded 50 in this country in 1979, but today, it has reached an incalculable figure. This tells us that concern in this field is mounting in Japan:

There are four kinds of high damping alloy to be studied: 1) composite type, 2) ferromagnetic type, 3 ) dislocation type, and 4) twinned crystal type. Besides the above, the following two kinds have been newly added in the last decade: 5) grain boundary corrosive-type stainless steel and 6) laminated composite steel plate. Although the number of researchers is rapidly increasing, the diffusion of high damping alloy is rather slow in actual fact, in spite of wide interest and popularity. This is because, in addition to hardware represented by alloy development, the role of software in utilizing the specific, developed material is more important, and it usually takes a lot of time to resolve a problem. The development of high damping alloy is one of the best example of the boundary research. The cause of the absorption of acoustic waves occurring inside the alloy must be investigated from the aspect of material development. Extensive scientific research on material is required, putting fully to practical use fundamental knowledge related to acoustic-sound physical properties of solids, liquids, and gases. From the aspect of application of development, peripheral technology must be effectively used; for example, the theory of oscillation and noise, instrumentation engineering, computer hardware and software, and prototype manufacture.

As an iron-based alloy, flake graphite cast iron is well known, which uses a high attenuation of graphite. There is a new type of cast iron that reconciles low thermal expansion coefficients with high attenuation ability. This is done by adding a large quantity of $\mathrm{Ni}$, by which the matrix is transformed into austenite. Recently, attempts are being made to improve working accuracy using this new cast iron for precision tool machines/ which is noteworthy as a new technique for adding high value to cast iron material. The other type of iron-based alloy is ferromagnetic type and practical alloys with a large quantity of $\mathrm{Cr}, \mathrm{Al}, \mathrm{Mo}$, etc. are being trial-manufactured and studied. For further information except iron-based alloy, refer to Kinzoku Binran (Metal Mannual), 4th ed., ed. by The Japan Institute of Metals, Maruzen, Tokyo, (1982), 969.

\section{(4) Steel Fiber}

Steel fiber (SF) is a material which improves brittleness of the concrete. The effective mixing ratio is 0.5 to $1.5 \mathrm{vol} \%$. Table V.3.8 shows the shape and dimensions of SF which is sold at present. Development of the manufacturing method and utilization technique of SF began around 1973 in Japan which was about 10 years later than in the USA. However, Japan is the most advanced country regarding its practical use as civil engineering and construction materials.

Recent conditions in Japan, that is, movement for normalization of the steel fiber concrete (SFRG) demand trend of SF and application conditions to a new field are outlined here.

At first, SFRG design and execution recommendations were made by the Japan Tunnel Association in 1980 for normalization and SFRG has come to be used on a full scale in tunnel excavation. After that, recommendations which also regulated the quality of SF, that is, dimensions, materials and tensile strength $\left(\geqq 60 \mathrm{~kg} / \mathrm{mm}^{2}\right)$ was issued in 1983 from the Japan Society of Civil Engineering with the object of general civil engineering usage such as roads, bridges, dams, and slope protection.

On the other hand, the practical use of secondary products such as the stairs, partition walls, etc., have been done in the building field. Moreover, the study related to the shearing reinforcement of columns, beams and earthquake-resisting walls of a reinforcedconcrete structure is recently advancing as a committee activity of the Society and there is an indication that design guidance will also be stipulated.

The demands of SF in Japan in 1983 was about 
Table V.3.8. Type of steel fiber.

\begin{tabular}{|c|c|c|c|c|}
\hline \multirow{2}{*}{$\begin{array}{l}\text { Manufacturing } \\
\text { method }\end{array}$} & \multirow{2}{*}{ Shape } & \multicolumn{2}{|c|}{$\begin{array}{r}\text { Standard dimensions } \\
(\mathrm{mm}) \\
\end{array}$} & \multirow{2}{*}{ Material } \\
\hline & & $\begin{array}{r}\text { Diameter: } \\
d\end{array}$ & Length: $\ell$ & \\
\hline \multirow{4}{*}{$\begin{array}{l}\text { Thin plate } \\
\text { cutting method }\end{array}$} & 口 & $\begin{array}{l}0.25 \times 0.5 \\
0.5 \times 0.5 \\
\end{array}$ & $\begin{array}{l}25 \\
30 \\
\end{array}$ & \multirow{4}{*}{$\begin{array}{l}\text { JISG } 3141 \\
\text { iCold rolling } \\
\text { steel plate) } \\
\text { JISG } 4305 \\
\text { (Stainless } \\
\text { steel plate) }\end{array}$} \\
\hline & $\longdiv { \square }$ & $\begin{array}{l}0.35 \times 0.5 \\
0.35 \times 0.6\end{array}$ & $\begin{array}{l}20 \\
30\end{array}$ & \\
\hline & $\approx \approx \approx \approx$ & $\begin{array}{l}0.25 \times 0.5 \\
0.5 \times 0.5 \\
\end{array}$ & $\begin{array}{l}25 \\
32 \\
\end{array}$ & \\
\hline & $\approx \approx \approx 0$ & $0.5 \times 0.5$ & 30 & \\
\hline $\begin{array}{l}\text { Wire rod cutting } \\
\text { method }\end{array}$ & $\square=\square=\square=\square=\square=\square$ & $0.25 \sim 0.65$ & $20 \sim 40$ & JISG 3532 \\
\hline $\begin{array}{l}\text { Molten steel } \\
\text { extracting method }\end{array}$ & $\Longrightarrow 0$ & $0.3 \sim 0.4$ & 30 & SUS 430,304 \\
\hline $\begin{array}{l}\text { Steel ingot } \\
\text { cutting method }\end{array}$ & $\square \Delta$ & $0.3 \sim 0.5$ & 30 & JISG 3101 \\
\hline
\end{tabular}

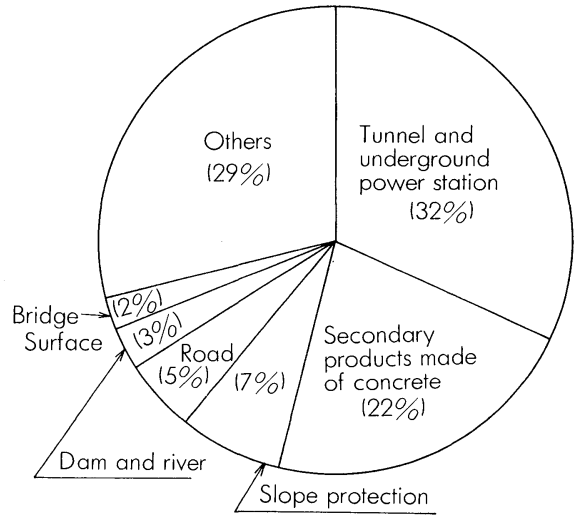

Fig. V.3.18. Ratio used due to the usage of steel fiber. (Estimated by Kozai Kurabu, 1983)

$3500 \mathrm{t}$ which shows an increase of more than two times in the past 5 years. Figure V.3.18 shows the composition ratio the field it is used. SF is mostly used for tunnels and underground power stations, then come secondary products made of concrete. Also, SF of SUS430, 304, etc. made of stainless steel for refractory castable occupy a large share of the market.

On the other hand, the micro fine fiber whose dimensions are smaller than those of the abovementioned fiber has also been developed. This is applied for electrical equipment, by mixing with plastics from 10 to $15 \mathrm{vol} \%$ and making satisfactory conductive plastics with the electromagnetic wave screening characteristic. It can be said to be noteworthy usage although it is at a tentative stage. The study of the new field except those of composite with concrete and refractory castable materials has just begun, but the possibility of further development is very great.

\section{(5) Super Fine Particles}

The super fine particle usable at present is mainly a particle of metal, ceramics or plastics within the range of $1 \mathrm{~nm}\left(\mathrm{~nm}=10^{-9} \mathrm{~m}=10^{-3} \quad \mu \mathrm{m}=10 \AA\right)$ to $100 \mathrm{~nm}$. Observation of a single particle became possible with the development of the electron microscope. Such particles are called super fine powder as they normally adhere together to form a powdered state in the gathering condition.

Particle smaller than about $1 \mathrm{~nm}$ is called a cluster particle. The cluster consists of less than a few hundred atoms. The super fine particle which is larger than a cluster, can be defined as an agglomeration of a few hundred atoms or more to several 10 million particles. There are two approaches of the study. The investigation of the cluster is to know, for example, what happens when atoms of iron are combined one by one. The study and development for super fine particles is, for example, to know if interesting material is created when the solid (lump) is made into super fine powder. The size of the magnetic domain (unit magnet) such as $\mathrm{Fe}, \mathrm{Ni}$, and $\mathrm{Co}$ is known to be about $100 \AA$, thus the super fine powder having a particle diameter of about $200 \AA$ of such magnetic alloy has been made and deliberately arranged to increase the recording density, for example, of magnetic recording tape. It can be easily estimated (calculated) that when the particle diameter becomes smaller, the ratio of surface area/volume becomes larger and the physical and chemical activity is emphasized. Peculiar electronic characteristics are anticipated from the fact that individual super fine particle has only a limited number of free electrons.

With regard to super fine particle and super fine powder, there are elaborated articles in two special editions which were recently issued. ("Super Fine Particles", Kotai Butsuri (Solid State Physics) Special Issue, (1984), Agne Technical Center, Tokyo; "Super Fine Particles", Japan Science and Technology, 25 (1984), No. 227, 5-6, Japan Science Foundation). To take some of the interesting examples; astrophysicists say that Fe super fine particles of about $10 \mathrm{~nm}$ can be found in many locations in space. Some fresh-water bacteria form magnetite super fine particles of about $50 \mathrm{~nm}$ in their own bodies.

There are signs that the study of the cluster is remarkably increasing in Europe, the USA, USSR, etc. The study is being executed using, for example, the laser spectral technique, super high vacuum technique and extremely low temperature technique. It is clear that the nature of crystallization in the range of the cluster (the short range order) has a profound relation with the science of the amorphous structure.

Table V.3.9 takes a bird's-eye view of the world of the super fine particle (powder) by paying attention not only limited to metal or ceramics but to the size regardless of constituting atoms. Super fine 
Table V.3.9. Application of ultra fine particles and typical detector.

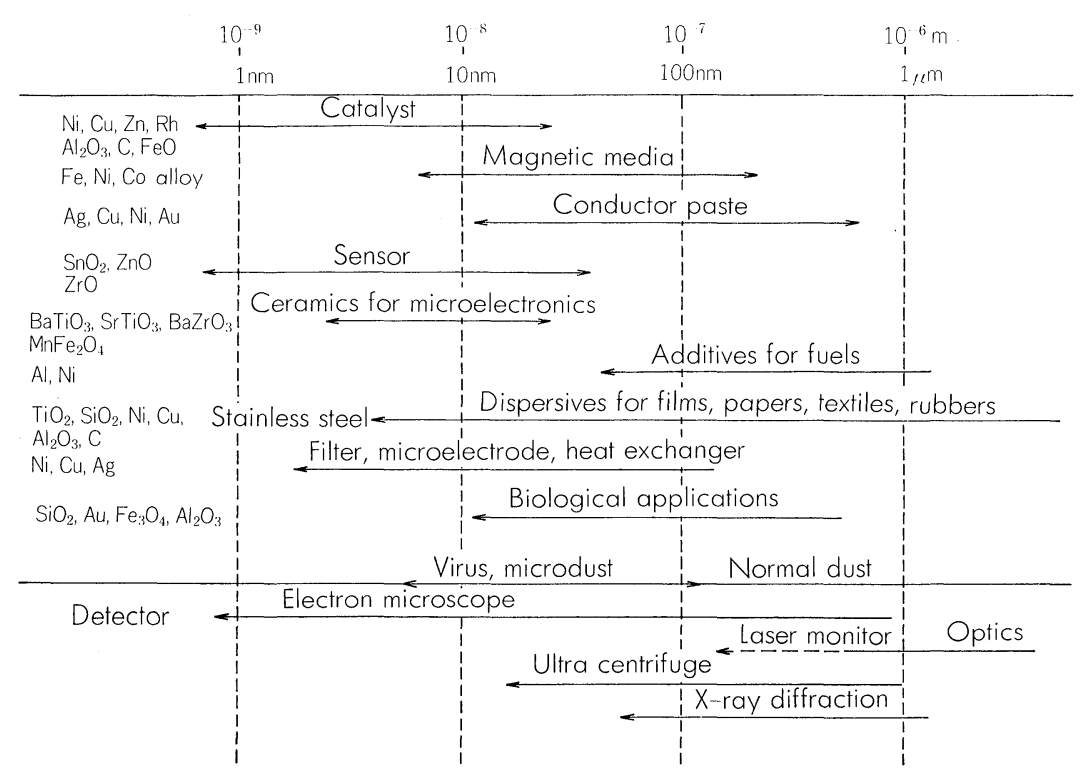

particles together with the super fine fiber will be developed as materials for the composite and amorphous or as the material related to the micro-organism.

\section{(6) Iron and Steel Foil}

The term "iron foil" includes, in a broad sense, both steel foil with a thickness below $150 \mu \mathrm{m}$ which is produced by rolling and what we call iron foil which is produced by the electrolytic method. Wide steel foil with a thickness of down to $50 \mu \mathrm{m}$ produced by the 4 high mill is already being offered on the market by several companies, and utilized for various purposes. Original plates for steel foil are cold rolled and annealed from a hot rolled coil and rolled again down to the fixed thickness. If the work roll diameter is reduced (e.g., to $320 \mathrm{~mm}$ or below), the thickness of 20 to $30 \mu \mathrm{m}$ can be attained. The Flexible Flatness Control (FFG) mill (having small diameter rolls is advantageous to obtain better flatness) and recently in this country, it has been made possible to supply steel foil of $30 \mu \mathrm{m}$ using 5 or 6 high FFG mills. These extremely thin steel foils are usually plated with tin or zinc before the secondary cold rolling, which are what we call "Sn first" and " Zn first ", respectively, and temper is of a hard type.

On the other hand, a method has been put to practical to obtain another thin foil, which includes iron-plating on to a rotary drum made of $\mathrm{Ti}$ etc., and continuous peeling of the electrodeposition. This extremely thin foil is called iron foil because the base material is electrolytic iron. Iron foil has more flat shape and better workability as compared with hard steel foil. While, since the method used for making iron foil is one that increases its thickness from zero, in theoretical point of view, foils of any thickness can be manufactured, $15 \mu \mathrm{m}$ is the minimum thickness available today because there are restrictions in practical, such as the peeling operation from the drum and passing-through processing within the facilities. Iron foil is usually plated with $\mathrm{Zn}, \mathrm{Ni}$, etc., and because it can be combined with other materials without previous degreasing, it serves as a good material suitable for lamination. While the structure of steel foil is fibrous extended in the rolling direction, iron foil has a columnar structure which grows in the thickness direction and has no directionality. The surface of iron foil has the following characteristics: the surface in contact with the drum is a mirror surface; the other is grainly patterns formed by a large number of crystals in the shape of pyramids which are peculiar to the electrodeposited layer. Iron foil can be easily torn to pieces and has the feeling of paper rather than iron.

Both steel foil and iron foil are the same steelbase material and superior to other metal foils in strength, stiffness and electromagnetic shielding. The susceptibility to magnet is one of features. Steel foil is utilized for a comparatively thicker field, i.e., $50 \mu \mathrm{m}$ or above, and typical examples of which are dry battery electrodes, gaskets, flexible tubes, resister caps, inner shields, etc. Iron foil having a thickness of 20 to $25 \mu \mathrm{m}$ is mainly used for such items as white boards, teaching materials, magnetic card cases, floppy disk cases, electronic parts, wallpaper, adiabatic boards and for many other purposes. Iron and this steel foil are most likely to be used for electro-magnetic shields to cope with Electromagnetic Interference (EMI). For the measures, against EMI, to be taken to comply with the U.S. Federal Communication Commission (FGG) regulations, various methods are being used such as conductive coating, conductive plastic and $\mathrm{Zn}$ spray. The application of metal foil is one of the effective measures and, among others, iron foil, because its shield properties are superior, has begun to be used for the inner lining of cases and divisional shields of circuits.

(7) Rapidly Quenched Thin Sheet

Quenched thin foil, usually so called, is the crystalline thin sheet rapidly solidified by supplying mol- 
ten metal directly and continuously on cooling substrate. The root of the technique can be traced to the era of Bessemer. However, the recent development has started by the impact from success of rollerquench of amorphous alloys ribbon at the beginning of the 1970s and progress of the laboratory-research on non-equilibrium phase shortly later.

A representative result is high silicon steel ribbon. Tsuya et al. obtained ribbons of $6.5 \% \mathrm{Si}-\mathrm{Fe}$ using double rooler method. This material is well known as having excellent soft magnetic properties owing to reduced magnetostriction and enhanced electrical resistivity, while maximum $\mathrm{Si}$ content in conventional silicon steel is about $3.5 \%$ due to brittleness. As a consequence of the subsequent studies in academic and corporate research, clues to doubly or non-oriented $\mathrm{Si}$ steels are obtained most promising by making best use of the (100) $[0 \mathrm{k} l]$ texture which develops in the double roller method. The single roller and double roller methods are the typical rapid quenching techniques. In the single roller method, a thinner sheet with thickness less than $60 \mu$ is obtained. The double roller method is used for a sheet with thickness up to $0.5 \mathrm{~mm}$. In the case of high $\mathrm{Si}$ steel by the double roller method, the cooling speed of $10^{5}$ to $10^{6} \mathrm{~K} / \mathrm{s}$ and solidification rate of about $15 \mathrm{~mm} / \sqrt{\mathrm{min}}$ were obtained, and solidification was controlled by dendrite growth accompanied with the diffusion of Si.

In this field, on the basis of progress in the last decade, a new development are on the way for manufacturing of new materials with a higher performance and for saving of the manufacturing cost and energy.

\section{(8) Amorphous Alloys}

During the past that metals have been used by humans, their structures have composed of crystalline aggregates. As a new state of matter, amorphous metals have naturally aroused wide scientific curiosity and the applications activity.

Amorphous alloys can be obtained by the methods of liquid quenching or vapor phase quenching on a substrate. For commercial production, liquid quenching at a speed of $10^{4}$ to $10^{6}{ }^{\circ} \mathrm{C} / \mathrm{sec}$ is favorable to make continuous their strips, wires or powder of amorphous alloys directly from liquid.

In the present, amorphous alloys are produced with a strip width of $150 \mathrm{~mm}$ and thickness of $0.05 \mathrm{~mm}$ by quenching on a rapidly rotating roll (Fig. V.3.19(a)) and with a wire diameter of $0.2 \mathrm{~mm}$ by the rotating liquid spinning method (Fig. V.3.19 (b)). Trials are in progress of production of their films and ultra fine particles by sputtering method. Furthermore, wide applications are developing: surface coating by laser heating, forming by impact or explosive bonding and joining by laser meeting or ultrasonics.

Amorphous materials are known to consist of metals plus metalloids or metals plus metals. In a variety of amorphous materials, alloys with the approximate composition $T_{90-70} M_{10-30}$ and $T_{90} \mathrm{Zr}_{10}$, where $T$ is transition metals such as $\mathrm{Fe}, \mathrm{Ni}$, and $\mathrm{Co}$, and $M$ is metalloids such as $\mathrm{B}, \mathrm{C}, \mathrm{P}$, and $\mathrm{Si}$, are excellent
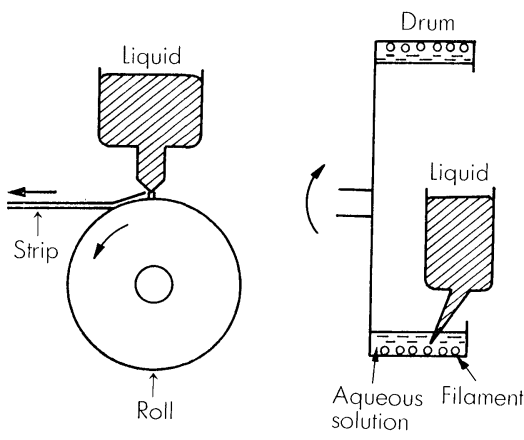

(a) Single roll method

(b) Rotating liquid spinning method

Fig. V.3.19. Methods of amorphous strip and wire production from liquid metal.

in their magnetic properties, corrosion resistance, and strength. $\mathrm{Ni}, \mathrm{Ti}$, and $\mathrm{Zr}$ base alloys can be used as the superconducting and the hydrogen storage materials and Pt and Pd base alloys as the electrodes.

These amorphous materials possess attractive characteristics as a consequence of their peculiar atomic structure as summarized in Table V.3.10 in terms of the properties and the applications. In addition to the outstanding strength, corrosion resistance, and ease of magnetization, selected alloys are shown to have a capacity of easy propagation of acoustic wave through them. Some become superconductors at low temperatures and others are excellent as gas absorbents or catalyzers. In the present commercialization of the amorphous alloys is focused on soft magnetic materials and further advances in science and technology of the amorphous materials will provide rich fields of the applications.

\section{(9) Superplastic Steels}

During the past decade applications of superplasticity has made a rapid progress, whereas it has already elapsed more than 50 years since the discovery of superplastic phenomenon. An integrated research and development project for the development of heat resisting Ni-base superplastic alloys and high strength Ti-base superplastic alloys and the evaluation of their performance, are being implemented within the framework of the "Research and Development Project of Basic Technology for Future Industries" which was inaugurated in October, 1981 sponsored by the Agency of Industrial Science and Technology.

Although the variety of fine-grained superplastic materials are still limited in famous alloys as is shown in Table V.3.11, applications of these alloys are expected to extend to wider areas other than the use for structural material as the high performance materials making use of their solid bonding ability, high dumping capacity, and good stamping formability.

Superplastic materials are easily formed in nearnet-shape and the worked articles can be heat treated to meet for the required performance such as strength and toughness. In many cases superplastic materials are made in composites or worked into composites with other materials to provide with a good combination 
Table V.3.10. Properties and practical applications of amorphous alloys.

\begin{tabular}{|c|c|c|}
\hline Properties & Characteristics & Practical applications \\
\hline Strength, toughness & $\begin{array}{l}\text { High yield strength : } E / 30 \text { to } E / 50 \text { ( } E: \text { Young's modulus) } \\
\text { High tensile strength: } \sim 4.5 \mathrm{GPa} \\
\text { High hardness : } \sim 1400 \text { Vickers hardness }\end{array}$ & $\begin{array}{l}\text { Razor blade, composites, spring, strain } \\
\text { gauge material, wire, etc. }\end{array}$ \\
\hline Corrosion & $\begin{array}{l}\text { High corrosion resistance (in acid, neutral, and alkali } \\
\text { solution), resistance to pitting and crevice corrosion }\end{array}$ & Filter, electrode, blending material, etc. \\
\hline $\begin{array}{l}\text { Soft magnetic } \\
\text { properties }\end{array}$ & $\begin{array}{l}\text { Low coercive force: } \sim 0.1 \mathrm{~A} / \mathrm{M} \\
\text { High permeability: } \sim 10^{5} \\
\text { Low core loss: } \sim 0.1 \mathrm{~W} / \mathrm{kg} \\
\text { High induction: } \sim 1.7 \mathrm{~T}\end{array}$ & $\begin{array}{l}\text { Magnetic shielding, magnetic head, wound } \\
\text { core, magnetic filter, distribution trans- } \\
\text { former, etc. }\end{array}$ \\
\hline Magnetostriction & $\begin{array}{l}\text { High magnetostriction: } \sim 50 \times 10^{-6} \\
\text { High electro-mechanical coupling constant: } \sim 0.7\end{array}$ & Oscillator, transducer, sensor, etc. \\
\hline Invar, Elinvar & $\begin{array}{l}\text { Constancy of thermal expansion coefficient and elastic } \\
\text { modulus in a wide temperature range, high } \Delta E \text { effect }\end{array}$ & Spring, delay line, sensor, etc. \\
\hline $\begin{array}{l}\text { Resistance to } \\
\text { radiation damage }\end{array}$ & Resistance to embrittlement with neutron radiation & Radiation resistant material \\
\hline Superconductivity & $\begin{array}{l}\text { Superconductor type } 2 \\
T_{\mathrm{c}}: \sim 9 \mathrm{~K} \\
J_{\mathrm{c}}: \sim 10 \mathrm{~A} / \mathrm{cm}^{2}\end{array}$ & $\begin{array}{l}\text { Helium level gauge, temperature sensor, } \\
\text { magnetic field sensor, etc. }\end{array}$ \\
\hline Others & $\begin{array}{l}\text { Easy propagation of acoustic wave, hydrogen storage } \\
\text { capacity, efficient catalyzer, etc. }\end{array}$ & \\
\hline
\end{tabular}

Table V.3.11. Principal ferritic superplastic materials.

\begin{tabular}{|c|c|c|c|c|}
\hline Material name & Chemical composition (wt\%) & $\begin{array}{l}\text { Superplasticity } \\
\text { temperaure }\left({ }^{\circ} \mathrm{C}\right)\end{array}$ & $m$ value & $\begin{array}{c}\text { Elongation } \\
(\%)\end{array}$ \\
\hline Eutectic steels & $\mathrm{Fe}-0.91 \mathrm{C}-0.45 \mathrm{Mn}$ & 716 & 0.42 & 133 \\
\hline Hyper-eutectic steels & $\mathrm{Fe}-1.3 \sim 1.9 \mathrm{C}$ & $600 \sim 800$ & 0.52 & 750 \\
\hline Alloy steels (AISI 1340) & $\mathrm{Fe}-0.42 \mathrm{C}-1.9 \mathrm{Mn}$ & 727 & 0.5 & 460 \\
\hline Alloy steels & $\mathrm{Fe}-1.5 \mathrm{Mn}-0.8 \mathrm{P}$ & $800 \sim 900$ & 0.52 & 400 \\
\hline Alloy steels & $\mathrm{Fe}-1.5 \mathrm{Ni}-1.0 \mathrm{P}$ & $800 \sim 900$ & 0.52 & 400 \\
\hline IN 744 (Unitoy 326) & $\mathrm{Fe}-26 \mathrm{Cr}-6.5 \mathrm{Ni}$ & $870 \sim 980$ & 0.5 & 600 \\
\hline High alloy steels & $\mathrm{Fe}-4 \mathrm{Ni}-3 \mathrm{Mo}-1.6 \mathrm{Ti}$ & 900 & 0.58 & 820 \\
\hline Tool steels & $\mathrm{Fe}-0.88 \mathrm{C}-1.15 \mathrm{Mn}-0.48 \mathrm{Cr}-0.5 \mathrm{~W}-0.22 \mathrm{~V}$ & 650 & 0.5 & 1200 \\
\hline
\end{tabular}

of strength and required performance. Multilayered composite materials, made by bonding of superplastic hyper-eutectic steel sheets with structural steel sheets through rolling in the superplastic temperature range, shows high strength satisfying the rule of mixtures and also excellent toughness with lower brittle-to-ductile transition temperature and improved crack propagation resistance. The composite materials bonded by rolling the non-ferrous fine-grained superplastic alloy sheets with steel sheets, possess good stamping formability, dumping capacity and accoustic absorbing power in combination and are practically utilized as structural materials for resonance-point shifting purposes.

Various forming processes utilizing superplasticity other than rolling, are also widely carried out and superplastic materials in the form of foil or powder are useful for bonding of 2 or more pieces of products.

The working techniques such as isothermal forging, direct forming, high and slow-speed combination forging in the region of superplastic-exhibiting temperature, and composite material extrusion process have promoted the sophistication of the control techniques of temperature and strain rate, which in turn, has stimulated the development of the forming techniques of general material. Therefore, it is considered that the repercussion of superplasticity will widely expand.

\section{(10) Titanium and Its Alloys}

During the $1960 \mathrm{~s}$, which marked a rapid growth of petrochemical industry in Japan, $\mathrm{Ti}$ was used mainly in the equipments for production of acetaldehyde, acetone, terephthalic acid, caprolactam, and acrylonitrile from naphtha to be synthesized into fibers such as nylon, tetron, and cashimiron this promoted the development of $\mathrm{Ti}$ as material for chemical apparatus. Besides, a large amount of $\mathrm{Ti}$ was employed in elevated-temperature and highpressure vessels in the production plants of urea fertilizer, melamine, and synthetic rubber. However, with the turn of period $1970 \mathrm{~s}$, the oil crisis came to suppress further demand of Ti for chemical industry.

At the same time, on the other hand, a new demand of $\mathrm{Ti}$ as an electrode for the soda industry arises in a sharp increase. To meet this need, Japanese steel industry has established the mass production technology of Ti strip in the middle of the 1970s using the hot and cold tandem rolling mills or Zendzimir mills 
in its modernized plants. Titanium has promoted replacement of graphite as the electrode material in the surface treatment equipment because of the excellent electrode characteristics and it is considered that more than $4000 \mathrm{t}$ of $\mathrm{Ti}$ has been supplied in these areas.

Mass production of strip has enabled manufacturing of Ti thin-wall welded-tubes with the continuousforming and welding method. Use of $\mathrm{Ti}$ tubes for the power plants in the coastal area has been steadily expanding in Japan, the USA, and various countries in Europe, because of the superior heat transfer characteristic and corrosion resistance to seawater to that of $\mathrm{Cu}$ alloys.

The International Congress of Titanium which has been the event of every 4 years in the year of the Olympics was held of its 4th meeting in Kyoto in 1980 with participation of specialists from various fields such as power plant engineers, turbine designers, and titanium metallurgist in Japan, France, Sweden, West Germany, U.K., the USA, and other countries. One of the remarkable results is recognition of the successful application of $\mathrm{Ti}$ in the components of the condensers installed at Hirono Thermal Power Plant and at Fukushima No. 2 Nuclear Power Plant of Tokyo Electric Power Co. Those condensers were constructed by Toshiba with the TIG welding of $\mathrm{Ti}$ thin-wall as-weld tubes with a thickness of $0.5 \mathrm{~mm}$
(JISH 4631 TTH $35 \mathrm{~W}$ ) and large-diameter heavywall $\mathrm{Ti}$ tube plates (JISH $4600 \mathrm{TP} 49 \mathrm{H}$ ). More than $8000 \mathrm{t}$ of $\mathrm{Ti}$ have been used in the maintenancefree condensers. At about the same time, the thinwall welded-tubes were exported to the oil-producing countries in Middle and Near East for building of the desalination plants, amounting more than $3000 \mathrm{t}$.

In contrast to the advanced technologies for manufacturing and application of sponge $\mathrm{Ti}$ (total production capacity $34000 \mathrm{t} /$ year) and pure Ti for industrial use (total melting capacity $16800 \mathrm{t} /$ year) in Japan production of Ti alloys is extremely limited. It is estimated that approximately $21000 \mathrm{t}$ of the raw material of Ti alloys have been used in the USA for the passenger aircrafts of Boring B-747 and more tonnage for some types of the military aircrafts. The Ti products by various US makers (total melting capacity $51300 \mathrm{t} /$ year) mainly consists of the Ti alloys, the amount of production coping with that in USSR. The extent of application of $\mathrm{Ti}$ alloys is still limited in Japan compared with in Europe or the USA. However, there are potential needs for employment of the light, and strong Ti alloys in spacecrafts and aircrafts, ocean development equipments, deep-sea research-vessels, power generators, automotives, buildings, medical appliances, cameras, frames eyeglasses, watches, sporting goods, and for other special purposes. 